\title{
Consensus Paper: Cerebellar Development
}

\author{
Ketty Leto $^{1,2}$ - Marife Arancillo ${ }^{3}$ - Esther B. E. Becker ${ }^{4}$ Annalisa Buffo ${ }^{1,2}$. \\ Chin Chiang ${ }^{5}$ - Baojin Ding ${ }^{6}$ - William B. Dobyns ${ }^{7,8}$ - Isabelle Dusart ${ }^{9,10}$. \\ Parthiv Haldipur ${ }^{7}$ • Mary E. Hatten ${ }^{11}$ • Mikio Hoshino ${ }^{12}$ • Alexandra L. Joyner ${ }^{13}$. \\ Masanobu Kano ${ }^{14}$ • Daniel L. Kilpatrick ${ }^{6}$. Noriyuki Koibuchi ${ }^{15}$ - Silvia Marino ${ }^{16}$. \\ Salvador Martinez ${ }^{17} \cdot$ Kathleen J. Millen $^{7}$ - Thomas O. Millner ${ }^{16}$. Takaki Miyata ${ }^{18}$. \\ Elena Parmigiani $^{1,2}$ - Karl Schilling ${ }^{19}$ - Gabriella Sekerková ${ }^{20}$ • Roy V. Sillitoe ${ }^{3}$. \\ Constantino Sotelo $^{21}$ • Naofumi Uesaka ${ }^{14}$ - Annika Wefers ${ }^{22}$ • Richard J. T. Wingate ${ }^{23}$. $^{2}$ \\ Richard Hawkes ${ }^{24}$
}

Published online: 6 October 2015

(C) The Author(s) 2015. This article is published with open access at Springerlink.com

\begin{abstract}
The development of the mammalian cerebellum is orchestrated by both cell-autonomous programs and inductive environmental influences. Here, we describe the main
\end{abstract}

Ketty Leto

ketty.leto@unito.it

1 Department of Neuroscience Rita Levi Montalcini, University of Turin, via Cherasco 15, 10026 Turin, Italy

2 Neuroscience Institute Cavalieri-Ottolenghi, University of Turin, Regione Gonzole 10, 10043 Orbassano, Torino, Italy

3 Departments of Pathology \& Immunology and Neuroscience, Baylor College of Medicine, Jan and Dan Duncan Neurological Research Institute of Texas Children's Hospital, 1250 Moursund Street, Suite 1325, Houston, TX 77030, USA

4 Medical Research Council Functional Genomics Unit, Department of Physiology, Anatomy and Genetics, University of Oxford, Oxford OX1 3PT, UK

5 Department of Cell and Developmental Biology, Vanderbilt University Medical Center, 4114 MRB III, Nashville, TN 37232, USA

6 Department of Microbiology and Physiological Systems and Program in Neuroscience, University of Massachusetts Medical School, 368 Plantation Street, Worcester, MA 01605-2324, USA

7 Seattle Children's Research Institute, Center for Integrative Brain Research, Seattle, WA, USA

8 Department of Pediatrics, Genetics Division, University of Washington, Seattle, WA, USA

9 Sorbonne Universités, Université Pierre et Marie Curie Univ Paris 06, Institut de Biologie Paris Seine, France, 75005 Paris, France processes of cerebellar ontogenesis, highlighting the neurogenic strategies used by developing progenitors, the genetic programs involved in cell fate specification, the progressive
10 Centre National de la Recherche Scientifique, CNRS, UMR8246, INSERM U1130, Neuroscience Paris Seine, France, 75005 Paris, France

11 Laboratory of Developmental Neurobiology, The Rockefeller University, New York, NY 10065, USA

12 Department of Biochemistry and Cellular Biology, National Institute of Neuroscience, National Center of Neurology and Psychiatry, 4-1-1 Ogawa-Higashi, Kodaira, Tokyo 187-8502, Japan

13 Developmental Biology Program, Sloan Kettering Institute, New York, NY 10065, USA

14 Department of Neurophysiology, Graduate School of Medicine, The University of Tokyo, Tokyo 113-0033, Japan

15 Department of Integrative Physiology, Gunma University Graduate School of Medicine, 3-39-22 Showa-machi, Maebashi, Gunma 371-8511, Japan

16 Blizard Institute, Barts and The London School of Medicine and Dentistry, Queen Mary University of London, 4 Newark Street, London E1 2AT, UK

17 Department Human Anatomy, IMIB-Arrixaca, University of Murcia, Murcia, Spain

18 Department of Anatomy and Cell Biology, Nagoya University Graduate School of Medicine, Nagoya, Japan

19 Anatomie und Zellbiologie, Anatomisches Institut, Rheinische Friedrich-Wilhelms-Universität, Bonn, Germany

20 Department of Physiology, Feinberg School of Medicine, Northwestern University, Chicago, IL 60611, USA

21 Institut de la Vision, UPMC Université de Paris 06, Paris 75012, France 
changes of structural organization, and some of the betterknown abnormalities associated with developmental disorders of the cerebellum.

Keywords Cerebellum · Progenitors · Purkinje cells · Specification $\cdot$ Differentiation

$\begin{array}{ll}\text { Abbreviations } & \\ \text { BG } & \text { Bergmann glia } \\ \text { CH } & \text { Cerebellar hypoplasia } \\ \text { CN } & \text { Cerebellar nuclei } \\ \text { CF } & \text { Climbing fiber } \\ \text { DWM } & \text { Dandy Walker Malformation } \\ \text { E } & \text { Embryonic day (all timings are } \\ & \text { mouse unless stated otherwise) } \\ \text { ES } & \text { Embryonic stem cell } \\ \text { EGL } & \text { External granular layer } \\ \text { FGF } & \text { Fibroblast growth factor } \\ \text { GL } & \text { Granular layer } \\ \text { GC } & \text { Granule cell } \\ \text { GCP } & \text { Granule cell progenitors } \\ \text { HH } & \text { Hamburger and Hamilton stage } \\ \text { INs } & \text { Interneurons } \\ \text { IsO } & \text { Isthmic organizer } \\ \text { JSRD } & \text { Joubert syndrome and related } \\ & \text { disorders } \\ \text { MB } & \text { Medulloblastoma } \\ \text { ML } & \text { Molecular layer } \\ \text { VZ } & \text { Neuroepithelium of the } \\ & \text { ventricular zone of the 4th } \\ \text { NTZ } & \text { ventricle } \\ \text { PF } & \text { Nuclear transitory zone } \\ \text { PIPs } & \text { Parallel fiber } \\ \text { P } & \text { Pax-2 }{ }^{+} \text {IN progenitors } \\ \text { PWM } & \text { Postnatal day (all timings are } \\ \text { PC } & \text { mouse unless stated otherwise) } \\ \text { PCPs } & \text { Prospective white matter } \\ \text { RL } & \text { Purkinje cell } \\ \text { r1 } & \text { Purkinje cell progenitors } \\ \text { SCA } & \text { Rhombic lip } \\ & \text { Rhombomere 1 } \\ & \text { Spinocerebellar ataxia } \\ \text { Thyroid hormone } \\ \end{array}$

22 Center for Neuropathology, Ludwig-Maximilians-University, Munich, Germany

23 MRC Centre for Developmental Neurobiology, King's College London, London, UK

24 Department of Cell Biology \& Anatomy and Hotchkiss Brain Institute, Cumming School of Medicine, University of Calgary, Calgary T2N 4NI, AB, Canada
(TH; L-triiodothyronine,

T3; L-tetraiodothyronine, thyroxine, T4)

UBCs Unipolar brush cells

\section{Introduction (C. Sotelo)}

The work done on cerebellar development from the late nineteenth century until the 1970s provided substantial and significant information; however, it was only descriptive and barely addressed the mechanisms involved. Over the last two decades, thanks to the technological revolution in molecular biology, our understanding of cerebellar development has drastically changed. We are now going through an exceptional period in our understanding of the mechanisms that underlie the complex development of the cerebellum. An understanding of cell specification regulated by the expression of region-specific combinations of transcription factors or proneural genes, and the formation of synaptic circuits, seems within reach.

Ferdinando Rossi, a few months before his death, undertook the monumental task of writing a monograph on the spectacular advances in our understanding of cerebellar development achieved in the last 20 years. Sadly, Ferdinando died a few months after beginning his monograph. This consensus paper, based on Ferdinando's initial design, summarizes many of these advances and is dedicated to his memory.

The review comprises 18 brief sections, ranging from the early molecular specification of the cerebellar anlage to its mature architecture and pathology. It also includes information on neurogenesis, mainly the specification and origins of neuronal and glial progenitors. An important part of the paper is devoted to Purkinje cells (PCs) as key neurons of the cerebellar cortex responsible for the proliferation of granule cells (GCs) and the establishment of "crude" projection maps with extracerebellar afferent fibers. Finally, the biochemical heterogeneity of PCs allows for a cortical subdivision into distinct functional bands, a presumptive protomap for the development of circuit topography (see in [1]). In this context, the problem of synapse elimination in the process of refinement and stabilization of climbing fiber $(\mathrm{CF})$ connections is also summarized.

\section{The Molecular Specification of the Cerebellar Anlage: The Isthmic Organizer (S. Martinez)}

The description of morphogenetic regulatory processes at specific locations of the developing neural primordium has led to the concept of secondary organizers, which regulate the identity and regional polarity of neighboring neuroepithelial regions [2]. These organizers usually develop within the previously broadly regionalized neuroectoderm with defined genetic boundaries. Their subsequent activity refines local neural 
a

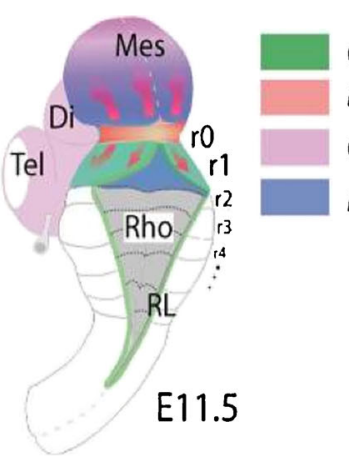

b

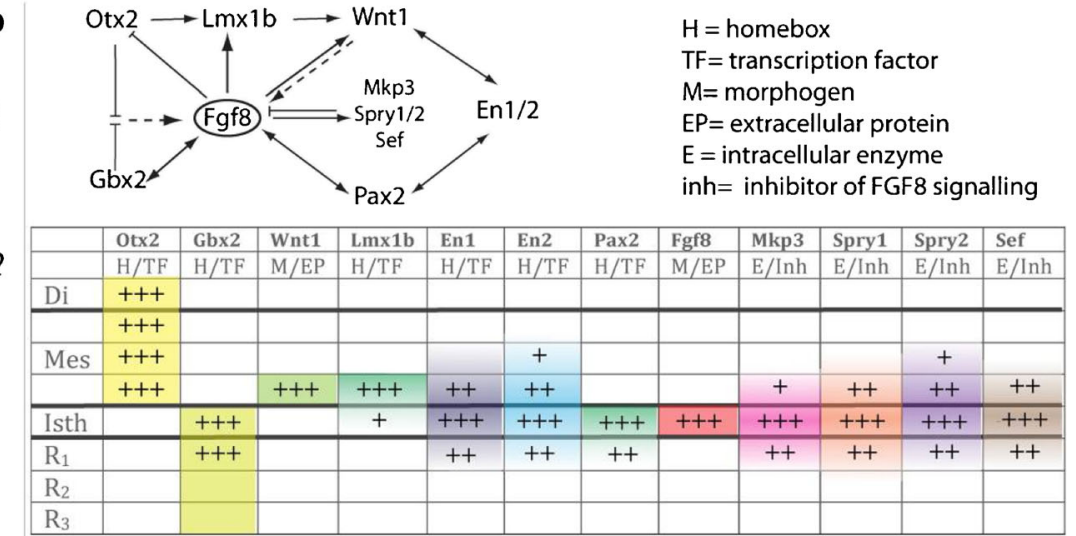

Fig. 1 Topographical location of the mid-hindbrain boundary in the E11.5 mouse embryo. a Dorsal view of an E11.5 mouse embryo illustrating the isthmic constriction (isth) located between the mesencephalon and rhombomere 1 (r1). Rhombomeres $\mathrm{r} 0$ and $\mathrm{r} 1$, which give rise to the cerebellum, are highlighted in (a). The different color codes depict the expression pattern of the most important genes related to the morphogenetic activity and the capacity of the IsO. b Functional interactions (induction/inhibition) of genes that, together with Fgf8, are involved in the molecular maintenance of the isthmic region at E9.5. The table summarizes the expression intensity and expression range of genes along the $\mathrm{AP}$ axis of the neural tube, focusing on the isthmus: the level of RNAm expression for each gene is represented by the number of $(+)$ and the color signifies the region of expression and the expression pattern (homogeneous or gradient), extending rostrally or caudally from the isthmus. $\mathrm{Tel}$ telencephalon, $\mathrm{Di}$ diencephalon, Mes mesencephalon. Modified from [4] identities along the anteroposterior or dorsoventral axes, thus regionalizing the anterior neural plate and neural tube [3, 4].

The isthmic constriction of the neural tube contains the isthmic organizer (IsO; Fig. 1a), which provides structural polarity to the adjoining regions and orchestrates the complex cellular diversity of the mesencephalon (rostrally) and the cerebellum (caudally; [5, 6]; for reviews see [4, 7]). Cerebellar development is dependent on IsO signaling [5]. The molecular nature of the signal has been identified as a member of the fibroblast growth factor (FGF) family, FGF8, which is highly expressed in the most anterior hindbrain. Indeed, beads containing FGF8 protein mimic the activity of the IsO tissue when ectopically transplanted [8] (Fig. 1a).

The earliest molecular event in IsO specification is the differential expression in the neural plate of Otx2 and Gbx2. In the avian embryo at Hamburger and Hamilton (HH) stage 8 [9], an Otx2 and Gbx2 negative neuroepithelial gap separates these domains, but by HH9 they come to overlap across the prospective mid-hindbrain boundary [10]. Then, $F g f 8$ expression is activated (at HH9 in chick and at embryonic day (E) 8.5 in mice) at the interface of the OTX2- and GBX2-positive neuroepithelial domains. The co-expression of $\mathrm{Otx} 2$ and $G b \times 2$ in the IsO territory essentially disappears by HH11-12 (chick) and E10 (mouse), and both domains become thereafter mutually excluded and complementary. The limit determined by Otx 2 and Gbx 2 marks the mid-hindbrain molecular boundary (MHB) [10-13]. Secondarily, Lmx1b and Wnt1 are coexpressed in a thin band confined to the caudalmost Otx 2 expression domain, abutting the Fgf8 domain at the most rostral edge of the hindbrain. Note that although early Fgf8 expression appears in the territory co-expressing $O t \times 2 / G b x 2$, double deletion of these two genes encoding transcription factors does not primarily affect the activation of $F g f 8$ expression $[13,14]$. Other genes expressed at early stages across the prospective MHB, such as Pax-2 and Iroquas (Irxs), seem also to be required for the expression of $O t x 2, G b x 2$, and $F g f 8$ and the proper formation of the mesencephalic and rhombencephalic vesicles. Moreover, FGF8 signaling may act at the IsO in concert with other signaling molecules, such as WNT1, sonic hedgehog (SHH), and transforming growth factor (TGF)- $\beta$ family members. The morphogenetic activity of the IsO is thus the consequence of the specific temporospatial expression of molecular signals that regulate the specification and structural development of mesencephalic and cerebellar neuroepithelial territories (Fig. 1b). Alterations of $F g f 8$ and $G b x 2$ gene expression lead to massive disruption of the mid-hindbrain neural territory due to gene patterning deregulation [15]. A decreasing gradient of FGF8 protein concentration in the alar plate of the isthmus and rhombomere 1 (r1) is fundamental for cell survival and the differential development of cerebellar regions [7, 16, 17].

Finally, in the proposed mechanism by which FGF8 signaling spreads over a field of target cells, at least in zebrafish, patterning is established and maintained by two essential factors: first, the free diffusion of FGF 8 molecules away from the secretion source through the extracellular space and secondly an absorptive function of the receiving cells regulated by FGF receptor-mediated endocytosis [18]; reviewed in [4]. The differential orientation and polarity of the FGF8 signal seems to be directly dependent on the spatial position of FGF8-related secondary organizers and on the activity of the negative modulators MKP3, SEF, and sprouty1/2 (SPRY1/2). FGF8 may also translocate into the nucleus, and this nuclear FGF8 may function as a transcriptional regulator to induce Spry2 in the 
isthmus independently of ERK phosphorylation. Similar findings in mouse showed that maintenance of the Spry2 expression pattern along the isthmic region occurs in the absence of both FGF8 in the extracellular compartment and ERK phosphorylation (reviewed in [4]).

At E9, following territorial specification and the closure of the neural tube, murine cerebellar histogenesis begins with the specification of cerebellar progenitors. Several studies have demonstrated that all cerebellar cells are generated by the neuroepithelium of the alar plate of r1 [19-22]. Conversely, the most dorsal region of $\mathrm{r} 1$ gives rise to the roof plate, which produces cells of the choroid plexus [23].

\section{Specification of Cerebellar Progenitors (M. Hoshino)}

All cerebellar neurons are produced in the alar plate of $\mathrm{r} 1$ that is located rostrally adjacent to the isthmus. In this region, the dorsalmost part of the neuroepithelium gives rise to the roof plate while the ventrally and intermediately located parts become the ventricular zone (VZ) and the rhombic lip (RL).

Recent genetic and viral lineage tracing studies have clarified the origins and birthdates of distinct subtypes of cerebellar neurons. Cerebellar glutamatergic and GABAergic neurons are generated from the RL and the VZ respectively. In mice, glutamatergic neurons in the cerebellar nuclei $(\mathrm{CN})$ leave the cerebellar RL at early stages (E10.5-12.5) and GCs at middle to late stages (E13.5 onward) [24-26]. Unipolar brush cells (UBCs) are known to emerge at relatively late developmental stages [27]. In mice, PCs are born at E10.5E13.5, GABAergic interneurons (INs) in the $\mathrm{CN}$ at E10.5E11.5, and Golgi cells at approximately E13.5-postnatal (peak around E14-E16) [28-31]. Late-born GABAergic INs, including stellate and basket cells, derive from secondary precursors in the prospective white matter (PWM) at later stages (from E13 to P5 with a peak around birth) [32, 33]. Thus, cerebellar neuronal subtypes depend on when and where they are generated from neural progenitors. This leads to the idea that cerebellar progenitors with their own spatial and temporal identities produce specific neuronal subtypes.

Two basic-helix-loop-helix (bHLH) proteins, ATHO1 (also called MATH1) and PTF1a, participate in the specification of the spatial identities of cerebellar progenitors. Atohl is expressed in the progenitors of the RL, and targeted Atoh1 disruption results in the loss of glutamatergic neurons in the cerebellum [24-26]. On the other hand, Ptfla is expressed in the VZ progenitors and Ptfla deletion results in the loss of all cerebellar GABAergic neurons [34, 35]. Furthermore, misexpression of ATHO1 and PTF1a in the VZ and the RL results in the ectopic production of glutamatergic and GABAergic neurons, respectively [36]. These facts suggest that Atohl and Ptfla confer the spatial identities of the RL and the VZ on cerebellar progenitors to produce glutamatergic and GABAergic neurons, respectively.

Atoh1 expression in the RL is regulated by TGF $\beta$ and Delta-Notch signaling [37-41]. Ptfla expression is influenced by SHH signals [42]. PTF1a and ATHO1 can downregulate each other's expression-forced expression of Atohl suppresses Ptfla and, conversely, forced expression of Ptfla suppresses Atoh1 [36, 43]. Consistent with this view, Atoh1 expression ectopically expands into the VZ in Ptfla mutants [35, 36]. However, ectopic Ptfla expression is not observed in the RL of Atoh1 mutants [36], suggesting that PTF1a suppresses the expression of Atohl but the converse is not physiologically true in the cerebellar primordium.

\section{Glutamatergic Phenotypes}

In contrast to the GABAergic neuron progenitors in the VZ, the machinery to specify cerebellar glutamatergic neuron subtypes remains elusive. However, even when glutamatergic neurons are ectopically produced from the VZ by ectopic expression of ATHO1, the generation of neuronal types follows the temporal schedule of the normal glutamatergic neurons derived from the RL [36]. This suggests that, as for GABAergic neuron progenitors, glutamatergic neuron progenitors in the RL may change their temporal identities from "glutamatergic $\mathrm{CN}$ neuron-producing type" to "GC/UBCproducing type" during development (Fig. 2). In the RL at late stages, some progenitors express either GC (PAX6) or UBC (TBR2) markers [27]. This suggests that GCs and UBCs may be produced from distinct progenitors in the RL, although some cells in the RL are found to express both markers (see also "Unipolar brush cells" section). Because the loss of the roof plate or targeted disruption of genes expressed in the roof plate affects the morphology and the nature of the RL [23, 44, 45], extrinsic factors from the roof plate may also play important roles to regulate the identities of glutamatergic neuron progenitors in the RL.

\section{GABAergic Phenotypes}

Cerebellar GABAergic neurons can be categorized into two subtypes: PCs and Pax- $2^{+}$INs. Each subtype is generated from a distinct progenitor in the VZ:PC progenitors (PCPs) and $\mathrm{Pax}-2^{+}$IN progenitors (PIPs). At the early stages, only a small number of PIPs are located in the rostralmost region of the $\mathrm{VZ}$ and a large number of PCPs occupy the remaining regions in the VZ. As development proceeds, PCPs gradually transit to become PIPs spreading from ventral to dorsal. This temporal identity transition of cerebellar GABAergic neuron progenitors from PCPs to PIPs is negatively regulated by Olig2 and positively by Gsx1 [46]. 
Fig. 2 Progenitors and neurons in the cerebellum. Right is dorsal, left is ventral. GNPS

glutamatergic neuron progenitors, PIPs Pax $-2^{+}$IN progenitors, $P C P S$ Purkinje cell progenitors, $r p$ roof plate, GABA-INS $(C N)$ GABAergic interneurons in the cerebellar nuclei, Glu-CN glutamatergic neurons in the cerebellar nuclei

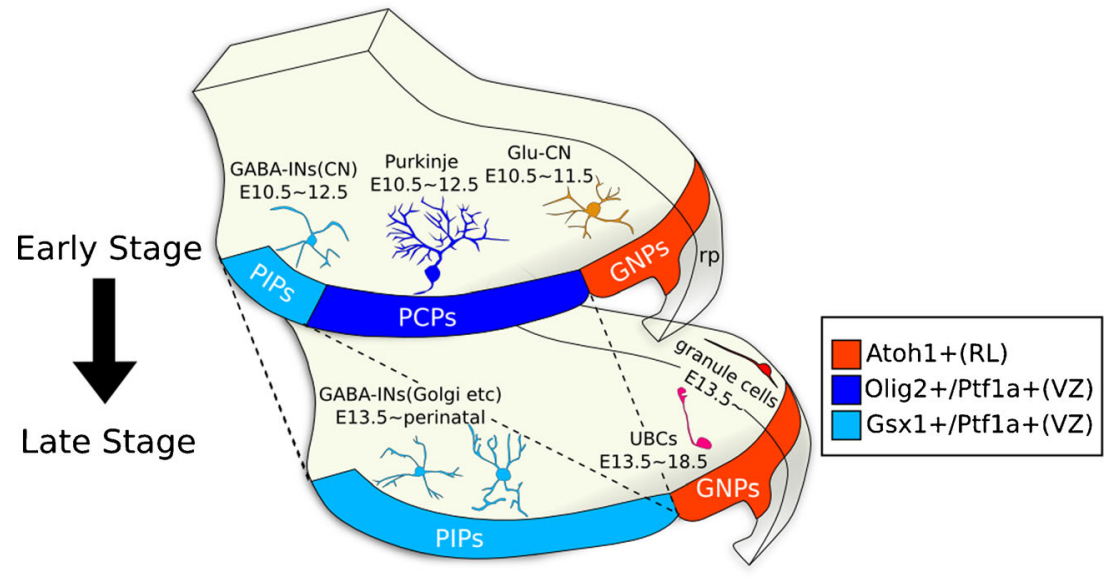

The VZ subregion containing PCPs is also characterized by the strong expression of E-cadherin and the cell surface marker Neph3, which is a direct downstream target gene of PTF1a [47, 48]. Moreover, downstream of PTF1a, Neurogenin 1 and Neurogenin 2 are expressed in the VZ and implicated in cellcycle control and PC development $[49,50]$. Expression of LHX1/LHX5 [23, 51] and Corl2 [52], seen in the subventricular zone, indicates the commitment of VZ-born daughter cells to a PC fate, and these markers are useful for assessing the differentiation of embryonic stem (ES) cell-derived PCs [53].

Based on the birthdates of distinct PAX-2 $2^{+}$INs, PIPs may first produce GABAergic INs in the $\mathrm{CN}$ (from $\sim \mathrm{E} 10.5$ ) and then generate Golgi cells (from $\sim$ E13.5; Fig. 2). At later stages of neurogenesis, PIPs may give rise to precursors in the PWM that eventually generate the stellate and basket cells.

\section{Patterning of the Cerebellar Cortex: Rhombic Lip-Derived Phenotypes}

\section{Granule Cells}

During cerebellar development, granule cell progenitors (GCPs) arise in the RL and undergo a prolonged clonal expansion that generates a population of granule neurons that outnumbers the total neuronal population of the cerebral cortex.

\section{Cerebellar Granule Cell Neurogenesis and Migration (M. E. Hatten)}

Between E12.5 and E16, RL-derived precursors spread across the dorsal surface of the cerebellar anlagen to form the external granular layer (EGL) [54]. At this stage, RL-derived progenitors express the bHLH transcription factor gene Atoh1 [25, 26, 55], the zinc finger protein genes Zic1 and Zic3 [56], the homeobox gene Meis 1 [51], the paired box gene 6 Pax6 [57], and the calmodulin-dependent phosphodiesterase 1C gene (Pdelc) [58] (Fig. 3). Atoh1 expression is induced by BMP signaling in the choroid plexus and the roof plate $[55,59]$ and maintained by the roof plate organizer [41]. While the vast majority of $\mathrm{ATOH}^{+}{ }^{+} \mathrm{RL}$ derivatives generate GCPs that migrate tangentially in the EGL, fate mapping experiments indicate that a subpopulation migrates rostrally to the nascent $\mathrm{CN}[25,26$, $51,60]$ (see "Development of the Cerebellar Nuclei" section below). Recent studies demonstrate that FGF signaling allocates discrete subpopulations of RL-derived $\mathrm{ATOH} 1^{+}$cells, with downregulation of FGF signaling being required to generate RL-derived cerebellar neurons [61].

During the early postnatal period, multiple mitogenic pathways expand the EGL from a thin layer to a layer six to eight cells deep. SHH provided by PC neurons is a major driver of GCP proliferation [62]. Molecular genetic studies demonstrate that ATHO1 [24] and MYCN [63] are required for GC specification and the expansion of the pool of GCPs in the early postnatal period. The importance of Shh to cerebellar histogenesis is underscored by elegant genetic analyses demonstrating that levels of SHH signaling control the foliation patterning of the cerebellar cortex [64] (see "Cerebellar Foliation" section), and studies on human medulloblastoma (MB) implicate defects in SHH signaling in MB formation (reviewed in [65], see "Deregulated Developmental Pathways in Medulloblastoma" section). The Notch2 pathway also stimulates the expansion of GCPs during cerebellar development as treatment of GCPs with jagged 1 (JAG1), a ligand of Notch2, markedly stimulates GCP proliferation and inhibits GC differentiation [66]. Genetic studies demonstrate that one mechanism for the action of activated NOTCH2 involves antagonizing BMP signaling [67] and upregulating Atohl expression [40]. Support for these key steps in GCP neurogenesis comes from the differentiation of $\mathrm{mES}$ cells into GCPs by stepwise treatment with morphogens that establish the cerebellar territory (WNT1, FGF8) [68], followed by BMPs that specify a GCP identity [55]. Subsequent treatment with SHH and JAG1 expands the ES-derived GCPs and exposure to BDNF supports terminal differentiation [68]. Recent gene expression studies using ES cells that express a NeuroD1 translating ribosome affinity purification (TRAP) tag to facilitate purification of GCP RNA show that the transcriptome of ES- 


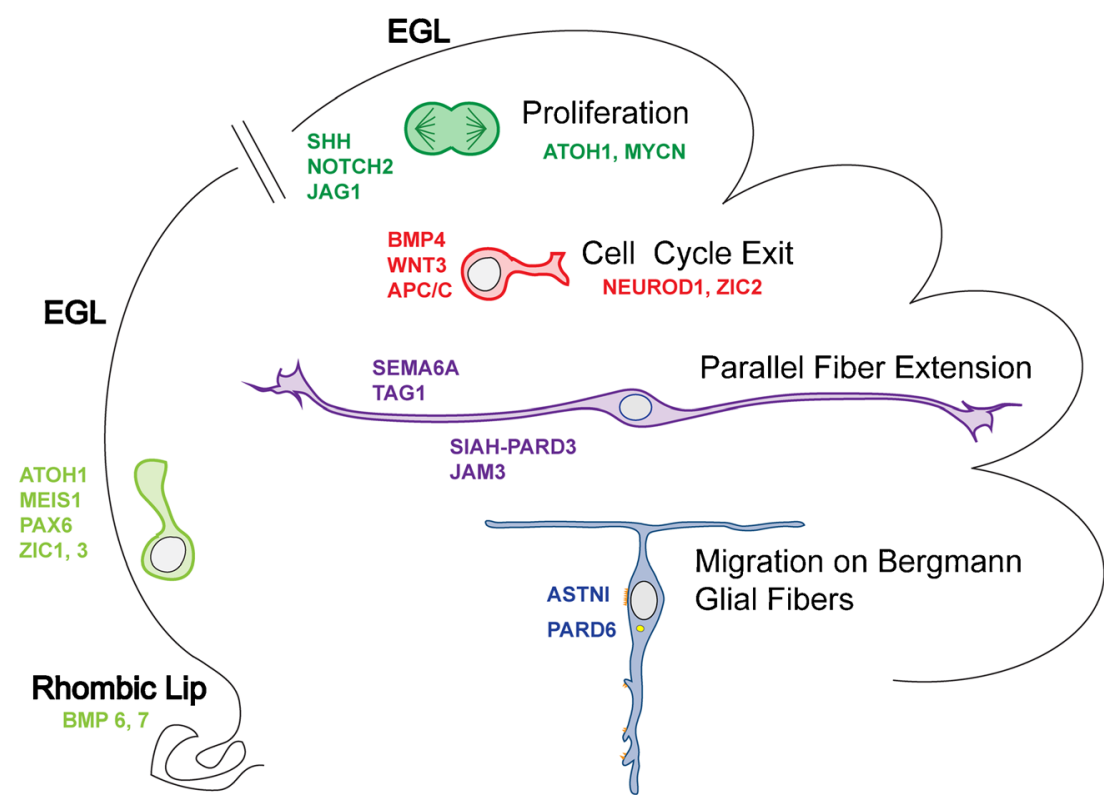

Fig. 3 Granule cell neurogenesis and migration. GCPs arise in the RL of the cerebellar anlagen, after which early, proliferating GCPs (light green) migrate across the surface of the anlagen to form the EGL. After birth (broken line), GCPs located in the outer aspect of the EGL (dark green) express the transcription factors (TFs) MATH1/ATOH1 and NMYC, and proliferate in response to the mitogens Shh and JAG1 (NOTCH2). BMP4, WNT3, and APC/C inhibit GCP proliferation and promote cellcycle exit. Postmitotic GCPs (red) express NEUROD1 and ZIC2. SIAHPARD3 and JAM3, as well as SEMA6A, promote exit from the outer

derived GCPs generated by this approach approximates that of P7 GCs (Zhu, Tamayo, Mesirov, and Hatten, unpublished results).

Following clonal expansion in the EGL, GCPs exit the cell cycle, downregulating ATOH1 and upregulating NeuroD1 [69], which is required for GCP differentiation [70]. Several pathways are thought to provide negative regulation of GCP proliferation, including BMP4, WNT3, and the anaphase-promoting complex/ cyclosome $\left(\mathrm{APC} / \mathrm{C}^{\mathrm{Cdh} 1}\right)$ ubiquitin ligase. WNT3 suppresses GCP growth through a non-canonical WNT signaling pathway, activating prototypic mitogen-activated protein kinases (MAPKs), the RAS-dependent extracellular-signal-regulated kinases 1/2 (ERK1/2) and ERK5, instead of the classical $\beta$-catenin pathway [71]. WNT3 inhibits GCP proliferation by downregulating proliferative target genes of the mitogen $\mathrm{SHH}$ and the bHLH transcription factor ATHO1 [71]. CK1 $\delta$ is another novel regulator of GCP expansion as a loss of $C k 1 \delta$ or treatment of GCPs with a highly selective small molecule CK1 $\delta$ inhibitor inhibits GCP expansion. CK1 $\delta$ is targeted for proteolysis via $\mathrm{APC} / \mathrm{C}^{\mathrm{Cdh} 1}$ ubiquitin ligase, and conditional deletion of the $\mathrm{APC} / \mathrm{C}^{\mathrm{Cdh} 1}$ activator, $C d h 1$, in cerebellar GCPs results in higher levels of $\mathrm{CK} 1 \delta$, suggesting an important role for the $\mathrm{APC} / \mathrm{C}^{\mathrm{Cdh} 1}$ complex in GCP cell cycle exit [72].

Postmitotic GCPs express the axonal glycoprotein TAG1 (CNT2), a contactin-related adhesion molecule [73, 74], which functions in parallel fiber (PF) extension. Genetic
EGL where GCPs extend TAG1 positive PF axons (purple). Migrating neurons (blue) extend a leading process tipped with short filopodia and lamellipodia that enwraps the glial fiber (not shown). As the neuron moves, a broad interstitial junction (yellow) is formed beneath the cell soma that contains the neuron-glial adhesion protein ASTN1. PARD6, localized at the centrosome (yellow), coordinates the forward movement of the soma and centrosome through activation of Myosin II-Actin motors that pull the cell forward. EGL external granular layer

experiments show Semaphorin 6A (Sema6A) functions in the switch from tangential migration in the EGL to radial migration along Bergmann glia (BG) [75] by a mechanism that involves binding to Plexin A2 [76]. Recent live imaging and functional studies also demonstrate a critical role for the SIAH E3 ubiquitin ligase, which controls proteosomal degradation the Pard3A polarity protein and regulates GCP adhesion during EGL exit via the junctional adhesion molecule JAM-C [77]. During PF extension, the cell soma extends a leading process along the radial BG fiber [78]. Live imaging experiments demonstrate that migrating GCPs form an extensive adhesion junction beneath the cell surface involving the neuron-glial adhesion protein ASTN1 [79-82] and extend a leading process with short filopodia and lamellipodia that enwrap the glial fiber [83, 84]. Forward movement of the cell soma follows the release of the neuron-glial adhesion junction beneath the cell body, after which the neuron glides along the glial fiber until a new adhesion forms [84]. Live imaging functional studies show that the PAR6 polarity complex localizes to the centrosome and coordinates the forward movement of the centrosome and soma [85] by a mechanism that includes activation of actomyosin contractile motors in the proximal region of the leading process [86]. These studies suggest a model by which actomyosin contractility in the leading process, rather than in a classical "leading edge" at the tip of the leading process, provides the force needed for forward 
movement. Postmigratory GCs settle in the nascent granular layer (GL) where they extend dendrites and form synapses with mossy fiber afferent axons (inter alia).

\section{Voltage-Sensitive Regulation of Dendrite Formation and its Timing in Granule Cells (B. Ding and D. L. Kilpatrick)}

GCs relay and process neural inputs into the cerebellum from mossy fiber afferents to PC efferents. Each GC dendrite apparently synapses with a single mossy fiber, which has the capacity to promote combinatorial encoding and the enhanced processing of sensory input to the cerebellum [87]. The developmental regulation of GC dendrite/synapse formation is therefore central to cerebellar circuitry.

Studies of dendrite-related timing mechanisms in GCs initially focused on the Gabra6 gene encoding the $\mathrm{GABA}_{\mathrm{A}}$ receptor $\alpha 6$ subunit, which exhibits delayed or "late" gene expression in maturing GCs [88]. These and related studies revealed that the Nuclear Factor One (NFI) transcription factor family, and in particular NFIA, is important for dendrite formation and Gabra6 expression in maturing GCs [88-90]. Further, while NFI proteins are constitutively expressed in the nucleus throughout GC maturation, the occupancy of an essential NFI binding site within the Gabra6 promoter closely mirrors the temporal onset of Gabra6 expression [88]. These studies directly implicated NFI occupancy as a timing mechanism for Gabra6 expression.

What regulates NFI temporal binding to the Gabra6 gene in developing GCs? Wang et al. [88] found that NFI occupancy in pre-migratory GCs, prior to departure from the EGL and arrival in the GL, is inhibited by binding of the trans-repressor REST to the Gabra6 promoter. REST expression and DNA binding decline as GCPs initiate differentiation, and knockdown of REST selectively enhances the onset of Gabra6 expression and its binding by NFI at early, but not later, developmental times [88]. Thus, REST is an early repressor of NFI occupancy, preventing premature onset of NFI binding to the Gabra6 gene in pre-migratory GCs within the EGL.

Since GC dendrite/synapse formation takes place within the GL additional, post-migratory mechanisms must also be involved in the timing of NFI occupancy. Recent studies identified an NFI developmental "switch" program operating in GCs maturing within the GL [91]. This program consists mainly of several hundred NFI-regulated genes expressed with two distinct time frames: "early" genes downregulated by NFI as the GL matures, and "late," temporally upregulated genes associated with mature GCs that are activated by NFI [91]. Importantly, many late-expressed genes participate in dendrite/synapse formation and function, directly implicating the NFI switch program as an essential component of GC synaptic maturation.

As observed for Gabra6, a central feature of the NFI switch program is delayed NFI occupancy of late genes as GCs mature [91]. So what regulates NFI temporal binding of late genes within the GL? Resting membrane potential is more depolarized in immature GCs and becomes hyperpolarized as the GL matures [92]. Maintaining cerebellar tissue in a depolarizing medium prevents the maturation of GC dendrites in the GL [92]. This depolarization block involves activation of voltage-gated $\mathrm{Ca}^{2+}$ channels (VGCCs) and the $\mathrm{Ca}^{2+}$-dependent stimulation of calcineurin phosphatase, which inhibits a gene expression switch [93].

Voltage-driven mechanisms also regulate the NFI switch [91]. Importantly, depolarization blocks NFI temporal occupancy of late genes via activation of VGCCs and calcineurin [91]. Calcineurin activity is elevated in the immature cerebellum and declines with development, consistent with its inhibitory role during $\mathrm{GC}$ dendritogenesis in vivo [91]. Calcineurin promotes NFAT nuclear localization, and NFATc4 mediates the actions of calcineurin on the NFI switch by binding to late genes in immature GCs and repressing NFI occupancy [91]. This led to a model in which declining calcineurin activity and resultant NFATc4 departure from late genes in the maturing GL becomes permissive for the onset of NFI temporal binding and NFI switch programming (Fig. 4). Calcineurin also inhibits GC dendritogenesis via the repressor MEF2A [94]. Thus, transcriptional de-repression plays an important role in initiating GC dendrite formation.

Finally, late-expressed trans-activators (e.g., ETV1 [95]) also may control the timing of NFI binding and dendritogenesis in the developing GL, subsequent to NFATc4 departure (Fig. 4). This may provide greater flexibility in the temporal expression and function of distinct gene subsets during GC dendritogenesis-synaptogenesis.

\section{Unipolar Brush Cells (G. Sekerková)}

UBCs are a class of small excitatory INs associated with the cerebellar cortex and cerebellar-like structures [96-100]. They are especially enriched in the flocculonodular lobules of the cerebellum $[100,101]$ and the dorsal cochlear nucleus $[100$, $102,103]$, regions that process sensorimotor signals regulating head, body, and eye position. Although our knowledge of UBCs derives mainly from studies in rodents, the main features of UBCs are highly conserved across species: UBCs are already recognized in teleosts and are found virtually unchanged in all mammals, including humans [100, 104-111]. A typical UBC has a single thick dendrite ending in a brush of fine dendrioles, which form a specialized giant synaptic junction with a single mossy fiber terminal (Fig. 5a; [100, 112]). UBC axons branch locally within the GL where they create an intrinsic mossy fiber system superimposed on the canonical extrinsic mossy fiber system [100, 113, 114]. All UBCs are characterized by these morphological features, yet they are classified into type I and type II UBCs, which represent two chemically and functionally distinct subclasses [102, 115, 


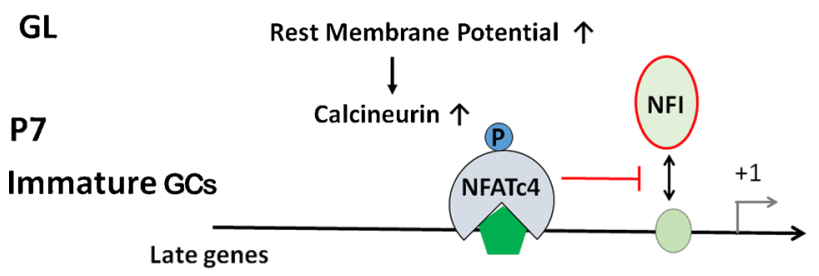

P9 $\rightarrow$ P21
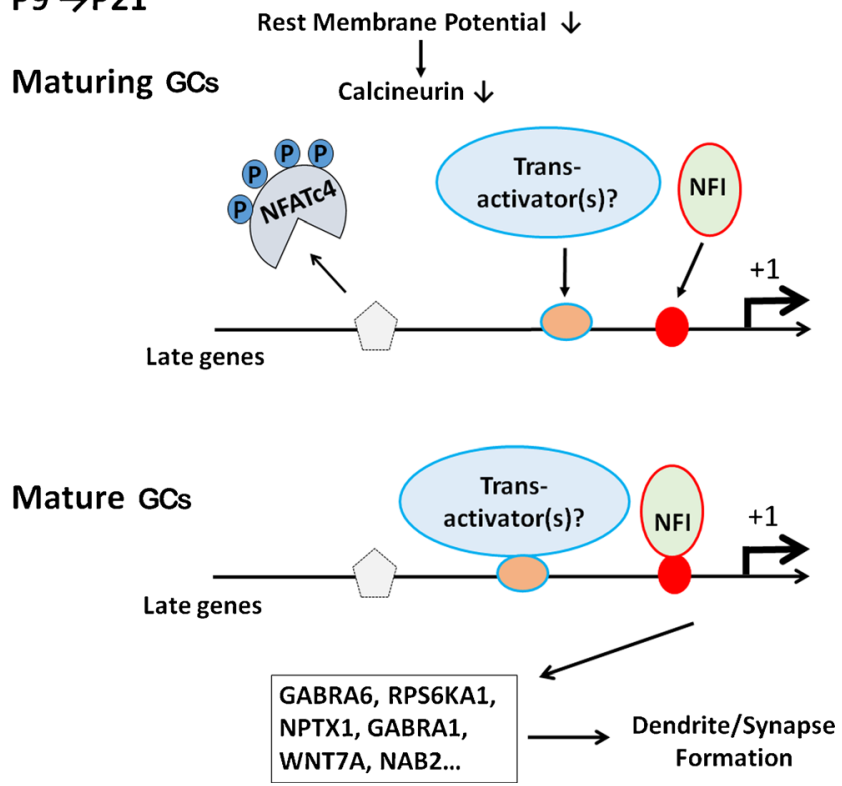

Fig. 4 Voltage-sensitive regulation of NFI temporal occupancy in maturing GCs. In the immature GL of the cerebellum (P7), a more depolarized resting membrane potential elevates calcineurin $(\mathrm{CaN})$ activity, leading to NFATc4 nuclear localization and binding to NFI-late genes. NFATc4 occupancy represses late-gene binding and activation by NFI, which is present in the nucleus throughout CGN development. As the cerebellum matures (P9-P21), the resting membrane potential becomes more hyperpolarized and $\mathrm{CaN}$ activity and NFATc4 nuclear localization and promoter occupancy decline. This becomes permissive for NFI binding to and activation of late genes in more mature GCs within the GL, promoting dendrite and synapse formation. NFI temporal occupancy of late genes may also be stimulated subsequent to NFATc4 departure by the binding and/or activity of trans-activators that also regulate late gene expression. $G L$ granular layer, $G C s$ granule cells

116] that correspond to the previously identified calretinin (CR)-positive and metabotropic glutamate receptor (mGluR) $1 \alpha$-positive UBCs, respectively [100,101, 117-121].

Birthdating studies with bromodeoxyuridine labeling revealed that the two UBC types are also generated within different although overlapping time windows [120]. In rats, type I UBCs are born around embryonic day E16-19 ( E14-17 in mouse) while type II UBCs are produced over a longer period of time extending from E18 (in mouse E16) presumably to early postnatal days (P) $0-1$. Initially, they were suggested to originate from a hotspot in the EGL [122], but subsequent histological studies indicated a VZ origin [123]. The definite origin of UBCs was however revealed by genetic fate mapping studies. Englund and colleagues [27] using TBR2, a T- domain transcription factor, as a marker showed that the UBCs - just as for the other glutamatergic neurons of the cerebellum and cochlear nucleus $[25,26]$ - originate from ATHO1-expressing progenitors of the RL. The UBC progenitors also express WNT1 early in development (E10.5-13.5), but the expression is downregulated before UBCs migrate from the RL [124]. The newly generated UBCs remain in the RL for an additional 1-2 days after which they exit through a narrow channel and migrate to their final destination $[27,38,125]$. The cerebellar UBCs migrate dorsally through the white matter and avoid the cell masses of future $\mathrm{CN}$ neurons. Most UBCs reach the GL by P10, several days before GC neurogenesis is complete [27]. The final differentiation of UBCs occurs between P2 and P28. Morin et al. [126] divided the maturation of type I UBCs into four distinct stages based on the morphological appearance of the dendritic brush (the protodendritic, filopodial, intermediate brush, and dendriolar brush stages). In the last stage (P21-P28), the UBCs already exhibit mature UBC morphology and, although their brush keeps expanding, it does so without qualitative changes in the dendriolar pattern. Unpublished data (Sekerková et al.) suggest that somato-dendritic differentiation of the two subtypes is also differentially regulated. In long-term organotypic cerebellar cultures (from P8 mice; 20-25 days in culture), only type II UBCs develop brushes while most of type I UBCs produce long, "branching" dendrites (Fig. 5b, c). Moreover, in vivo, type I UBCs undergo chemical changes (Fig. 5d). Around the first postnatal week, a subset of UBCs coexpresses both CR (the marker of type I) and mGLUR $1 \alpha$ (the marker of type II UBCs) and fewer than $10 \%$ of UBCs express only CR. By the third week, the number of doublelabeled UBCs decreases dramatically (they virtually disappear by 2 months of age; $[100,115])$ and concomitantly the number of the purely CR-positive UBCs increases (to $\sim 33 \%$ of total UBCs). This suggests different postnatal differentiation mechanisms for the UBC subtypes. The differentiation of the brush and the downregulation of mGLUR $1 \alpha$ in type I UBCs seem to coincide with the establishment of the first synaptic contacts with external mossy fibers $(\sim \mathrm{P} 12)$.

\section{Patterning of the Cerebellar Cortex: Ventricular Zone-Derived Phenotypes}

GABAergic neurons of the cerebellar cortex comprise projection PCs and local INs. All these cells derive from progenitors pools (PCPs and PIPs, respectively) located in different VZ subregions (see "Glutamatergic Phenotypes" section).

\section{Purkinje Cell Migration (T. Miyata)}

Morphologically, PCPs span the ventricular (apical) and pial (basal) surfaces of the cerebellar primordium, taking an 

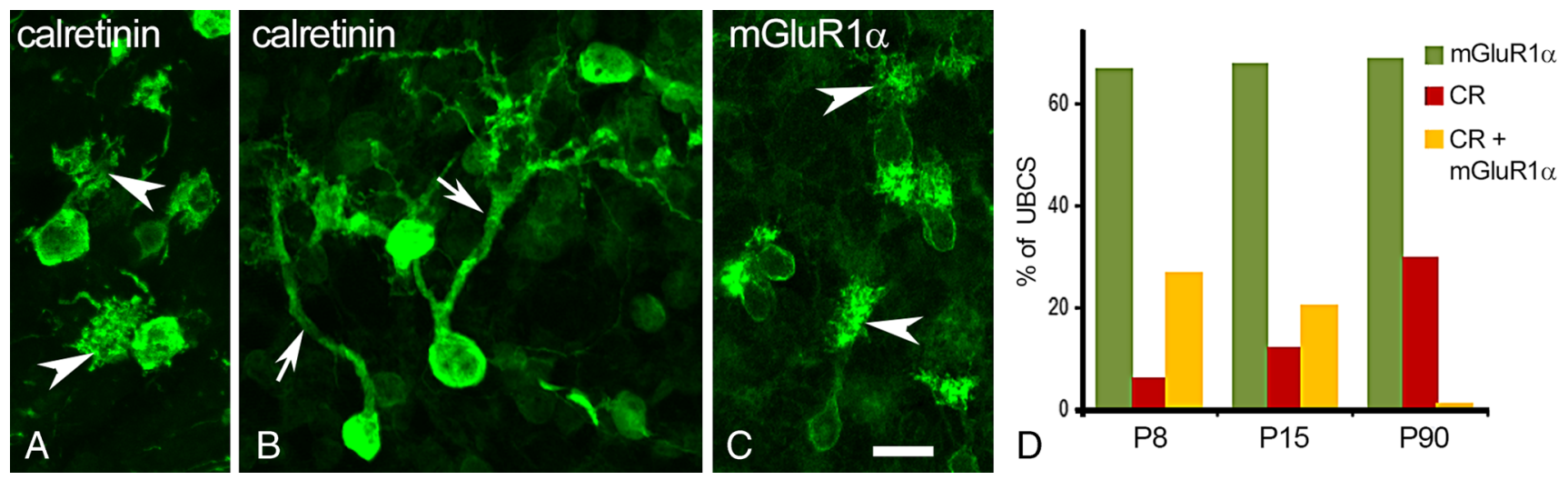

Fig. 5 UBCs visualized by cell type specific markers. a The typical morphological features of UBCs; a short thick dendritic shaft and brush-like dendrioles (arrowheads). Calretinin immunolabeling of a P28 mouse cerebellum. b, c Images obtained from long-term organotypic mouse cerebellar cultures. In this experiment, the cerebellar nodulus was isolated at P8 and kept in culture for 22 days. During this time, most of the CR-positive type I UBCs (b) instead of a dendritic brush have long, branching processes (arrows). Under the same condition, all mGluR1 $\alpha$ positive type II UBCs develop distinct brushes (arrowheads). Scale bar in

elongated (neuroepithelial or radial glial) shape [127]. How PCPs behave is not well understood: whether they divide symmetrically or asymmetrically, how they undergo interkinetic nuclear migration, and the morphology of newly generated PCs in the VZ all remain unknown. Also, whether (and how) a single class of PCPs changes in a temporally regulated manner to generate the different $\mathrm{PC}$ subclasses or whether PCPs are inherently heterogeneous within VZ needs to be studied.

Nascent PCs from E14 in mice form a layer several cells thick called the PC plate [128, 129]. This transient structure normally spreads through the presumptive cerebellar cortex until late embryonic days, followed by PC-monolayer formation during the early postnatal stage triggered by RELN signaling (see "Development of Cerebellar Compartmentation" section). The supply of PCs to the cortex occurs sequentially $[129,130]$. PCs generated at E10, especially ones born at the posterior VZ close to the RL, are the first to finish their migration and form the plate [131,132]. This may be because the distance between their birthplace and the goal is the least among the entire PC population (no more than $\sim 200 \mu \mathrm{m}$ ). PCs generated at E11 join the plate from E15, followed by E12-born PCs from E16. These later-born PCs (as well as PCs generated anteriorly at E10) need to migrate over much longer distances than the posteriorly E10-born PCs (up to 700$800 \mu \mathrm{m}$ in mice).

The early/posterior-born PCs take a tangential migratory route (which is parallel to the pial surface) until E13. They are characterized by long leading processes $(100 \mu \mathrm{m}$ or longer), which morphologically and molecularly resemble axons, and a much shorter trailing process containing the Golgi apparatus. This tangential migration crosses radial glial fibers (c) $=10 \mu \mathrm{m}$ and applies to panels (a)-(c). d Developmental regulation of rat cerebellar UBC chemotype. The UBC fraction expressing only mGluR $1 \alpha$ (green bars) remains about the same between P8 and P90. However, at P8, a substantial fraction of UBCs expresses both calretinin and mGluR1 $\alpha$ (yellow bars). These double labeled cells become rare at P90. By P90, UBCs either express calretinin (type I UBCs) or mGluR1 $\alpha$ (type II UBCs). The red bars represent the UBC fraction expressing only calretinin

and is reminiscent of that exhibited by RL-derived cells. The initial departure of this early/posterior-born population from the $\mathrm{VZ}$ and the subsequent tangential migration are normal in the cerebellum of reeler mice. The early/posterior-born PCs then change orientation by sending the original Golgi-rich trailing process into the cortical region that intensely expresses RELN (produced at E13 by RL-derived tangentially migrating cells of the nuclear transitory zone, NTZ) [131]. This switchback-like, tangential-to-radial orientation change between E13 and E14 is strictly dependent on RELN. These observations suggest a short-range action of RELN. This model is supported by co-culture experiments showing that PCs (both normal and reeler-derived) will align in vitro along an artificial RELN-rich zone [133]. However, transgenic reeler mice artificially expressing RELN under the control of the nestin promoter showed an apparently normal (rescued) arrangement of PCs [134], suggesting that RELN may regulate PC behavior in a context-dependent manner.

In contrast to the posterior-born PCs, PCs born more anteriorly exhibit radially oriented somatal morphologies during migration. The close spatial relationship between these PC somata and radial glial fibers supports the prevailing model that PC migration is guided by radial glial fibers $[129,135]$. These radially oriented PCs at E12 or E13 have axon-like fibers that ascend towards the pia [131], while postmigratory (late embryonic) PCs forming the plate have downward-directing axons [129, 130, 136]. Several points remain to be elucidated: how these anterior-born PCs proceed the mid-embryonic migration processes, whether these cells are also affected by dynamic changes of cellular orientation or polarity, and how RELN contributes to histogenesis by these radially oriented PCs. 


\section{Development of Cerebellar Compartmentation (M. Arancillo, R. Hawkes, R. V. Sillitoe)}

The fundamental architecture of the cerebellum is an elaborate pattern of transverse zones and parasagittal stripes [137, 138] that is highly reproducible between individuals and conserved across birds [139, 140] and mammals (reviewed in [141, 142]). Compartmentation is revealed by intrinsic differences between subsets of PCs (e.g., zebrin II/aldolase C (ZII [143]; phospholipase C (PLC) $\beta 3 / 4$ [144]; HSP25 [145]), the restriction of INs (reviewed in [146]), patterns of pathological PC death (reviewed in [147]), the phenotypes of multiple cerebellar mutants (e.g., lurcher $\left(\right.$ Grid $\left.^{L C}\right)$ - [148]; rostral cerebellar malformation $\left(\right.$ Unc $\left.\mathrm{c}^{\mathrm{rcm}}\right)$ - [149]; weaver $\left(\mathrm{Kcnj}^{\mathrm{wv}}{ }^{\mathrm{w}}\right)$ - [150]; cerebellar deficient folia $\left(\right.$ Ctnna $\left.2^{\text {cdf }}\right)$ - [151]), and the topography of afferent and efferent projections (reviewed in [152]).

Cerebellar compartmentation appears to start at $\sim \mathrm{E} 10$ in the VZ of the fourth ventricle but not earlier, e.g., [153-156]. PC subtype specification likely occurs when PCs undergo terminal mitosis between E10 and E13 [54] in the Ptfla-expressing progenitor domain of the VZ ([23, 34, 49]: see "Glutamatergic Phenotypes" section). Birthdating studies have identified two distinct PC populations: an early-born cohort (E10-E11.5) destined to become zebrin II (ZII) ${ }^{+}$and a late-born cohort (E11.5-E13) destined to become ZII. A direct correlation is also found between PC birthdates and their adult stripe location, suggesting that both subtype specification (e.g., $\mathrm{ZII}^{+}$vs. ZII) and positional information (which zone or stripe) are acquired at this time, e.g., [30, 157-160]; both are cerebellum-intrinsic and not activity- or afferent-dependent, e.g., [161-164]. However, there is no reason to believe that individual PC stripes have a clonal origin. During the same interval, the cerebellar anlage undergoes a $90^{\circ}$ rotation, which converts the embryonic rostrocaudal axis into the mediolateral axis of the cerebellar primordium [156]. This suggests the possibility that the adult mediolateral stripe array derives from the anteroposterior patterning of dorsal $\mathrm{r} 1$.

A Ptf1a-Neurogenin 1/2 (Neurog1/2)-Early B-cell factor 2 $(E b f 2)$ regulatory network is implicated in PC subtype specification [49]. By this model, the early-born PC cohort expresses neither Neurog1/2 nor Ebf2 and therefore expresses the $\mathrm{ZII}^{+}$phenotype in the adult. Soon after E11, Neurog $1 / 2$ is upregulated by Ptfla in the later-born PC progenitors (e.g., [36]). In this context, neurogenin 2 regulates cell-cycle progression, neuronal output, and early dendritogenesis of PC progenitors [50], but neither Neurog1 nor Neurog 2 deletions affect cortical patterning (Hawkes, unpublished observation). In turn, Neurog $1 / 2^{+}$precursors express EBF2, which represses the $\mathrm{ZII}^{+}$phenotype ([132, 159]: Ebf2 deletion results in transdifferentiated PCs that express markers characteristic of both the $\mathrm{ZII}^{+}$and $\mathrm{ZII}^{-}$subtypes - the only manipulation known to alter a PC subtype phenotype). In addition, Ebf2 plays an anti-apoptotic role in ZII ${ }^{-}$PCs by locally regulating
Igfl gene expression [165]. As a result of these events, earlyborn PCs become $\mathrm{ZII}^{+}$in the adult and late-born PCs adopt the ZII ${ }^{-}$phenotype.

Postmitotic PCs migrate dorsally from the VZ, in part along radial glia processes ([51]: also see Section 4.1), and stack in the cerebellar plate with the earliest-born (Ebf2 ${ }^{-}$) PCs located most dorsally. Starting at $\sim$ E14, the cerebellar plate undergoes a complex redisposition, such that by E18 a reproducible array of clusters of multiple molecular phenotypes is present on each side of the midline ([166-170], etc.: reviewed in $[171,172])$. The cellular processes that guide cluster formation are not understood but grafts of dissociated PCs also organize into discrete $\mathrm{ZII}^{+/-}$compartments [173], pointing to cell-cell adhesion molecules as possible organizers: cadherins are strong candidates reviewed in [174]. Over 50 distinct clusters have been identified $[175,176]$. The mapping between embryonic clusters and adult stripes is complex: in some cases, one cluster yields a single stripe, e.g., [175, 177, 178], but in others single stripes derive from the fusion of several clusters, e.g., [179], or single clusters split into multiple stripes, e.g., [136].

The embryonic cluster architecture is the scaffold around which other cerebellar elements are organized. First, clusters likely restrict the distribution of cerebellar INs and their processes (GCs-[180]; Golgi cells-[181]; stellate/basket cells - [146]; UBCs - [182]: reviewed in [146]: also gliae.g., $[183,184])$. Secondly, most afferent projections also enter the cerebellum between E14 and E18 and target specific PC clusters (the so-called matching hypothesis - reviewed in [185]). There are two major sources of sensory input to the cerebellum: CFs from the inferior olive, and mossy fibers from a number of brain and spinal cord regions. Both afferent systems invade the cerebellum at around E 13/14 in mouse $[186,187]$, and thereafter they terminate with a spatial organization that parallels the pattern of PC stripes [137, 188] (Fig. 6a, b). PC subtype organization is thought to play a key role in instructing circuit wiring into topographic maps. Spontaneous and engineered mouse mutants that display disrupted PC stripes have equivalent alterations in the spatial arrangement of mossy fiber and CF terminals [189-191]. But, what molecular mechanisms trigger cluster dispersal and wiring?

From $\sim$ E18, the embryonic PC clusters disperse, triggered by RELN secreted by the EGL [192-194]: recently thoroughly reviewed in [195]. RELN is critical as its deletion in the reeler mouse (Reln ${ }^{r l}:[192,196]$ blocks dispersal, e.g., [128, 197]). One model is that secreted RELN binds two surface receptors on PCs-Apolipoprotein E receptor 2 and the Very Low Density Lipoprotein Receptor. Deletion of either receptor $\left(\operatorname{Lrp} 8^{t m 2 \mathrm{Her}}\right.$ or $\left.\mathrm{Vldl} r^{t m 1 \mathrm{Her}}\right)$ produces a partial, stripe-specific disruption of cluster dispersal [198]: deletion of both receptors blocks dispersal [199]. In turn, RELN binding induces receptor clustering [200] and activates two Src-family kinases- 

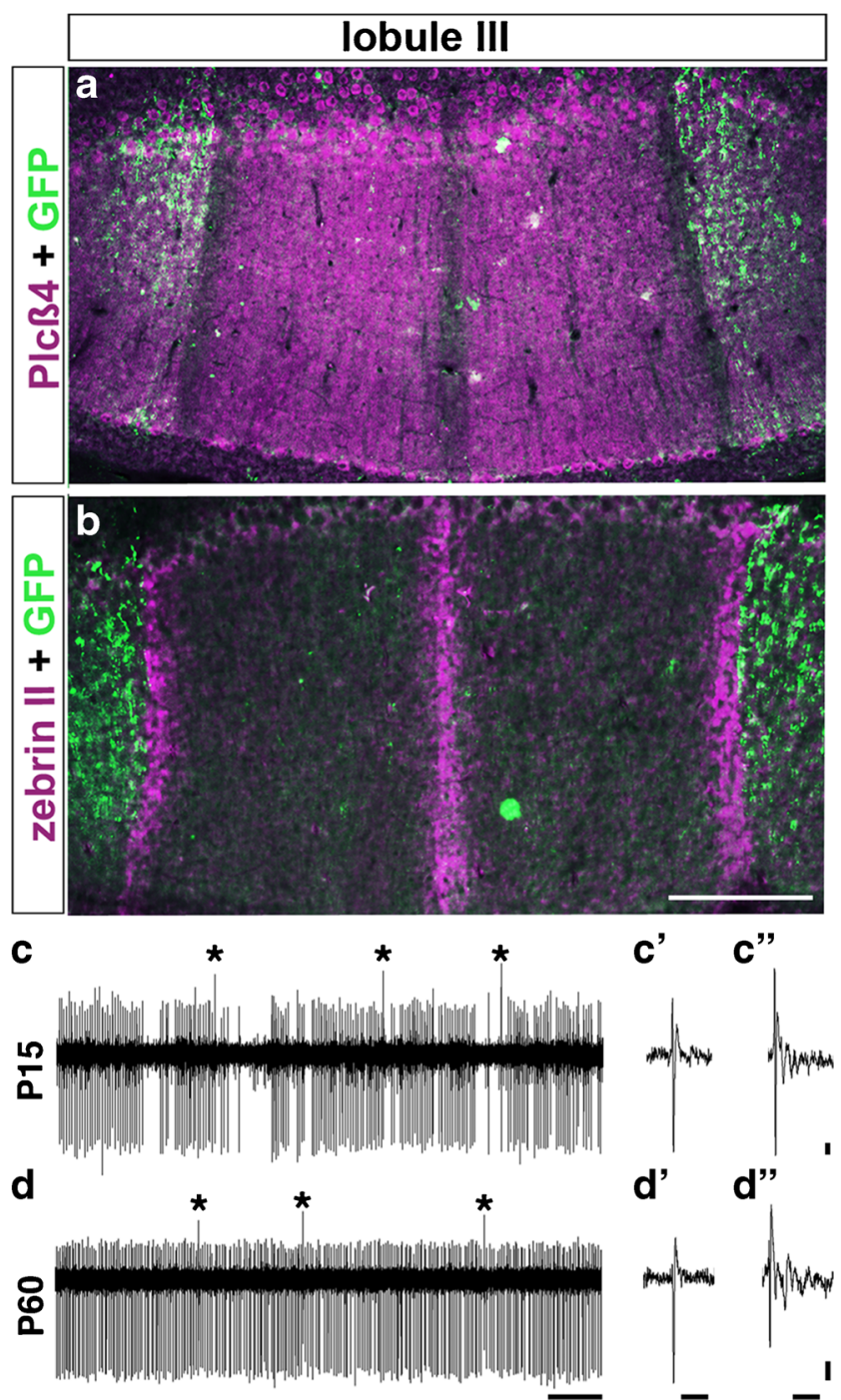

d'

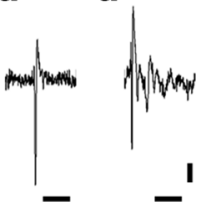

Fig. 6 Purkinje cell organization and firing activity can define how cerebellar circuit topography is assembled. a CF zones, which were labeled with the transgenic marker Npy-GFP (green), are arranged in broadly spaced parasagittal stripes from the midline and overlap with PC zones that are immunopositive for the marker PLC $\beta 4$ (magenta). b NpyGFP-labeled CF zones (green) are restricted according to PC stripe boundaries and do not cross zebrinII-immunopositive stripes (magenta). Scale bar $=250 \mu \mathrm{m}$. c At P15 in mouse, PCs fire simple spikes with a relatively low firing rate and an irregular "burst" pattern (as shown in sample trace). $\mathbf{c}^{\prime}$ An example of a simple spike at P15. $\mathbf{c}$ An example of a complex spike at P15. d PC activity is dynamically sculpted during key events of circuit formation, until a mature firing pattern (as shown in sample recording trace at P60) is established at about 4 weeks of age. $\mathbf{d}^{\prime}$ An example of a simple spike at P60. d" An example of a complex spike at P60. Scale bar in $\mathrm{d}: \mathrm{x}=0.5 \mathrm{~s}$. Scale bars in $\mathbf{c}^{\prime}, \mathbf{c}^{\prime \prime}, \mathbf{d}^{\prime}$, and $\mathbf{d}^{\prime \prime}: \mathrm{x}=5 \mathrm{~ms}, \mathrm{y}=2 \mathrm{mV}$. (a) and (b) were adapted from [191]. (c) and (d) were adapted from [214]

Fyn and Src [201, 202] — which tyrosine phosphorylate [203, 204] the intracellular adaptor docking protein Disabled1 (DAB1-[205-209]: phosphorylation is essential and key tyrosine point mutations phenocopy reeler-[210]). DAB1phosphorylation results, at least in the neocortex, in Repressor activator protein 1 (Rap1)-mediated homophilic cadherin 2 cell-cell interactions that promote neuronal migration [211, 212]. The upshot is that by $\sim \mathrm{P} 20$, as cerebellar lobulation matures, the PC clusters string along the rostrocaudal axis into the adult array of long parasagittal stripes. However, one critical question is how do these dynamically changing stripes acquire their functional properties during development?

During postnatal development, chemo- and activitydependent mechanisms may play important (and possibly distinct) roles in establishing the afferent topographical map. There is a long-standing hypothesis that first a "crude" topographic map is established by genetic cues. And one of the most compelling hypotheses postulates that cues in the afferent source domains match up with cues in the PC map [185]. The molecular cues that would mediate this mechanism have not been resolved, although it may involve a chemoaffinity mechanism mediated by eph/ephrin and cadherin signaling. But, one has to also consider how the circuit is then sculpted into a "fine" map, and does the mechanism for refining the map also involve PC patterning? Alternatively, are there nongenetic mechanisms that also contribute? Indeed, it was recently shown that the striped patterning of PCs is disrupted when neurotransmission in the PCs themselves is selectively silenced [213]. Interestingly, the patterning of spinocerebellar mossy fiber terminals into distinct stripes was also altered in the absence of PC activity. The sharp stripe boundaries that are typically observed were severely compromised, although the basic features of the topographic map were left intact. These data argue that neuronal activity may play an important role in fine-tuning the cerebellar map into topographic domains. But maybe PCs are not the only players. Perhaps inhibitory INs in the developing molecular layer (ML) or the millions of excitatory GCs also influence circuit topography by modulating the levels of PC activity. INs, after all, are also organized into stripes [146] and they integrate into the PC microcircuit at a time when they could have a powerful affect on how the circuit is firing when it is wiring [31].

Which features of neuronal firing need to be examined in order to understand how circuits assemble? PCs provide the best starting point since these cells exhibit two distinct types of action potential that are experimentally tractable with in vitro and in vivo paradigms. The first are complex spikes that are triggered by CF inputs, and the second are simple spikes generated intrinsically within the PCs but modulated by mossy fiber inputs (Fig. 6c-c , d-d ). Recent work in anesthetized and awake mice used in vivo electrophysiology to record PC activity in postnatal mice [214]. The study found that the rate of complex spike firing increased sharply at 3 weeks of age, whereas the rate of simple spike firing gradually increased until 4 weeks of age. They also found that compared to adult, the pattern of simple spike firing during development was more irregular as the cells tended to fire in "bursts" that were interrupted by long pauses (Fig. 6c, d). The 
regularity in simple spike firing only reached maturity at 4 weeks of age. These data show that PC activity is dynamically sculpted throughout postnatal development, traversing several critical events that are required for circuit formation. Importantly, the establishment of PC firing properties seems to overlap with the final stages of stripe maturation [139]. However, there are also data that support an alternate view which suggests that activity-dependent mechanisms may not be involved in topographic wiring. Surgically lesioning the neonatal spinocerebellar afferent tracts did not induce a competitive sprouting of the adjacent cuneocerebellar pathway [215] and the regression of supernumerary CFs appears spatially and temporally unlinked to the formation of stripe patterns - both processes may be strictly dependent on molecular cues [216]. Therefore, it is interesting to speculate that compared to molecular cues, the rate and pattern of spikes, at particular ages, could shape a more subtle level of topography by refining the connectivity within stripes rather than between individual stripes. If this was to be the case, then chemical tags might define the fundamental patterns of stripes irrespective of sensory experience, and perhaps only later during postnatal development is when activity might tune and complete the existing map.

\section{GABAergic Interneurons (K. Leto, E. Parmigiani, K. Schilling, A. Wefers)}

The term "GABAergic interneuron" is traditionally used to refer to a diverse set of neurons that, in the healthy adult cerebellum, result in local inhibition (Fig. 7). Actually, it is somewhat of a misnomer since in CN and the GL, the majority of GABAergic INs also use glycine as a co-transmitter, and a few are strictly glycinergic [217, 218]. Distinct differences in their afferent and efferent wiring, their morphology, and the differential expression of a set of molecular markers (inter alia mGluR2 and neurogranin) allow us to distinguish, in the GL, at least four discrete sets of Golgi cells sensu stricto as well as Lugaro and globular cells. While these clearly distinct inhibitory INs of the GL are sometimes collectively referred to as Golgi cells, INs of the ML are traditionally classified as basket or stellate cells. Today, the weight of the evidence rather supports the view that these two terms describe two exemplary variants of one population that shows gradual morphological [219] and molecular [220] differences which may be secondary to their position in the ML (discussed in [146]). Lastly, the still rather enigmatic candelabrum cell [221] may be yet another member of the basket/stellate class (see [222] for a broader discussion).

GABAergic INs are produced from late embryonic life to the second postnatal week, according to a precise inside-out sequence (Fig. 7). The proliferation of inhibitory INs peaks during the first postnatal week and exclusively occurs in the PWM, a postnatal niche containing heterogeneous cell types at different maturation stages [29, 32, 223-227]. CN INs are the first to be born during embryonic and early postnatal life, followed by GL INs (Golgi and Lugaro cells) and, finally, by those of the ML (basket and stellate cells; [29, 31, 225, 228]).

The first studies of cerebellar neurogenesis postulated that ML INs derive from the EGL, the only germinal layer known at that time to be active during postnatal development [229, 230]. Later, analysis of chick-quail chimeras, transplantation experiments, and retroviral injections demonstrated that the EGL exclusively generates GCs and indicated that all the GABAergic neurons, including the ML INs, derive from the VZ [154, 231-234]. While these diverse cells all originate from the VZ, there is little evidence that this germinal layer is pre-patterned, say by differential gene expression, such as to presage the diversity of cerebellar inhibitory INs in the adult. One possible exception may be the expression of Neurog1, which may distinguish the lineages leading to cerebellar cortical and CN inhibitory INs $([235,236]$ : the interpretation of these results is ambiguous because the BAC used may not faithfully recapitulate cognate $\mathrm{Ngn} 1$ expression, specifically in $\mathrm{CN}$ [235]). In contrast, there is compelling experimental evidence that PIPs maintain a high degree of plasticity and acquire their definitive fate only as they migrate through the deep cerebella mass (i.e., the PWM) on their way into the $\mathrm{CN}$ or the nascent cerebellar cortex [237]. This is particularly striking as individual subsets of cerebellar cortical inhibitory INs withdraw from the cell cycle over an extended period from E13 through the second postnatal week. However, cells collected at any point through this long generative phase are capable, when heterochronously transplanted, of acquiring a fate temporally appropriate to the host tissue [237]. Significantly, fate determination by transplanted cells is critically dependent on migration through the recipient's PWM. These findings have led to the recognition of the nascent white matter as an instructive niche critical for the maturation and diversification of cerebellar inhibitory INs [237]. Unfortunately, we are still quite ignorant as to how this instruction is realized on the molecular level. There is experimental evidence that PCderived SHH regulates proliferation of precursors of cerebellar inhibitory INs in and near the ventricular epithelium [33, 238]; yet, whether PCs also influence the diversification of these cells remains unclear.

The dividing intermediate progenitors that are responsible for the extensive amplification of the inhibitory interneuron populations strongly express Ptfla [33]. At later stages, the precursors of inhibitory INs are seen as a population of Pax- $2^{+}$ cells that appears in the VZ around E12.5 and later moves into the cerebellar parenchyma $[32,228]$.

The precise lineage relationships linking $\mathrm{Ptfla}^{+}$interneuron progenitors to the other precursor pools in the PWM (namely, progenitors of astrocytes and oligodendrocytes) remained obscure for many years. The existence of multipotent progenitors in the postnatal cerebellum has been 


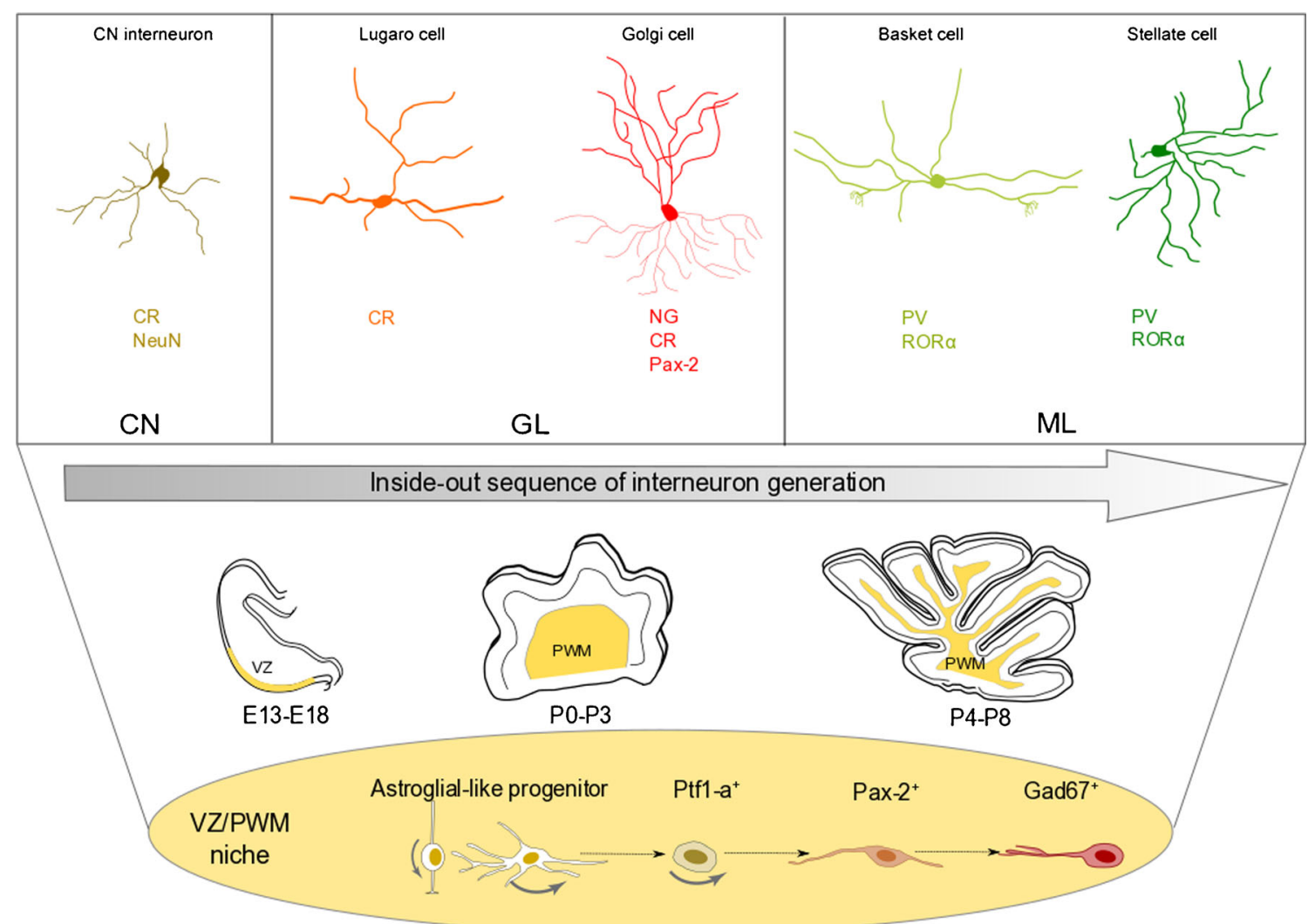

Fig. 7 Production of inhibitory interneurons. Different subtypes of GABAergic INs are present at different levels of the cerebellar cortex and $\mathrm{CN}$ and are characterized by the expression of specific markers. All these cells are produced through an inside-out sequence from common Pax $-2^{+}$progenitors residing in the VZ/PWM niches during cerebellar

proposed by two independent studies [239, 240], in which the isolated progenitors were able to form neurospheres and to differentiate into neurons, astrocytes, and oligodendrocytes both in vitro and in vivo after grafting into newborn mice $[239,240]$.

A series of more recent studies have clarified the properties of PWM progenitors and the relationships between the different lineages. For instance, it has been shown that the postnatal cerebella of mice lacking the proneural gene Ascl-1 have fewer PAX- $2^{+}$INs and increased numbers of $\mathrm{SOX}^{+}$astrocytes compared to controls [241]. Conversely, overexpression of ASCl-1 in the VZ results in more INs at the expense of astrocytes [241], suggesting the existence of lineage relationships between these cell types throughout cerebellar development. It is not clear whether similar relationships between INs and astrocytes are also present at earlier embryonic ages. Indeed, previous fate mapping analyses tagging embryonic progenitors producing PCs or INs only rarely generated astrocytes $[34,50]$, suggesting that the bulk of cerebellar astrocytes do not derive from these progenitors. Subsequent lineage analysis during embryonic and postnatal development showed that both INs and astrocytes derive from ASCL- $1^{+}$precursors [31]. Similarly, fate-mapping studies of progenitors with development. Interneuron progenitors derive from astroglial-like bipotent progenitors, which also give rise to parenchymal astrocytes (see text). $C N$ deep cerebellar nuclei, $G L$ granular layer, $M L$ molecular layer, $V Z$ ventricular zone, $P W M$ prospective white matter

astroglial traits - such as the expression of hGFAP [242], TenascinC [33], and GLAST [227] — reveal that the progeny of such progenitors often comprise a mixed population of astrocytes and GABAergic INs. In particular, in the study of Fleming et al. [33], a population of primary $\mathrm{CD} 133^{+} \mathrm{TenC}^{+}$ astroglial progenitors was identified in the PWM as the putative source of both PTF1- $\mathrm{a}^{+}$intermediate IN progenitors and $\mathrm{CD} 15^{+}$intermediate astrocyte precursors. The existence of these bipotent progenitors has been confirmed by a recent study in which mixed clones of INs and astrocytes were derived from PWM astroglial progenitors both in vitro and in vivo [227].

Finally, PCs are critical for the terminal differentiation and morphogenesis of cerebellar INs. Specifically, the complexity of basket/stellate cell axonal arborizations and their positioning on PCs is critically dependent on neurofascin [243, 244] and also Semaphorin (Sema3a)/neuropilin-1-mediated signaling between PCs and differentiating ML INs [245]. Further, the preferential orientation of basket/stellate cell axons in the sagittal plane may be due to PC guidance, as they extend in the ML [146]. Conversely, dendritic differentiation of basket/ stellate cells appears primarily sensitive to GC-derived input, including BDNF [246] and signaling through the GluD1 
receptor. In fact, ablation of this receptor, which is highly expressed in ML INs and concentrated at their synapses with PFs, results in reduced survival and stunted growth of early post-migratory ML INs [247].

\section{Development of the Cerebellar Nuclei (R. J. T. Wingate)}

The description of cerebellar development above is focused on the cerebellar cortex. The $\mathrm{CN}$ develop in parallel, using much of the same molecular machinery. The $\mathrm{CN}$ dictate the participation of the cerebellum in a range of circuits by providing an almost exclusive efferent connectivity via axon pathways to more caudal structures (from medial nuclei) and more rostral structures projections (from lateral nuclei; [248]). Their largely spontaneously active output can be excitatory or inhibitory and nuclei contain several different local interneuron types [249-253]. Nuclei receive collateral input from afferents to the cerebellar cortex (CFs and mossy fibers) in addition to inhibitory input from PCs. Decoding both the development and integrative function of nuclear circuits is likely to be critical for understanding the broader function of the cerebellum. Despite their functional significance, our knowledge of $\mathrm{CN}$ development is incomplete. Furthermore, the number of $\mathrm{CN}$ varies between tetrapod species suggesting that the developmental mechanisms responsible for their patterning are a key locus of evolutionary adaptation [254].

The perhaps surprising absence of a detailed description of $\mathrm{CN}$ specification and maturation can to some extent be explained by a major conceptual revision of their development over the last 10 years following insights from a series of studies of gene expression $[51,60]$ and genetic fate-maps $[25,26$, $34,255]$. Prior to this, $\mathrm{CN}$, which condense initially in a "nuclear transitory zone" at the margin of the cerebellar anlage, were assessed by birthdate to be derived exclusively from the VZ [256]. This assumption was overturned by genetic lineage maps using an Atohl reporter showing that excitatory $\mathrm{CN}$ neurons arise by tangential migration from the RL prior to GCP production [25, 26]. More recent mapping using a Ptfla reporter [36] reveals that the VZ gives rise only to inhibitory neurons of the $\mathrm{CN}$. Hence, just as for the cerebellar cortex, the assembly of $\mathrm{CN}$ is defined as the coordinated integration of $\mathrm{PTF} \mathrm{a}^{+}$and $\mathrm{ATHO}{ }^{+}$lineages in local circuits. However, patterns of temporal specification in either lineage suggest important differences compared to the cerebellar cortex in how these lineages interact.

Ptfla-derived $\mathrm{CN}$ neurons are generated as the first of a sequence of inhibitory neurons destined for progressively more superficial fates [29]. To some extent, this reflects a progressive dorsal expansion of a $\mathrm{Gsx} 1^{+} / \mathrm{Ptfla}$ domain that gives rise to INs, which occupy the Olig2/Ptfla domain and give rise to PCs (see "Specification of Cerebellar Progenitors" section). However, fate determination in the former Pax $-2^{+}$ lineage is notably a product of local microenvironmental factors. Migrating PIPs persist in the white matter, continuing to contribute to the $\mathrm{CN}([29,36]$ : see "GABAergic Interneurons" section) well beyond the production of the first, inhibitory projection neurons (Fig. 8). By contrast, cell fate in the $\mathrm{ATHO}^{+}{ }^{+} \mathrm{CN}$ derivatives of the RL not only correlates with birthdate $[25,26,257]$ but appears determined at the RL [258]. This raises the possibility that the temporal pattern of RL derivatives establishes a template around which GABAergic neurons are organized.

The allocation of a temporal framework of RL-derived CN components is accompanied by a characterized sequence of transcriptional maturation $[51,60]$ that results in a first born $\mathrm{LHX9}^{+}$lateral nucleus (projecting to midbrain and thalamus), followed by a TBR $1^{+}$medial (fastigial) group, which sends axons to the hindbrain via the fasciculus uncinatus, or hook bundle [257]. The progressive deposition of cells in more dorsal (ultimately medial) positions reflects a decreasing sensitivity to netrin signaling from ventral midline in migrating cells $[259,260]$. Netrin receptors are also responsible for determining the laterality of the projections of $\mathrm{CN}$ axons [261], which extend seamlessly from the leading processes of migrating cells [260]. Target selection itself (rostral or caudal CNS) appears to be a property of LHX9 [257] versus TBR1 [59] expression.

If this process of RL cell fate specification provides a template for nucleus assembly, it places a special emphasis on poorly understood events at the NTZ. It is here that neurons segregate into a series of mediolaterally distributed nuclei as they are subducted under the rapidly expanded cortex by either passive displacement, or possibly active translocation [256]. To understand whether lineage interactions are part of this process, let alone underlying mechanisms of nucleogenesis, will rely on a better description of neurons subtypes. For example, it is unclear whether only more lateral nuclei contain inhibitory projection neurons $[252,262]$ or indeed how much of the repertoire of neurons seen in the lateral nucleus is recruited to other nuclei [263]. Similarly, the embedded nature of nuclei within a series of re-entrant loops that include the inferior olive, in addition to pontine neurons and PCs, has implications for later developmental events. How does the convergence of afferents onto nuclei influence the organization of INs into precise, geometric functional units [249]? These elements of fine-grained developmental detail, which are so significant for the function of the cerebellar circuit, are almost completely unexplored.

\section{Gliogenesis in the Cerebellum (A. Buffo)}

In contrast to other CNS areas in which gliogenesis follows neurogenesis, in the cerebellum the generation of glia parallels the generation of GCs and INs. What triggers the activation of gliogenesis and regulates its course in this territory is still poorly understood. 


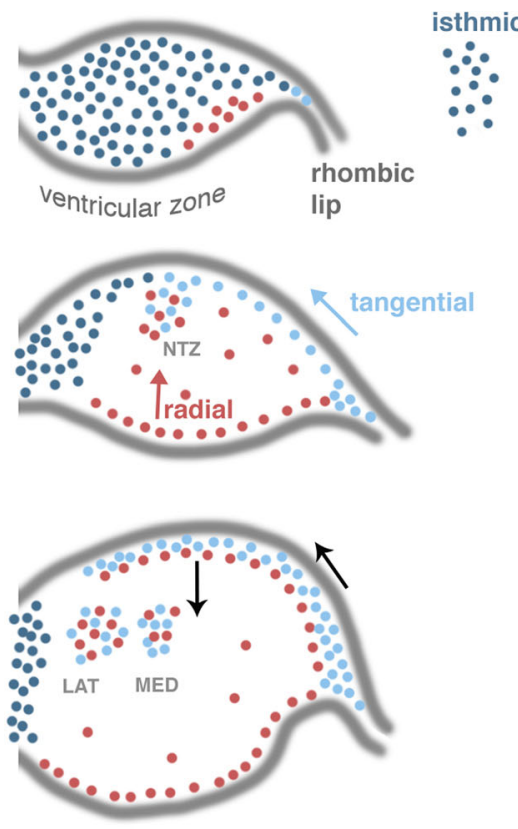

Fig. 8 The assembly of cerebellar nuclei requires the complex spatiotemporal integration of neurons from $\mathrm{Atoh}^{+}$and $\mathrm{Ptfla}{ }^{+}$lineages. Schematic profiles to the left plot the distribution of the Atoh $1^{+}$lineage (FGF-dependent, dark blue; BMP-dependent, light blue) and Ptfla ${ }^{+}$ lineage (red) in the developing embryo (after [456]). To the right, the approximate timeline of different neuron groups is shown next to

In the mature mammalian cerebellum, four astroglial subtypes are classically distinguished, including fibrous astrocytes in the white matter (WM), stellate multipolar astrocytes with profuse tiny processes (velate astrocytes) or more slender morphologies (protoplasmic astrocytes) in the GL, and neuroepithelial cells displaying radial BG basal processes spanning from the cells bodies in the PC layer through the entire ML, up to the subpial basement membrane (Fig. 9a, $[130,229,264])$. In the future, this classification may expand to comprise more astroglial subtypes based on neurochemical, topographical, and morphological criteria, as shown by a recent detailed investigation on the human cerebellum [265].

Through the comparative analysis of different mammalian species, Ramón y Cajal [229] proposed that cerebellar astroglia derive from the VZ. Cajal's interpretation has been fully proved by means of fate mapping analyses in mice in which radial glial progenitors (RG) at the ventricle were targeted based on the expression of stem-cell markers [266-268], or VZ-restricted tags [34]. A small contribution of the RL to cerebellar astrogliogenesis has also been proposed [269] but so far remains controversial (see [270] and references therein). As showed by anatomical investigations and functional manipulation of regulatory pathways, in a first astrogliogenic wave (up to about E14 in mouse), RG detach from the ventricle and displace the cell body towards the nascent PWM, transforming into progenitors of BG ([229, 266, 271, 272]: the relationship between astrocytes and GABAergic INs is reviewed in "GABAergic Interneurons"

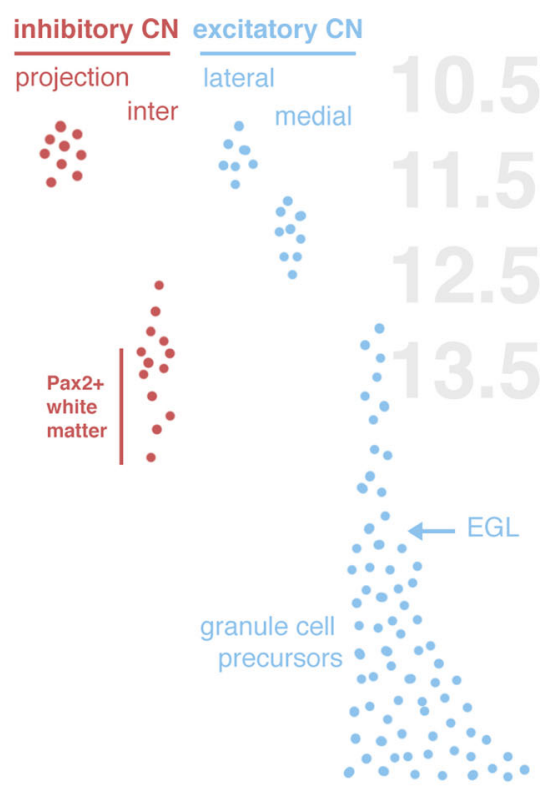

embryonic days in mouse. Light-blue and red arrows indicate tangential and radial migration of, respectively, excitatory and inhibitory $\mathrm{CN}$ neurons. Black arrows show the direction of the CGPs. NTZ nuclear transitory zone, $C N$ deep cerebellar nuclei, $E G L$ external granular layer, lat lateral, med medial

section). A subset of these precursors appears to be already postmitotic at the moment of translocation [31] and readily differentiates into BG. Conversely, other precursors form a proliferative layer that expands $[130,266,271]$ up to the first postnatal week in parallel with the tangential expansion of the cerebellar surface. At later stages of embryonic development, a second wave of astroglial-like progenitors lacking the basal process delaminates from the VN into the cerebellar PWM where they proliferate, forming astrocytes populating the prospective GL and white matter $[130,271]$. Whether PWM astroglial progenitors also produce some BG or whether proliferating BG contribute astrocytes to other cortical layers remains to be established. Similarly, the dynamics and timing of the amplification of astroglial progenitors are largely unknown.

How the specialization of the astroglial subsets is achieved is only partially clarified. BG morphogenesis requires a tight and timely regulated interaction with the surrounding cerebellar microenvironment (basement membrane, PCs, migratory and proliferative GCs, see Fig. 9b). Notably, impairment of these regulatory mechanisms results in BG malpositioning and/or the acquisition of a stellate morphology, which may thus represent a default differentiation pathway for cerebellar astroglial precursors. Yet, it is likely that the refinement of the variety of multipolar morphologies in the GL and WM is instructed by local cues. Further, few intrinsic determinants are known that take part in the establishment of distinct astroglial cerebellar phenotypes (see [270]). 
Fig. 9 Astrocyte morphological heterogeneity in the mouse cerebellum and factors promoting Bergmann glia maturation. a Distinct morphologies define astroglial cell subtypes in the adult mouse cerebellum. b Components of the cerebellar microenvironment [270, 457-459] regulate signaling pathways that modulate the acquisition and maintenance of the $\mathrm{BG}$ phenotype. $M L$ molecular layer, $P C L$ Purkinje cell layer, $G L$ granular layer, $W M$ white matter

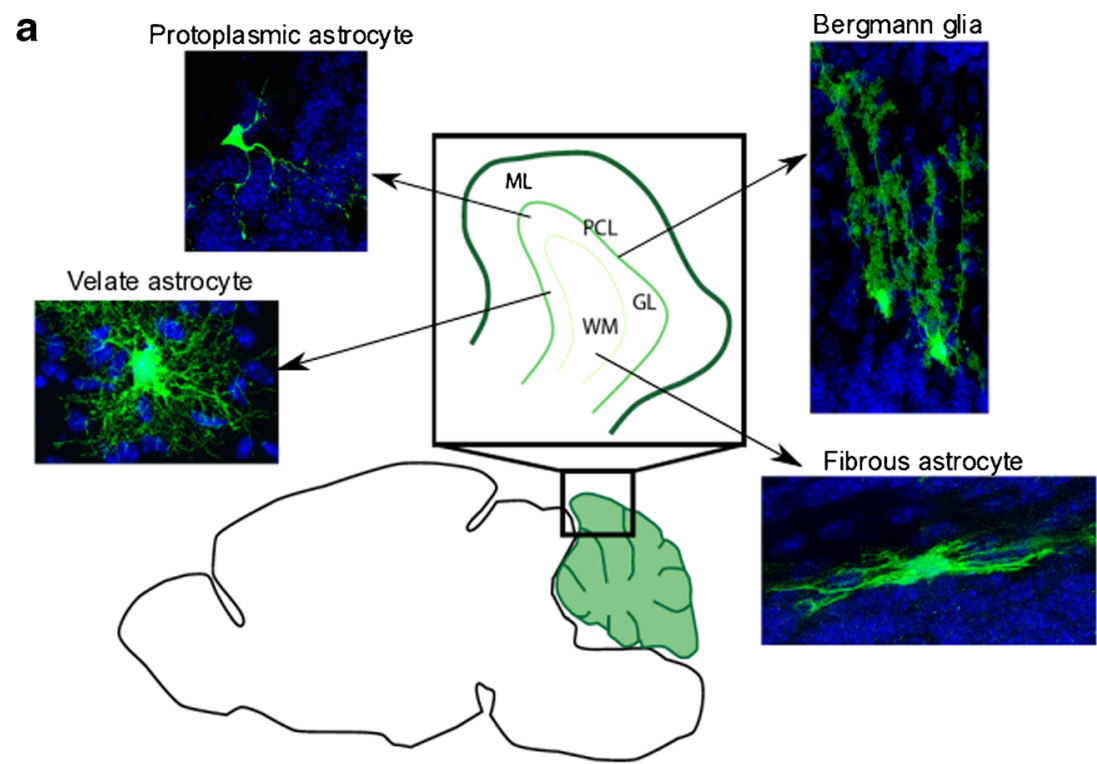

b

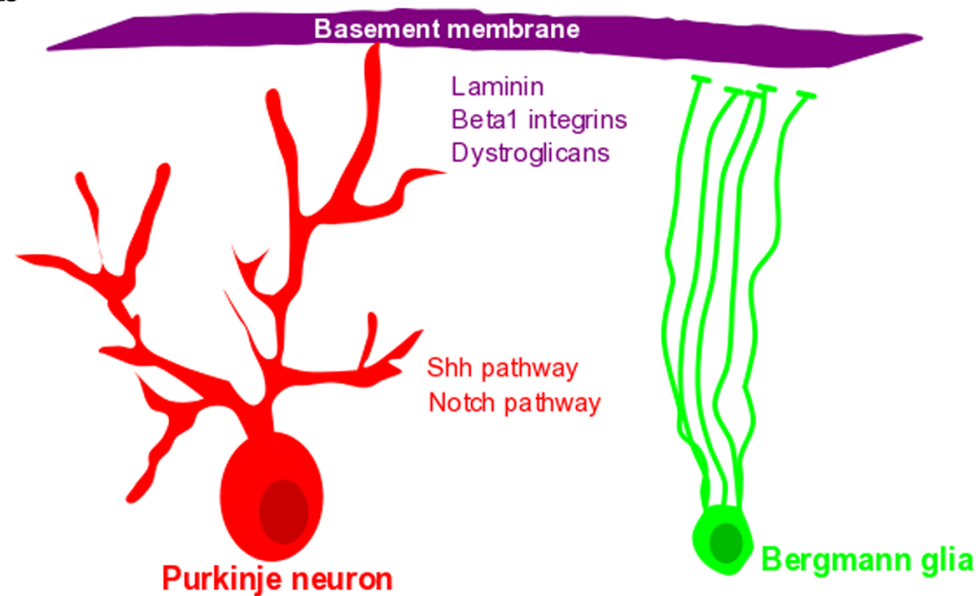

Neuregulin-ErbB signalling FGF-ERK signalling Notch pathway

In contrast to astrocytes, so far no evidence clearly demonstrates the derivation of oligodendrocytes from the cerebellar VZ [241]. Rather, a minor oligodendroglial fraction appears to derive from progenitors in subventricular positions, likely residing in the PWM [31, 273]. Alternatively, mouse transplantation experiments indicate an extracerebellar origin for the majority of oligodendrocytes [241]. In line with these data, experiments in chick-quail chimeras and in ovo transplants in the chick brain demonstrated that cerebellar oligodendroglia are generated in the chick mesencephalic neuroepithelium and only subsequently invade the cerebellum via the velum medullare [274]. A similar extracerebellar source in the mammalian brain remains to be identified. Further, fatemapping analyses [242] support the hypothesis that the majority of cerebellar oligodendrocytes have no lineage relationships with cerebellar astrocytes (and neurons). However, ex vivo experiments [275] and functional deletion of the polycomb group protein Bmi1 [273] pointed to the existence of bipotent gliogenic precursors, whose identity remains to be established.

Once settled in the cerebellar primordium, oligodendrocyte progenitors first surround the $\mathrm{CN}$ and gradually invade the nascent cortical lobules, progressing in a centrifugal direction. The same pattern is reflected in the course of both 
differentiation and myelination that proceed from the inner cerebellar portions to the lobule apices [276-279].

Despite the fact that most intrinsic and extrinsic mechanisms regulating oligodendrocyte differentiation appear to be common to multiple CNS sites, including the cerebellum $[280,281]$, a particular role in the regulation of the maturation of cerebellar oligodendroglia is exerted by thyroid hormones (TH; L-triiodothyronine, T3; L-tetraiodothyronine, thyroxine, T4; see "The Role of Thyroid Hormone in Cerebellar Development" section) and PC-derived signals. In particular, PCs secrete SHH, which stimulates oligodendrocyte progenitor proliferation at early postnatal stages, whereas by the end of the first postnatal week, they start producing vitronectin, which drives oligodendrocyte maturation and myelin formation [282].

\section{Extrinsic Regulators of Cerebellar Development: The Role of SHH (C. Chiang)}

The SHH pathway has been extensively studied in the context of GCP proliferation. However, more recent studies have revealed additional roles for this important pathway during different phases of cerebellar development. The common theme emerging from these studies is that $\mathrm{SHH}$ is a key mitogen for the expansion of functionally diverse neuronal and glial cell types from spatially and temporally restricted precursors. However, the mechanisms by which $\mathrm{SHH}$ stimulates proliferation of these precursors appear to be distinct, involving both cerebellar and extracerebellar strategies (Fig. 10).

In the cerebellum, Shh expression is restricted to PCs starting at E16.5 and continuing throughout adulthood [42, 283]. The early phase of $S h h$ expression is critical for rapid clonal expansion of GCPs as blockade of Shh expression in PCs leads to drastic reduction of GCP number in the EGL [62, 283-285]. The expansion of GCPs requires the cell surface proteins BOC and GAS1 [286], which synergistically promote $\mathrm{SHH}$ binding to its receptors PTCH1/2. In the absence of Shh, PTCH1 functions as a negative regulator of $\mathrm{SHH}$ signaling by suppressing the activity and localization of a seven-pass transmembrane protein, smoothened (SMO) to the primary cilium, a slim, microtubule-based non-motile structure that projects from the surface of nearly all vertebrate cells [287, 288]. Therefore, SHH binding to PTCH1 relieves SMO from inhibition, triggering $\mathrm{SHH}$ signaling and subsequently activating downstream target gene expression mediated by the GLI family of transcription factors [289]. Accordingly, mutations in ciliary components that disrupt SMO localization to the tip of the cilium all lead to altered $\mathrm{SHH}$ signaling and reduced GCP proliferation [290, 291]. Among the three GLI proteins, GLI2 acts as the primary transcriptional activator in GCPs [292]. In addition to canonical GLI target genes Gli1, Hhip, and Ptch1, several others including MycN and CcndD1 involved in cell-cycle regulation of GCPs have been reported [293, 294]. Notably, cerebellar phenotype in the absence of $M y c N$ function resembles that of Shh mutants [63]. Recent studies show that activation of GLI-dependent target genes is facilitated by JMJD3, a H3k27me3 demethylase involved in epigenetic conversion of inactive to active chromatin state [295], highlighting the importance of chromatin modification in enabling GCPs to respond to SHH during cerebellar development.

While Shh expression persists in PCs, GCPs eventually exit the cell cycle and differentiate to GCs. This process, as shown by recent studies, appears to be promoted by the transcriptional repressor BCL6 through recruitment of BCOR co-repressor and SIRT1 deacetylase to the Gli1 and Gli2 promoter regions, thus epigenetically silencing their expressions [296]. Indeed, loss of BCL6 impedes the differentiation of GCPs, which however do not continue to proliferate, likely due to p53mediated cell death. Removal of p53 rescues GCPs from cell death and restores their proliferation. However, it is unclear how BCL6 is activated in the immature GCs [296].

In addition to GCPs, $\mathrm{SHH}$ signaling is also required for the expansion of GABAergic INs by regulating precursors in two different neurogenic niches $[33,42]$. In the $\mathrm{VZ}$ niche, $\mathrm{SHH}$ signaling is activated in multipotent radial glial cells after E12.5. Defective SHH signaling in VZ severely impairs the proliferation of radial glial cells and their ability to generate GABAergic interneuron progenitors during the embryonic period [42]. Conversely, persistent activation of $\mathrm{SHH}$ signaling greatly expands their numbers. The source of SHH signal acting on VZ radial glial cells appears to be extracerebellar as $\mathrm{SHH}$ expression is not yet established in the emerging PC population. Indeed, $\mathrm{SHH}$ is prominently expressed in the hindbrain choroid plexus epithelium (hCPe), a secretory organ whose development is in close apposition with the cerebellar VZ (Fig. 10a). The presence of SHH protein in the circulating embryonic cerebrospinal fluid suggests that $\mathrm{SHH}$ is actively secreted from the hCPe and delivered to the adjacent $\mathrm{VZ}$ via a transventricular mechanism. Further support for this model comes from the observation that $\mathrm{VZ}$ progenitor proliferation is compromised in mice with reduced Shh expression in the hCPe [42].

The cerebellar VZ is also the source for stem-like astroglial cells of the secondary neurogenic niche residing in the PWM during late embryonic and postnatal period [33, 239, 242]. These astroglial cells transiently respond to $\mathrm{PC}$-derived $\mathrm{SHH}$ and express cell surface marker CD133 (also referred to as Prominin) as well as extracellular matrix glycoprotein Tenascin-C (Tnc) [33]. Lineage analysis reveals that the PWM astroglial cells generate intermediate progenitors of both astrocytes and GABAergic INs as marked by the expression of CD15 and PTF1a, respectively (Fig. 10b) [33]. Furthermore, attenuation of SHH signaling in astroglia during the neonatal period leads to a significant reduction of both intermediate progenitor classes, underscoring the importance of 


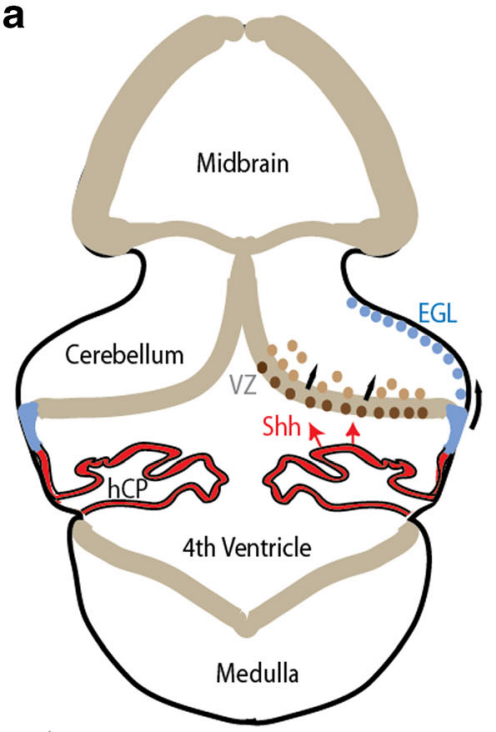

Fig. 10 Shh regulates the expansion of functionally diverse neuronal and glial cell types from spatially restricted precursors in the cerebellum. a Schematic illustration of a coronal section of the midbrain-cerebellummedulla region at E14.5. Beige regions represent the $\mathrm{VZ}$ neuroepithelium. The hChP epithelium, depicted in red, secretes Shh protein into the fourth ventricle which is then delivered to the cerebellar VZ to promote the proliferation of its resident radial glial cells (brown). The nascent EGL is shown in blue (modified from [45]). b PC-secreted Shh simultaneously

SHH signaling in the maintenance of the PWM niche. Surprisingly, PTF1a-expressing GABAergic progenitors represent an additional population that responds to SHH in PWM $[33,238]$. In contrast to cerebellar VZ [42], these PTF1aexpressing progenitors are proliferative and likely responsible for rapid expansion of the late-born GABAergic INs during the first week of the postnatal period [225].

\section{Cerebellar Foliation (A. L. Joyner)}

The most striking morphological feature of the cerebellum of birds, mammals, and some fish is its foliation pattern, or subdivision into lobes, lobules, and sublobules that are separated by a series of fissures [130, 171, 297, 298] (Fig. 11a). In most species, the foliation pattern is symmetrical with respect to the midline, and the fissures run perpendicular to the anteriorposterior (AP) axis in the medial cerebellum (vermis) of most species. The mammalian cerebellum is further subdivided into two lateral hemispheres and adjacent flocculi/paraflocculi, each with distinct foliation patterns with fissures that vary in their orientation. Nevertheless, the lobules of the hemispheres are continuous with lobules in the vermis (Fig. 11b). Larsell proposed a unified scheme for naming the lobules in the vermis of birds and mammals with roman numerals I-X from anterior to posterior $[299,300]$. To account for the variation in foliation pattern between species and the fact that the cerebellum has more than ten lobules in many species, lobules were subdivided into sublobules separated by shallower stimulates proliferation of GCPs and stem-like astroglia $\left(\mathrm{Tnc}^{+}, \mathrm{CD} 133^{+}\right)$ located respectively at the distant EGL and PWM. The PWM niche is comprised of lineage-related, but molecularly and functionally divergent progenitor subpopulations that descend from common astroglia (modified from [33]). $V Z$ ventricular zone, $E G L$ external granular layer, $P C L$ Purkinje cell layer, $P W M$ prospective white matter, $G C P$ granule cell progenitor

fissures (e.g., VIa and VIb, Fig. 11c). The vermis of mice has eight or nine lobules, as lobules I/II are not separated in some strains and IV/V are fused, and the hemispheres have four lobules $[301,302]$ that extend laterally from lobules VI and VII (Fig. 11b, c). The basic pattern of vermis foliation is conserved throughout mammals, but foliation in the hemispheres is more variable than in the vermis and is very complex in primates (see discussion in Chapter 1 of [130], [303]). As the cerebellum modulates the functions of all areas of the neocortex [304], by extrapolation the development of the two brain regions should have co-evolved. Indeed, the entire spinocerebellar tract projects only to the medial cerebellum, thus the hemispheres are enriched for connections to the neocortex. Furthermore, although the volume of the cerebellum as a percentage of the total brain is constant across species [305, 306], the greatest proportional increase in brain regions has occurred in the cerebellum and neocortex [306], and the ratio of the number of neurons in the cerebellum to the neocortex is remarkably constant across mammalian species [307]. It is therefore tempting to speculate that during evolution particular lobules in the hemispheres and folds (gyri) in the neocortex of gyrencephalic mammals that house interconnected neural circuits have arisen and expanded in unison [308]. Defining the circuits between the cerebellum and neocortex in primates as well as rodents is a major challenge and high priority for future cerebellar research, but dependent on development of effective tools for tracing across multiple synapses. It will be exciting to trace the axon pathways from a parasagittal stripe 
Fig. 11 Cerebellar foliation. a 3D rendering of MRI image of mouse cerebellum segmented at the EGL surface. $A$ anterior, $P$ posterior, $F / P f$ flocculus/paraflocculus. b Lobules that are continuous between the medial vermis $(\mathrm{V})$ and lateral hemispheres $(\mathrm{H})$ are color-coded. (a) and (b) provided by Kamila Szulc and Daniel Turnbull. c New anchoring centers and associated fissures form on particular days as the folia grow outward (modified from [64]). d Changes occur in the PC, GCP shape, and BG fiber projections in anchoring centers. Sagittal sections through the vermis (c, d), with lobules indicated in roman numerals [300]. $S$ simplex lobule, $C I / I I$ Crus I and II of the ansiform lobule, $P m$ paramedian lobule. e Clonally derived GCPs (yellow) do not cross the bases of fissures and disperse more along the $\mathrm{AP}$ axis than medial-lateral (ML) axis and have a greater cell number in long lobules compared to short lobules (provided by Emilie Legué). $E G L$ external granular layer, $G L$ granular layer, $G C P$ granule cell progenitor
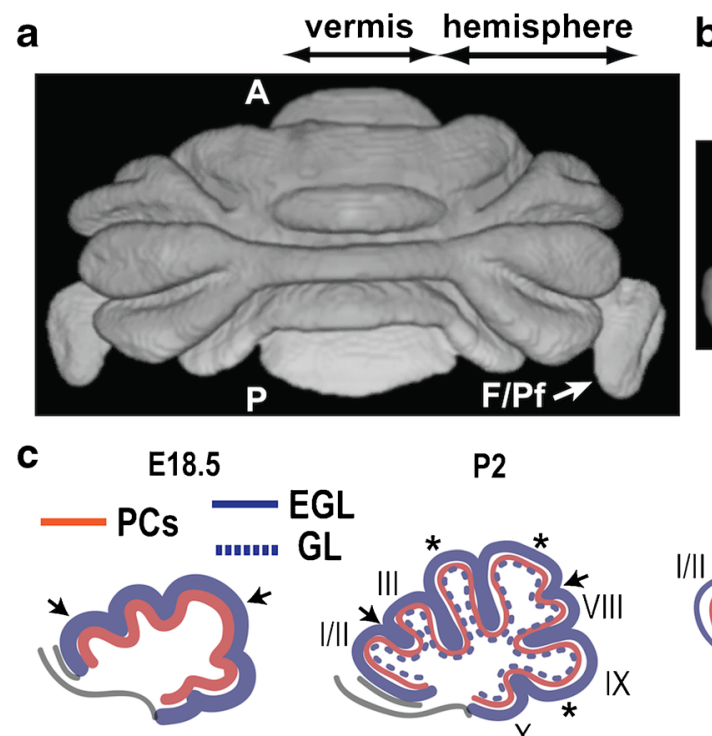

b

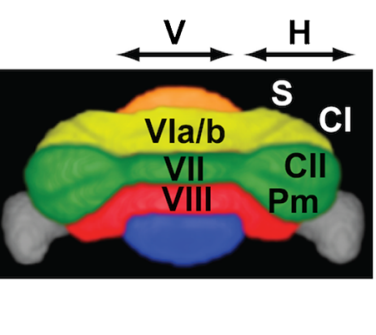

d
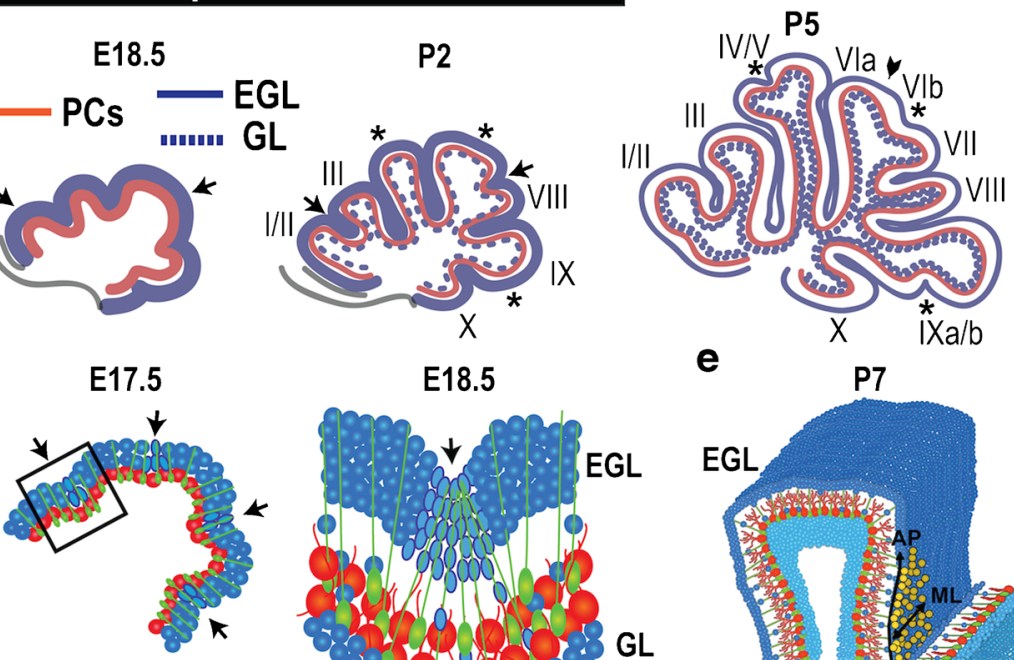

E18.5

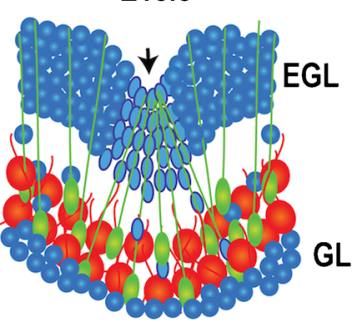

e P7
- Purkinje cell $\downarrow$ early to late

Bergmann glial cell appearing anchoring center cells in a GCP clone of PCs in one region of a particular lobule through to the neocortex and back to the cerebellum. One hypothesis is that this will reveal an elaborate spatial organization of neurons, with ones dedicated to similar functions being housed in distinct lobules in the cerebellum and gyri in the neocortex, and with new circuits discovered specific to humans.

The cerebellum undergoes its major growth in the third trimester and infant stage in humans, and the first 2 weeks after birth in mice, primarily due to expansion of GCPs $[130,309,310]$. The surface area of the cerebellum increases during development much more than its volume due to the formation of lobules [311-314]. The lobules thus serve to house a large number of neurons in a layered cytoarchitecture in a small area. Foliation begins at E16.5 in the mouse with the sequential formation of the base of each fissure, which we have termed anchoring centers [315]. The GCPs, PCs, and BG within anchoring centers have distinct characteristics, and the lobules grow out away from them [314, 315]. The first sign of formation of an anchoring center is an inward thickening of the EGL that is followed by formation of an indentation of the outer surface of the cerebellum and elongation of the bodies of the
GCPs (Fig. 11d, [315]). The underlying PC layer indents and then the surrounding fibers of $B G$ project to the base of the fissure. In the mouse vermis, four initial anchoring centers form that defines five initial lobes, which are further subdivided. Based on mutant analysis, the timing of formation and position of two adjacent anchoring centers define the morphology of the intervening lobule and thus the allocation of cells available for distinct long-range circuits [315-317]. Importantly, the homeobox engrailed genes $(E n 1 / 2)$ are fundamental to the patterning process as they determine when particular anchoring centers form [315-320]. A number of theories have been proposed for how foliation is regulated [130, 315, 321-323]. Fundamental questions remain, such as whether one cell type initiates formation of anchoring centers and how are they positioned.

Clonal analysis previously uncovered that GCPs divide symmetrically to expand each clone and then differentiate en masse [324]. Surprisingly, from a clonal analysis of GCPs, we recently found that the anchoring centers act as lineage restrictions that prevent GCPs from moving between lobules [325]. One possibility is that the restriction in GCP movement produces a mechanical force driving the lobules outward. 
Furthermore, the number of cells per clone in long lobules is almost twice that in short ones. In terms of clone geometry, the length is greater in the AP than medial-lateral axis in all EGL clones, especially in long lobules, accounting for the tremendous AP expansion of the cerebellum (Fig. 11e). Moreover, in En1/2 mutants with smaller lobules, the size and geometry of clones is similar to wild-type clones in short lobules [325]. Thus, the dynamics of GCP expansion is differentially regulated in lobules with different shapes/sizes. Whether this is a cell intrinsic property of GCPs that form different lobules that is established before anchoring centers are formed remains to be determined. What forces within and outside the cerebellum impact on the foliation process is an additional critical question to address. A further question is how scaling of all cell types in the cerebellum is regulated to ensure that the correct proportions of all neurons/glia are allocated to each lobule. One interesting possibility is that SHH secreted by PCs $[285,292]$ determines the expansion of INs and astrocyte/ BG progenitors in unison with regulating GCP proliferation [33, 64, 285, 326].

The cerebellum arose in gnathostomes, but the emergence of a stable transient amplifying population of GCPs in an EGL structure that is stimulated by SHH seems to date to the transition to amniotes [326-332]. While the production of the enormous number of granule neurons ( $>50 \%$ of all neurons in mouse and human [333, 334]) is thought to drive foliation [130] and has been experimentally linked to foliation, e.g., $[64,335]$, it is important to point out that some sharks have extensively foliated cerebella [336]. Interestingly, the degree of foliation seems to correlate better with the ecological environment and/or complexity of prey behavior within and between clades rather than with phylogeny $[306,336]$. An important question to resolve is whether the ratio of GCs to PCs is increased in sharks with highly foliated cerebella. Although it is not known whether SHH stimulates neurogenesis and of what cell types in sharks, it will be interesting to determine whether the SHH pathway has been co-opted to increase GC production in sharks since Shh has been detected in PCs of a shark but not in zebrafish [327]. Furthermore, given the different cytoarchitecture of the shark cerebellum, the mechanisms underlying foliation could be distinct from that in amniotes. Determining the similarities and differences in the foliation processes between sharks and amniotes and their implications for circuit allocation will be valuable, and likely to have implications for formation of folds in the neocortex of gyrencephalic mammals.

\section{Refinement of the Climbing Fiber Afferents (M. Kano, N. Uesaka)}

PCs in the adult cerebellum receive two distinctive excitatory synaptic inputs - from PFs, the axons of GCs, and from CFs arising from the inferior olivary nuclei in the medulla oblongata. Each PC receives functionally weak but numerous ( 100,000 in mice) PF synapses on spines of its distal dendrites. In contrast, most PCs are innervated by a single but functionally very strong $\mathrm{CF}$ on the stubby spines of their proximal dendrites. However, in the neonatal cerebellum, each PC is innervated on the soma by multiple CFs [337]. How is the adult one to one relationship between a $\mathrm{CF}$ and a PC established during postnatal development?

Immature olivocerebellar axons extensively ramify in the white matter and the GC layer, and give rise to many collaterals around PCs (creeper stage) [338]. Since immature PCs have no large primary dendrites, $\mathrm{CFs}$ terminate on perisomatic protrusions and thorns emerging from the PC somata. By P2$\mathrm{P}$, several individual CFs form multiple synapses with relatively similar synaptic strengths on a single PC (Fig. 12). During the first postnatal week, a single CF is selectively strengthened on the soma of each PC (termed "functional differentiation"). Mice deficient in Cav2.1, the $\alpha$-subunit of the P/Q-type voltage-dependent $\mathrm{Ca}^{2+}$ channel (VDCC), show impairment in the selective strengthening of a single $\mathrm{CF}$, suggesting that activity-dependent $\mathrm{Ca}^{2+}$ influx through VDCCs is crucial for establishing a single "winner" CF on each PC [339, 340]. Next, the strongest CF extends its innervation territory from the soma to the dendrites ("CF translocation": Fig. 12). As mentioned above, CFs initially establish synaptic contacts on the fine processes emerging from the soma and form a plexus ("pericellular nest" stage) [229]. As the dendrites of the PCs start to grow into the ML, from around P6, multiple CFs continue to innervate the PC somata until P9. After the functional differentiation of $\mathrm{CFs}$, only the "winner" $\mathrm{CF}$ extends its innervation territory from the soma to the stem dendrites from P9 ("capuchon" stage) [229]. In the "dendritic" stage [229], CF synapses undergo progressive translocation to the growing PC dendrites. In contrast, the "loser" CFs remain around the soma and are eventually eliminated in two distinct phases (the "early and late phases of CF elimination") mediated by distinct mechanisms $[216,339,340]$. The early phase of CF synapse elimination starts at around P7 soon after the functional differentiation is completed. Unlike the late phase of CF synapse elimination, the early phase is not dependent on the proper generation of GCs and PF-PC synapses. Several lines of evidence suggest that neuronal activity is crucial for this event $[339,340]$.

The late phase of CF synapse elimination starts at around $\mathrm{P} 12$ [216, 339, 340]. This process is critically dependent on the proper formation of excitatory PF synapses and inhibitory basket cell synapses on PCs. In mice deficient in mGluR1 or any of its downstream signaling molecules (G $\alpha \mathrm{q}$, PLC $\beta 4$, $\mathrm{PKC} \gamma$ ), the late phase of $\mathrm{CF}$ elimination is severely impaired. The immediate early gene Arc/Arg3.1, the neurotrophin receptor TrkB, and insulin-like growth factor 1 are also involved in CF synapse elimination $[339,340]$. A recent study has 
Fig. 12 Diagram showing postnatal development of CF-PC synapse. Until P3, synaptic strengths of multiply-innervating $\mathrm{CFs}$ are relatively uniform. From $\mathrm{P} 3$ to $\mathrm{P} 7$, one $\mathrm{CF}$ is selectively strengthened, which is termed the phase of "functional

differentiation." From $\mathrm{P} 9$ on, the strongest ("winner") CF undergoes translocation to growing dendrites (the phase of $\mathrm{CF}$ translocation). On the other hand, weaker ("loser") CFs remain around the soma and are eventually eliminated in two distinct phases (the "early and late phases of CF elimination"; from [340]). $C F$ climbing fiber

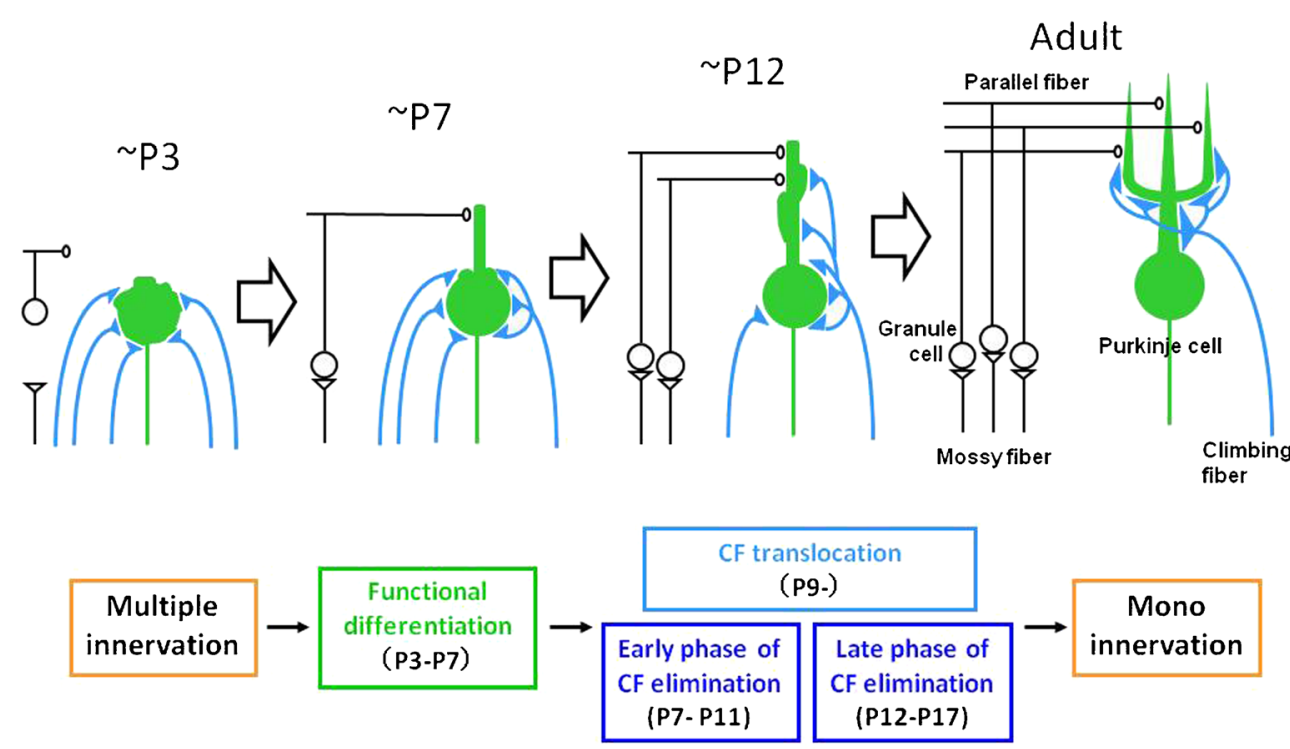

revealed that postsynaptic Sema7A, a GPI linked subtype of Semaphorin, and its receptors (ItgB1 and $\mathrm{PlxnC1}$ ) on CFs are involved in the cascade downstream of mGluR1 [341]. In contrast, Sema3A, a secreted class of Semaphorin, and its receptors (PlxnA4) on CFs maintain both weak and strong CFs from $\mathrm{P} 8$ to $\mathrm{P} 18$, and therefore oppose synapse elimination [341]. Thus, semaphorins mediate retrograde signals from PCs to CFs that regulate multiple processes of CF synapse elimination.

\section{Dendritic Differentiation of Purkinje Cells (I. Dusart)}

The PC stands as a neuronal model to study dendritic differentiation. In addition to being beautiful, PCs are also popular because of their convenience in terms of ease of immunohistochemical detection and genetic manipulation. Proteins such as calbindin or IP3R (inositol phosphate 3 receptor) are specifically abundantly expressed in PCs and label their dendritic tree, soma, and axon. Grafting experiments have provided major progress in our understanding of the biology of neurons [342]. The L7/pcp2 promoter drives gene expression specifically in PCs and retinal rod bipolar neurons [343]. Combining the $\mathrm{L} 7$ promoter and an inducible CRE/loxP system with in utero electroporation allows the specific regulation of gene expression in PCs in a temporally controlled manner [344]. Furthermore, different viral vectors target PCs specifically [345] for review. Last but not least, for the study of the development of the dendritic tree, PCs can develop in organotypic cultures. By using this technique, the morphology of individual PCs can be studied since they are isolated from their neighbors [346, 347].

Adult PCs are highly recognizable by their large dendritic tree with prototypical morphological characteristics (Fig. 13a). One characteristic of the PC dendritic tree is that its extension and ramification occurs in the sagittal plane, resembling an espaliered fruit tree [229]. This highly stereotyped and simple architecture in a two-dimensional plane is likely at the origin of the PC's popularity: many neurobiologists, among them Ferdinando Rossi, have been fascinated by their beauty, e.g., [348]. The development of this spectacular dendritic tree occurs during the first three postnatal weeks of the mouse life. Interestingly, it is not a linear process as there is a clear discontinuity at the end of the first postnatal week. During the first postnatal week, successions of growth and retraction have been described [349, 350]. Immature PCs present a panel of very different morphological forms (Fig. 13b,c). In the absence of time-lapse analyses, the relations between these different morphological forms are not yet well understood. It is only from the second postnatal week on that PCs develop their characteristic dendritic trees (Fig. 13d). At the beginning of the second postnatal week, the PCs have a single stem segment at the apical pole that already presages the form of the mature dendritic tree. During the second postnatal week, and up to the end of the third postnatal week, the dendritic tree grows first wider and then taller [351]. By using virus-mediated gene transfer followed by three-dimensional reconstruction of confocal images of labeled PCs, Kaneko et al. [352] demonstrated that PCs achieve their monoplanar configuration by the dynamic remodeling of an initially irregular arrangement extended in multiple sagittal planes during the third postnatal week in mice.

The transition between these two morphological developmental phases - a first phase of intense remodeling and a second phase of continuous development of the mature dendritic tree-occurs in parallel with profound functional transitions [353, 354]. As they occur in parallel with a circulating peak of $\mathrm{TH}$ and the acquisition of the ability to walk outside the mother nest, we have 
Fig. 13 Dendritic differentiation of Purkinje cells. PCs were filled with biocytin using patch-clamp pipette and revealed by incubation with streptavidin coupled to fluorochrome cy 3 from 2-month-old (a), newborn (b), 5-day-old (c), and 7-day-old (d) mice. (a) was imaged with a confocal microscope and its morphology reconstructed with Neuronstudio software. The tree model obtained was used as a mask to extracted single PCs from the background image. $(\mathbf{b}, \mathbf{c})$ and (d) were imaged with an epifluorescence microscope. Bar, $30 \mu \mathrm{m}$

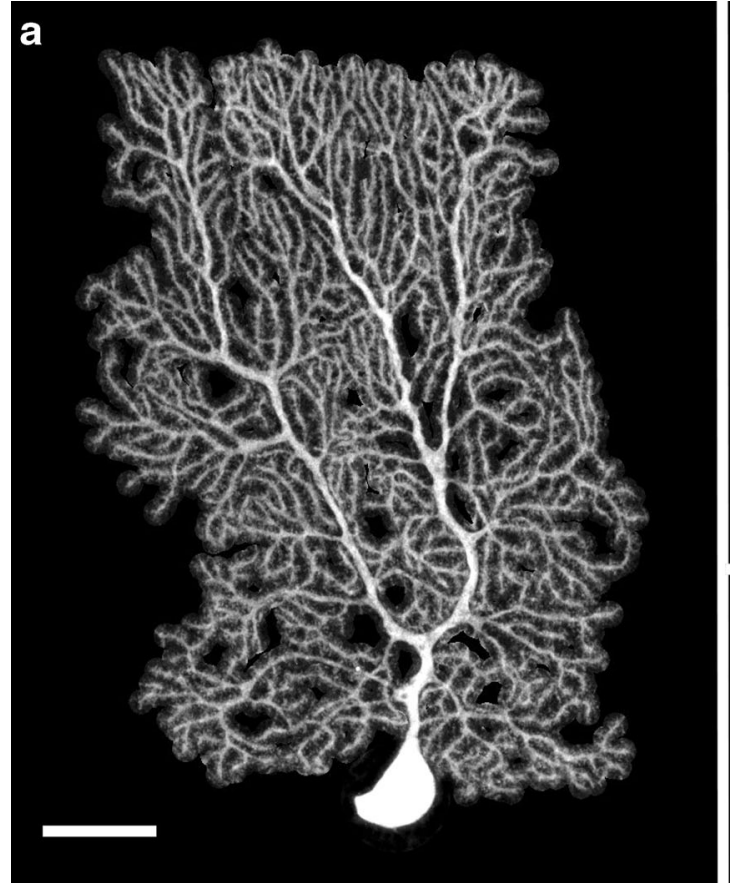

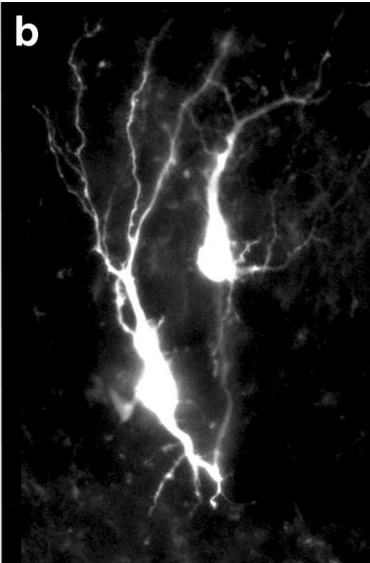
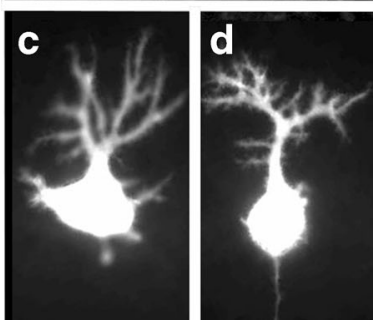

proposed that these transitions are reminiscent of amphibian metamorphosis $[354,355]$.

Numerous intrinsic or environmental factors regulate the dendritic development of PCs (for reviews see [342, 345, $356,357]$ ) and indeed, understanding the development and the maintenance of the dendritic tree is far from being accomplished. Recent studies of PCs have shed light on new mechanisms. For example, the PC is one of the rare types of neurons in which factors involved in the maintenance of dendritic tree have been identified [358]. In mammals, mechanisms of dendritic self-avoidance, a critical process in patterning neural circuits during development, has also been reported in [359, 360]. Last, in parallel to the classic neurotrophic theory for axons, developing PC dendrites compete for limiting amounts of Neurotrophin-3 (NT3) and require anterograde NT3 from their presynaptic partners in order to grow [361].

\section{Neurodevelopmental Disorders of the Cerebellum}

\section{Developmental Malformations (W.B. Dobyns, P. Haldipur, K. J. Millen)}

Numerous cerebellar malformations have been described in humans, primarily classified by MRI studies, and can occur in isolation or as part of a broader malformation syndrome involving multiple systems. Most cause cognitive in addition to motor and sensory integration deficits [362, 363]. Cerebellar developmental mechanisms are well conserved between humans and rodents, making studies in mice highly informative towards defining pathogenic mechanisms. Notably, however, cerebellar development in humans begins around the ninth gestational week and continues beyond birth. This protracted developmental timeline makes the human cerebellum particularly vulnerable to insult, especially during 24 40 weeks of gestation, when massive neurogenesis in the EGL causes a fivefold increase in size of the cerebellum [364]. Thus, while several malformations have a genetic basis, inflammation, fetal hemorrhage, and prematurity are often contributing factors. Here, we discuss some of the common and best understood human cerebellar malformations and their causes.

Dandy Walker Malformation (DWM) is the most common human cerebellar malformation with an estimated incidence of $1 / 3000$ live births $[365,366]$. DWM is an imaging diagnosis characterized by an enlarged posterior fossa, cerebellar vermis hypoplasia, and an enlarged fourth ventricle (Fig. 14a). DWM can occur in association with agenesis of the corpus callosum, but more often occurs as an isolated finding on MRI scans. DWM clinical features are variable. Patients may exhibit symptoms ranging from intellectual disability to autism or they may be completely unaware of any deficits until diagnosed as adults for unrelated reasons [367-369]. The genetic causes of DWM remain largely unknown. However, recent studies indicate that deletions in FOXC1 and ZIC1/4 are responsible for a small subset of DWM cases [370, 371]. Prenatal cerebellar hemorrhage however can also cause DWM [372], which may also be associated with genetic risk factors; however, these have yet to be determined. Research in animal models has led to the hypothesis that disruptions of posterior fossa signaling from the mesenchyme surrounding the brain to the underlying embryonic cerebellum are key. Signaling disruptions cause dramatic 

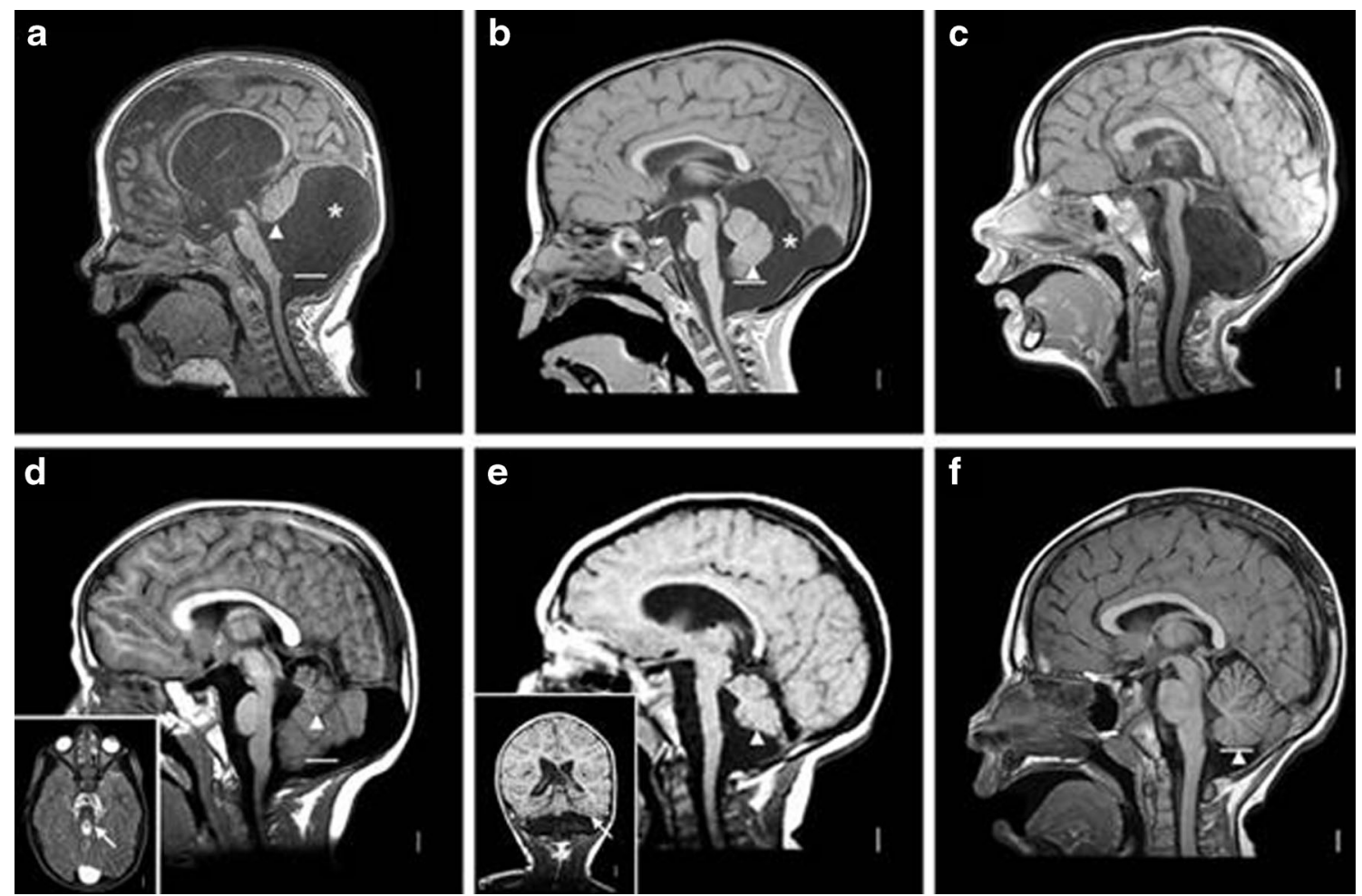

Fig. 14 Brain imaging in mid-hindbrain malformations. T1-weighted midline sagittal magnetic resonance images show the key features of classic DWM (a), cerebellar vermis hypoplasia with mega-cisterns magna (b), complete cerebellar agenesis (c), molar tooth malformation seen in JSRD (d), pontocerebellar hypoplasia (e), and normal (f). The solid white lines in most images mark the level of the obex, while the arrowheads point to the lower edge of the vermis (both landmarks are absent in $\mathbf{c}$ ). The asterisk denotes an enlarged posterior fossa. In (a), the vermis is small and rotated far upwards, the fourth ventricle is enlarged into a cyst-like structure, and the posterior fossa is greatly enlarged causing an elevated

reductions in cerebellar anlage neuronal progenitor proliferation, as well as abnormal migration of both RL- and VZderived cells. This ultimately leads to foliation and lamination defects [370, 373].

Joubert syndrome and related disorders (JSRD) is a group of disorders with an incidence of 1 in 80,000-100,000 live births $[374,375]$. JSRD is characterized by cerebellar vermis hypoplasia, thick and abnormally oriented superior cerebellar peduncles, and a deep interpeduncular fossa, all of which give it the pathognomonic Molar Tooth Sign (MTS) seen in axial brain scan images ([376], Fig. 14d). Patients with JSRD exhibit variable neurological symptoms such as ataxia, developmental delay, abnormal eye movements, and altered breathing patterns. To date, $\sim 23$ genes have been identified as causative for JSRD [377, 378]. Most have been linked to the primary cilia and its function, bringing JSRD under the umbrella of a highly heterogeneous group of disorders called ciliopathies. Studies in animal models as well as human fetal tissue from JSRD patients indicate reduced GC proliferation suggesting impaired SHH signaling ([290, 291, 379]: see "Extrinsic Regulators of Cerebellar Development: The Role of Sonic tentorium. In (b), the vermis is small but located in the anatomic position, but the posterior fossa is again greatly enlarged. A posterior extension of the cyst appears to scallop the inner table of the skull. In (c), the brainstem is thin without any landmarks other than the tectum, and no cerebellum is seen. In (d), the vermis is very small but located in the correct anatomic position, with portions of the cerebellar hemispheres seen beneath. The inset shows the associated "molar tooth" sign (arrow). In (e), the brainstem is thin but the obex can just be seen, and the vermis is moderately small. The even more "pancake-like" flattening of the hemispheres is shown in the inset (arrow)

Hedgehog" section). Additionally, the primary cilia also plays a role in the mediation of signaling pathways involving WNT and platelet-derived growth factor which can impact cerebellar anlage fusion earlier in fetal development [380, 381].

Cerebellar hypoplasia $(\mathrm{CH})$ refers to underdevelopment of the cerebellum. This category of cerebellar malformation is distinct from DWM, as it does not involve a concomitant enlargement of the posterior fossa. $\mathrm{CH}$ is also an extremely heterogeneous group of disorders, and often, other CNS abnormalities are observed, including lissencephaly, microcephaly, and cortical heterotopia. CH may be unilateral, global, vermian, or ponto-cerebellar, where in addition to the cerebellum, the volume of the pons is also reduced likely reflecting the common developmental origin of GCs and pontine nuclei neurons in the cerebellar RL ([20, 382], Fig. 14b, e). In contrast to DWM, almost all individuals exhibit cognitive and motor impairments. Several genes have been associated with CH including mutations in CASK, DAB1, OPHN1, RELN, CHD7, several tubulin genes, and several TSEN genes [209, 383-392]. Each causes developmental defects in a multitude of cerebellar developmental programs, including progenitor 
proliferation and neuronal migration and even developmental cell survival. Notably, $\mathrm{CH}$ can also occur due to a variety of non-genetic causes such as perinatal cytomegalovirus infection and perinatal exposure to alcohol and drugs such as cocaine [393-397].

Cerebellar agenesis is an extremely rare anomaly distinguished by a complete or near-complete absence of the cerebellum ([398]; Fig. 14c). Individuals show a number of neurological deficits particularly related to movement and speech, but can be otherwise surprisingly unaffected [399]. Homozygous mutations in PTF1A have been associated cerebellar agenesis in humans [400]. In mice, Ptfla is required for the generation of all VZ-derived GABAergic cerebellar neurons. Failure to generate these neurons means that RL-derived cells have no trophic support and these too are therefore lost, resulting in cerebellar agenesis in neonates [34]. Fetal hemorrhages that completely disrupt the early cerebellar anlage have also been predicted to cause cerebellar agenesis [401].

Recent developments in neuropathology and neuroimaging have tremendously improved the diagnosis of developmental disorders of the cerebellum. Several genes responsible for these heterogeneous malformations have been identified and animal models have revealed novel developmental mechanisms of interest to both clinical and basic science. A deeper appreciation of the cellular and signaling mechanisms responsible for these malformations will enable improved diagnosis and potential treatment of these disorders.

\section{The Role of Thyroid Hormone in Cerebellar Development (N. Koibuchi)}

The importance of T3 and T4 in brain development has been well documented [402, 403]. Deficiency of TH during fetal and early postnatal period results in severe mental retardation, known as cretinism in humans [404]. Since there is a distinct "critical period" of TH action in brain development, replacement of TH should be started as early as possible to prevent irreversible neurological disorders.

T4 enters the brain through the blood-brain barrier (BBB) more easily than T3, an active form of TH [405]. After crossing the $\mathrm{BBB}, \mathrm{T} 4$ is taken up by astrocytes and deiodinated to produce T3 by type 2 iodothyronine deiodinase [406]. T3 is then transferred to neurons or oligodendrocytes, possibly via monocarboxylate transporter 8 [407]. TH effects are mainly exerted through the nuclear TH receptor (TR; TR $\alpha 1$, TR $\beta 1$, and TR $\beta 2$ ), a ligand-dependent transcription factor [408]. TR binds to specific DNA enhancer sequences known as the THresponse elements located in the promoter region of target genes [408]. The rodent cerebellum is a good model to investigate the TH action. This is partly because the rodent cerebellar development occurs largely postnatally, allowing cerebellar TH status to be precisely manipulated at various developmental stages [402].
Perinatal hypothyroidism dramatically affects morphogenesis $[402,403]$ : the growth, dendrite arborization, and dendrite spine formation of PCs are all markedly decreased; synaptogenesis between PCs and PFs is dramatically repressed; the disappearance of the EGL is postponed as a result of the delayed proliferation and migration of GCs into the GL [409]. TRs are expressed in the most subsets of cells in the developing cerebellum [410]. TR $\alpha 1$ is abundant in GCs, whereas TR $\beta 1$ is mainly expressed in PCs. The expression of many cerebellar genes is altered by perinatal hypothyroidism [403]. Representative TH-responsive genes in the cerebellum include neurotrophins such as nerve growth factor, BDNF, NT3, and NT-4/5, and receptors such as the inositol trisphosphate 3 receptor, and retinoic acid receptor-related orphan receptor $\alpha$, hairless, and myelin basic protein [411, 412]. The expression of many of these genes is regulated by TH only during a limited period of development. (It should be noted, however, that although $\mathrm{TH}$ action in the brain is greater during development, TR levels are greater in the adult brain: [413].) Thus, TH sensitivity may be controlled by other unknown epigenetic mechanisms such as DNA methylation and histone modification.

Various animal models have been used to study $\mathrm{TH}$ in cerebellar development [414]. Interestingly, $\mathrm{TR} \alpha$ knock-out mice, TR $\beta$ knock-out mice and $\operatorname{TR} \alpha / \operatorname{TR} \beta$ double knock-out mice do not display obvious cerebellar defects, suggesting that most of the consequences of congenital hypothyroidism in the brain are due to the detrimental activity of unliganded TR. This hypothesis is supported by studies of transgenic animals expressing mutant TR, which show severe neurodevelopmental defects $[415,416]$.

Although these animal models have contributed greatly to our understanding on the role of TR in cerebellar development, these may not sufficiently address the mechanisms of direct TH action. Since TH acts not only in the brain but also in the peripheral organs, brain development may be affected by peripheral metabolic changes. Thus, cell or organ-specific inhibition/ activation of $\mathrm{TH}$ action is required. For such purpose, Fauquier et al. [417] used a L7/Pcp2 promoter to generate transgenic mice that express a mutant $\mathrm{TR} \alpha 1$ specifically in PCs after P8. Probably because the timing of transgene expression is slightly after the critical period, this mouse showed only limited alterations in cerebellar morphogenesis. On the other hand, by Ptfla-Cre recombination, mutant TR $\alpha 1$ was expressed in PCs and GABAergic INs from prenatal stages, showing the alteration of PC morphogenesis [417]. We have also generated a transgenic mouse using mutant human TR $\beta 1$ with $L 7 / P c p 2$ promoter (Fig. 15; [418]). Expression of mutant TR $\beta 1$ was observed as early as P2. This mouse showed decreased PC dendritic arborization and lower 
Fig. 15 Morphological alterations in the postnatal cerebellum by mutant TR in the Purkinje cell. Mutant human TR, which inhibits normal TR action, is expressed in PCs by using the L7/Pcp2 promoter. a Sagittal sections of the cerebellar vermis at P7, P15, and P30 were stained with mouse anti-calbindin-D28K $(1: 1000)$ and cresyl violet. Note that the EGL is seen in $\mathrm{He}$ and $\mathrm{Ho}$ mice on P15. EGL external granular cell layer, $M L$ molecular layer, $P C L$ Purkinje cell layer, $G L$ granular layer, $T g /$ - heterozygote, $\mathrm{Tg} / \mathrm{Tg}$ homozygote, -/- wildtype. Bar, $50 \mu \mathrm{m}$. b Changes in PC dendrite arborization in primary cerebellar culture. After 17 days in vitro, with or without $\mathrm{T} 4$, the cells were fixed, and immunocytochemistry was carried out using the anticalbindin antibody to visualize PCs. Bars, $50 \mu \mathrm{m}$. Tg/heterozygote, $\mathrm{Tg} / \mathrm{Tg}$ homozygote, $-/-$ wild-type. Adapted with permission from [418]. EGL external granular layer, $M L$ molecular layer, $P C L$ Purkinje cell layer, $G L$ granular layer

a

P7
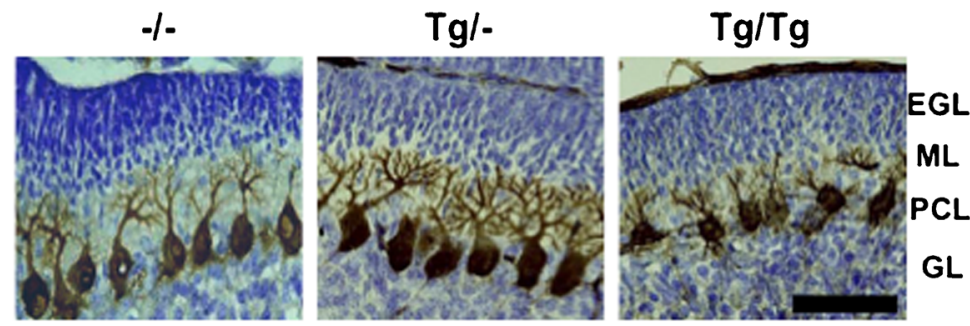

P15
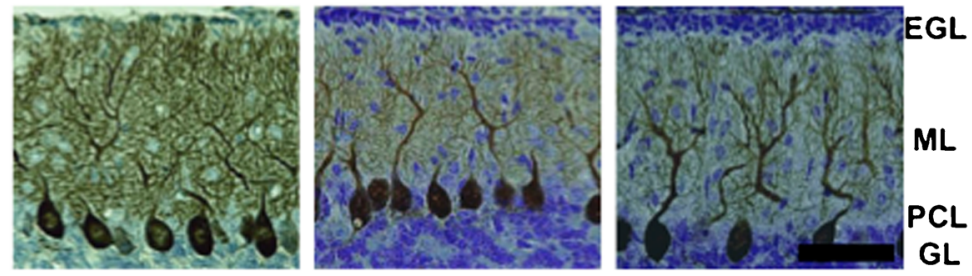

P30
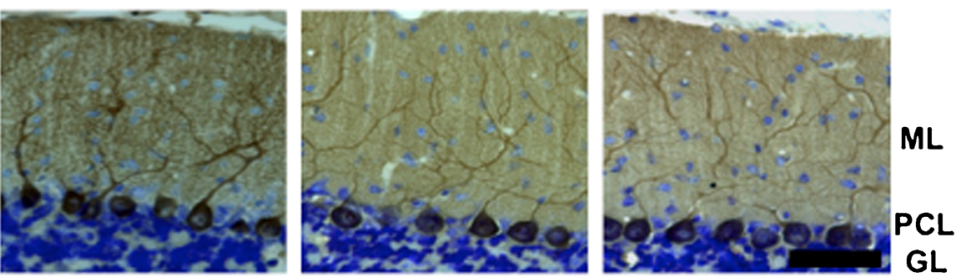

b
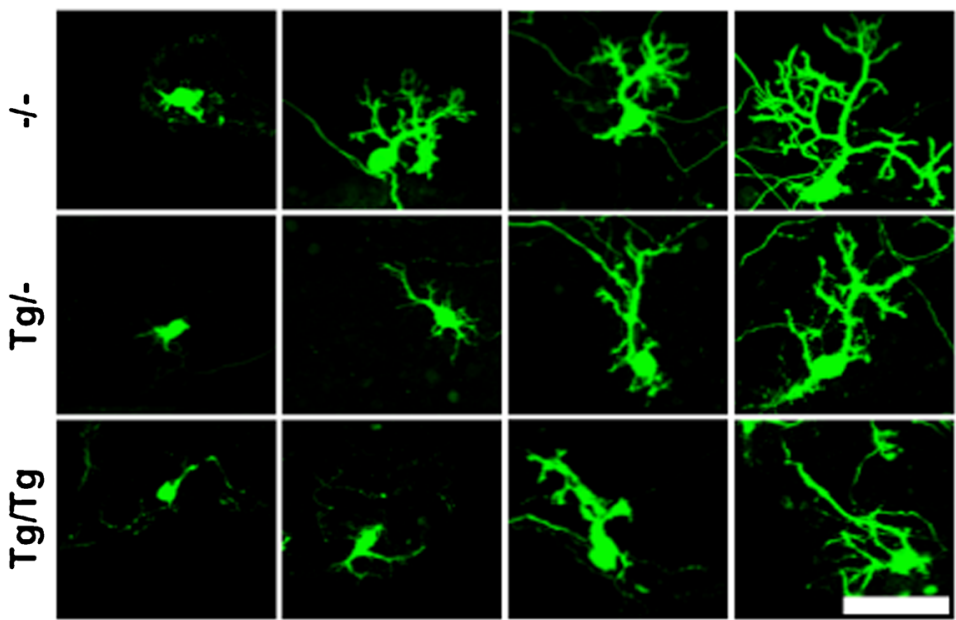

$10^{-10}$

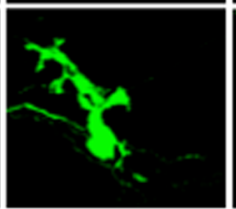

$10^{-9}$

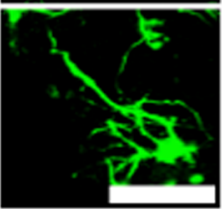

$10^{-8}$

T4 (M):

\section{Abnormal Purkinje Cell Development and Cerebellar} Ataxia (E.B.E. Becker)

The cerebellar ataxias comprise a heterogeneous group of neurological disorders characterized by gait disturbances, motor incoordination and imbalance, dysarthria, and oculomotor deficits $[420,421]$. The etiology of cerebellar ataxia is complex and includes acquired causes as well as a steadily growing number of inherited conditions [421-423]. The genetic ataxias are usually progressive. For many of these disorders, pathologic changes in PCs and a substantial loss of these neurons resulting in cerebellar atrophy are thought to cause the symptoms of the disease. However, accumulating evidence from cell- and animal-based models of cerebellar ataxia critical period may produce adverse effects [419]. 
suggest that abnormal PC development and related early changes in PC physiology might contribute to the disease, thus challenging our view of cerebellar ataxias as pure neurodegenerative disorders. Here, I briefly review the emerging concept that PC developmental abnormalities might be contributing to disease pathogenesis in cerebellar ataxia.

Spinocerebellar ataxia type 1 (SCA1) is caused by a CAG repeat expansion in the Ataxin1 (ATXN1) gene and is one of the most intensely studied dominant ataxias. Numerous mouse and other animal models have been generated for SCA1 that recapitulate different aspects of the human disease. For example, both transgenic mice overexpressing expanded $A T X N 1[82 Q]$ as well as knock-in mice $\left(S C A 1^{154 \mathrm{Q} / 2 \mathrm{Q}}\right)$ exhibit motor impairments and PC degeneration [424]. Interestingly, transgenic mice in which expression of the expanded transgene is delayed until well after the cerebellum has matured display a much reduced disease phenotype, suggesting that mutant ATXN1 interacts with a pathway involved in PC development [425]. Indeed, the same study demonstrated a key interaction of ATXN1 with retinoic acid-related orphan nuclear receptor $\alpha(\mathrm{ROR} \alpha)$, a transcription factor critical for cerebellar development. Moreover, ROR $\alpha$ expression levels were found to be reduced in the ATXN1[82Q] model [425]. Taken together, the results of this landmark study provided the first functional genetic evidence that compromising PC development contributes to the severity of neurodegeneration. Subsequent studies have shown that SCA1 transgenic mice display abnormalities in PC development, including a reduction of $\mathrm{CF}$ translocation along the developing dendritic tree and decreased pruning of CF terminals from the PC soma [426, 427]. Similarly, profound impairments in PC dendritogenesis, spine development, and synaptogenesis have been described in the staggerer mouse [428, 429], which harbors an autosomal recessive mutation in the Rora gene encoding $\operatorname{ROR} \alpha$, and is viewed by some as an extreme model of SCA1 [429].

Other studies have demonstrated similar PC developmental abnormalities in different mouse models of degenerative cerebellar ataxias. A PC-specific transgenic mouse model that expresses a truncated form of expanded human Ataxin-3, the disease protein causing SCA3, displays disarrangement of PCs and poor PC dendritic arborization [430, 431]. As described above for SCA1, the PCs in this SCA3 model express decreased levels of the developmental transcription factor ROR $\alpha$ [431], suggesting a potential molecular link between the observed developmental abnormalities in both models.

Impaired dendritic arborization of PCs as well as abnormal spine morphogenesis have also been described in mice lacking $\beta$-III spectrin, a model of SCA5 [432]. Similarly, cultured PCs overexpressing $\mathrm{PKC} \gamma$ with SCA14-causing mutations after adenoviral infection display a decreased dendritic arbor as well as decreased spine density [433]. In vivo lentiviralmediated expression of mutant $\mathrm{PKC} \gamma$ in PCs led to impaired pruning of $\mathrm{CF}$ synapses from developing PCs, although no dendritic abnormalities were observed [434]. However, the recently reported transgenic SCA14 mouse model shows abnormal dendritic development of PCs both in vivo as well as in organotypic slice cultures [435].

Besides models of the human SCAs, several other genetic mouse mutants have highlighted the relationship between abnormal PC development and ataxia. For example, the ataxic Moonwalker (Mwk) mouse harbors a dominant gain-offunction mutation in the TRPC3 ion channel, resulting in adult-onset PC loss but also impairments in PC dendritic arborization during cerebellar development [436]. TRPC3 is a key player in the mGluR1 signaling pathway vital for PC function [437, 438]. Interestingly, impaired mGluR1 signaling has been demonstrated in a number of the mouse models described above including SCA1 [439, 440], SCA3 [441], and SCA5 [442] models. Future research should help to clarify whether there is a causal relationship between impaired mGluR1 signaling at PC-PF synapses and developmental PC abnormalities in these and other models of ataxia.

In summary, PC developmental abnormalities are clearly evident in a wide range of ataxic mouse mutants including models of the degenerative SCAs. The observed PC developmental defects commonly include impaired dendritic arborization, resulting in synaptic deficits affecting $\mathrm{CF}$ and $\mathrm{PF}$ connections and ultimately altering PC physiology. It will be important to better understand the underlying-likely common-molecular mechanisms by which mutations in distinct genes cause abnormal PC development and function. These could offer attractive future therapeutic targets to alleviate motor dysfunction in cerebellar ataxia.

\section{Deregulated Developmental Pathways in Medulloblastoma (S. Marino, T.O. Millner)}

$\mathrm{MB}$ is the most common pediatric brain tumor and is the most common cause of pediatric death from cancer. Histologically, cases are classified into classic, nodular/desmoplastic, and large cell/anaplastic subtype [443], and prognosis is performed by combining histological subtype, clinical markers, namely, age, metastatic stage, and level of resection, as well as selected molecular markers. Morphologically, MB cells closely resemble GCs and GCPs; hence, it has been long postulated that a link exists between these tumors and the normal development of the cerebellum. Evidence gained from candidate gene approaches in mouse models and more recently "-omics" screening of large tumor series has shown deregulation of specific developmental pathways in subgroups of these tumors.

The current consensus is that MB can be sub-classified based on genetic, epigenetic, and transcriptomic characteristics [444, 445] into four distinct subgroups (Fig. 16): WNT, SHH, Group 3, and Group 4 [445]. The WNT and SHH subgroups have been associated with constitutive activation of the 
Fig. 16 Medulloblastoma subgroups and their cells of origin. The schematic shows the embryonic and early postnatal murine cerebellum and brainstem with the spatial and temporal locations of likely cells of origin of MB subgroups (green dots represent dorsal brainstem precursor cells, yellow dots represent GCPs, red dots represent cerebellar stem cells). The table shows the genetics, gene expression profile, predominant histology, and prognosis of the MB subgroups for each of these cells of origin

\section{Embryonic murine cerebellum} and brainstem

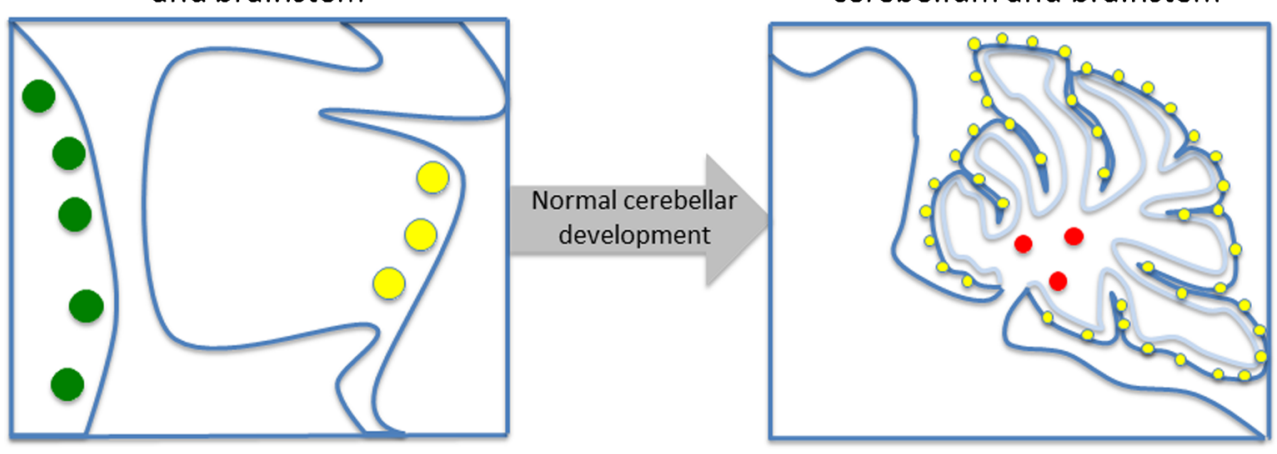

\begin{tabular}{|c|c|c|c|}
\hline Cell of origin & $\begin{array}{l}\text { Dorsal brainstem } \\
\text { precursor }\end{array}$ & Granule cell precursor & Cerebellar stem cell \\
\hline Genetics & $\begin{array}{l}\text { Monosomy } 6 \text {, } \\
\text { CTNNB1 mutation }\end{array}$ & $\begin{array}{l}\text { PTCH, SMO and SUFU } \\
\text { mutations, Gli2 and } \\
\text { MYCN amplification }\end{array}$ & $\begin{array}{l}\text { i17q, MYC } \\
\text { amplification }\end{array}$ \\
\hline $\begin{array}{l}\text { Gene } \\
\text { expression }\end{array}$ & WNT signaling & SHH signaling & MYC+++ \\
\hline $\begin{array}{l}\text { Predominant } \\
\text { Histology }\end{array}$ & Classic & Desmoplastic/nodular & Large cell/anaplastic \\
\hline Prognosis & Very good & Intermediate & Poor \\
\hline
\end{tabular}

$\mathrm{WNT} / \beta$-catenin and SHH pathways, respectively, whereas Group 3 and Group 4 MBs are less well characterized. Each of these subgroups have defining demographic, clinical, genetic, and epigenetic profiles, and emerging evidence links their origin to different cerebellar progenitor cells at different developmental time points. Here, we will summarize the key features of the current molecular stratification of MB from a developmental oncobiology perspective.

\section{GCPS and SHH-MB}

GCPs are the main cell of origin of SHH-MB, as shown in mouse models in which Ptchl is conditionally inactivated in GCPs. Importantly, constitutive activation of SHH signaling induces neoplastic transformation of more undifferentiated progenitor cells only upon commitment toward a GC lineage [446]. Pre-neoplastic lesions expressed Athol, a marker of the GC lineage, and showed activation of Gli1, Cyclin D1, and $M y c N$, which are SHH target genes. Their gene expression profiles were more similar (differing by 34 genes) to tumor cells than GCPs (differing by 75 genes) [447]. SHH-MBs have also been shown to originate from cells located in the cochlear nuclei of the brainstem [448].

MRI studies have shown differences in the location of MB subgroups, and MB location (as well as enhancement pattern) can predict the molecular subgroup of pediatric MBs. SHH tumors are mainly detected within the cerebellar hemispheres
[449-451] consistent with a GCP cell of origin. Moreover, in a series of 63 human MBs that were morphologically nodular/ desmoplastic, a histological subtype likely to be typical of the SHH subgroup [452], $33 \%$ had very close contact to the cochlear nuclei on MRI [448]. Human Shh MBs [445] have a 1:1 male-to-female ratio and a bimodal age distribution (very frequently seen in infants and adults), with a good prognosis in infants but an intermediate prognosis in other age groups. All histological nodular/desmoplastic MBs are likely SHHMBs [452], but $50 \%$ of SHH-MBs are of other morphology.

\section{Embryonic Dorsal Brain Stem Precursors and WNT-MB}

Mouse models have shown that WNT-MBs, characterized by activating mutations in the Wnt pathway effector CTNNB1, arise from cells outside the cerebellum, in the embryonic dorsal brainstem [449]. These studies also showed that the genes characterizing human WNT-MBs are more often expressed in the lower RL and embryonic dorsal brainstem than in the upper RL of the developing cerebellum. In addition, transcriptome analysis showed that the MBs arising in these mice matched human WNT-MBs.

MRI studies in patients have shown that WNT tumors are often found within the fourth ventricle (cerebellar peduncle/ cerebellopontine angle cistern) and infiltrated the dorsal brainstem $[449,450]$, with the majority of them being continuous with the cuneate nucleus [451], a region that corresponds 
to the origin defined for the murine WNT-MBs described above. Human WNT-MBs [445] have a 1:1 male-to-female ratio and occur at all ages (uncommon in infants). They have a very good long-term prognosis in comparison to the other subgroups of MB (survival rate likely exceeds $90 \%$ with current treatment). The large majority of WNT-MBs investigated so far have classic histology.

\section{Cerebellar Stem Cells and Their Role as MB Cell of Origin}

Cerebellar stem cells are a third likely cell of origin for human MBs. Models using $R b^{+} T p 53$ mutant mice were generated where MBs developed from neural stem cells in the cerebellar white matter [453, 454]. These tumors resembled human Group 3 MBs histologically while expressing high levels of neural stem cell markers (Nestin, Sox2, and Sox9). A further model using $\mathrm{Myc}^{+} \mathrm{Tp} 53$ mutant mice developed MBs from cerebellar neural stem cells and from GCPs, although the tumors that formed from GCPs lost their lineage specific markers first [455]. This model expressed high levels of neural stem cell genes and also resembled human Group 3 tumors at a histological and molecular level.

In the MRI studies to date, Group 3 and Group 4 MBs are characterized by brainstem contact with most of the tumors growing within the vermis. Most also contact both the cochlear and cuneate nuclei and always infiltrate the fourth ventricle [450, 451]. Group 3 MBs [445] are seen more frequently in males than females and almost never in adults, have a poor prognosis, and are frequently metastatic. Group 3 MBs most frequently have a classic morphology, but the Group 3 subgroup contains the majority of the large cell/anaplastic tumors.

Group 4 comprises $30 \%$ of MBs and it is the least well characterized molecularly. At present, it is also unclear from which cells these tumors originate. This subgroup has a maleto-female ratio of 2:1 and has an intermediate prognosis, similar to the SHH subgroup [445]. Group 3 and Group 4 MBs share some molecular features: amplification of the OTX2 oncogene, which is not seen in the other subgroups, and isochromosome 17q (26\% in Group 3 and $66 \%$ in Group 4 MBs [447]). However, there are also important differences. Group 3 MBs show high levels of MYC, and often gain of chromosome $1 \mathrm{q}$ and/or loss of chromosome $5 \mathrm{q}$ and $10 \mathrm{q}$, whereas Group 4 MBs have low levels of MYC and MYCN and loss of the $\mathrm{X}$ chromosome in $80 \%$ of females within the subgroup [445].

In summary, “-omics" datasets on large series of MB combined with the results of ontogeny studies performed in mouse models aiming at characterizing the cell of origin of the various subgroups together with magnetic resonance imaging (MRI) studies in patients lend additional support to the notion that $\mathrm{MB}$ is in fact a disease arising from deregulated cellular and molecular mechanisms involved in the development and homeostasis of the cerebellum.

\section{Concluding Remarks (C. Sotelo)}

The goal of our consensus paper is to provide an updated view of our current knowledge on cerebellar development. The broad spectrum of the work reviewed in such a short format leaves little room for specific debate. Nevertheless, many of the concepts reported here have already reached consensus.

The seminal discovery of the "isthmic organizer" and its inductive role has led to an understanding of the molecular regionalization of the neural tube with its precise frontiers between domains expressing homeobox-containing genes. The interface between caudal GBX2 and rostral OTX2 expressing domains marks the location of the "isthmic organizer" which, through Fgf8 secretion, initiates the molecular cascade required for the specification of cerebellum.

Next come the germinal epithelia of the cerebellum. For over a century, the cerebellum was known for the dual origins of its neuronal populations: the VZ and the RL. However, the categories of neurons generated in each of these epithelia have only recently been established. Genetic fate mapping proved that glutamatergic neurons (most of the $\mathrm{CN}$ neurons, and all GCs and UBCs), specified by the transcription factor ATOH1, originate from the RL and migrate via the EGL. In contrast, GABAergic neurons (PCs, ML INs, Lugaro and Golgi cells, and GABAergic neurons of the $\mathrm{CN}$ ), specified by PTF1a, originate from the VZ. Moreover, both neuroepithelia are divided into subdomains, each one specified by distinct transcription factors to generate the corresponding population of neurons.

Following specification comes neuronal migration and differentiation. Despite recent progress, the data are less complete. For example, broad areas of the early development of PCs remain obscure, even while later events such as dendritogenesis are well understood. Our knowledge on the mechanisms leading to the biochemical heterogeneity of PCs and their aggregation into longitudinal and transverse compartments has improved: there is a dichotomy among PCs, those born between $\mathrm{E} 10$ and $\mathrm{E} 11.5$ will become $\mathrm{ZII}^{+}$and those born later will be ZII, indicating that specification might exist among progenitors. Related to PC compartmentalization, the formation of circuit topography and the elimination of $\mathrm{CF}$ multiple innervation opens the vast domain of synaptogenesis and the role of functional activity in the fine-tuning of the cortical circuit's specificity-a chapter that, at this moment, remains little explored and is an anticipated topic for future consensus papers. Similarly, the ways in which cerebellar INs and glia become integrated into the mature cerebellum are also beginning to be understood. Finally, in parallel with these events, we are now seeing how the development of the characteristic cerebellar foliation fits into the picture.

We have also updated on the role of the TH (a cerebellists' old friend because of its multiple effects on cerebellar development) describing recent advances using transgenic animals 
with conditional nuclear TH receptor knock-outs targeted to PCs or/and IN that allow for the suppression of secondary effects on other neurons or peripheral organs.

Finally, our review has briefly touched upon cerebellar pathology. For example, the analysis of the role of SHH, secreted by PCs as mitogen for GC proliferation, provides a basis for better understanding of the origins of MBs, and inherited disorders of cerebellar development can now be placed in a stronger developmental context.

In conclusion, following the outline proposed by Ferdinando Rossi in his planned monograph, the data presented here provide our brief consensus of the current knowledge on cerebellar development.

Acknowledgments We dedicate this Consensus Paper to the memory of Professor Ferdinando Rossi, a brilliant neuroscientist and a passionate expert on cerebellar development. We apologize to all our colleagues whose work has not been cited due to the focus and space constraints of this review.

Arancillo and Sillitoe: R.V.S is supported by funds from Baylor College of Medicine and Texas Children's Hospital, The Bachmann-Strauss Dystonia and Parkinson Foundation, Inc., Baylor College of Medicine IDDRC grant 1U54HD083092-01, and NINDS grant 1R01NS08966401. M.A. is supported by a postdoctoral award from the National Ataxia Foundation (NAF).

Becker: E.B. is the recipient of a Research Fellowship from the Royal Society.

Dobyns and Millen: This work is supported by NIH grants NS050375 to W.B.D. and NS080390 to K.J.M.

Hoshino: I thank Satoshi Miyashita for drawing Fig. 2.

Leto: This work was supported by grants from University of Turin and Research Fund for the Promotion of Basic Research Grant RBFR10A01S.

Joyner: I thank my lab members (present and past) for stimulating discussions and Emilie Legué for helpful comments on the manuscript and for drawing Fig. 11e. Our cerebellar research is supported by grants from the NIH (R37MH085726 and NS092096).

Kilpatrick: We thank Mr. George Gagnon for his invaluable and gracious assistance in all aspects of this work. This work was supported by Public Health Services grant NS063047.

Sekerková: This work was supported by NIH grant RO1 09904.

Conflict of Interest The authors declare that they have no competing interests.

Open Access This article is distributed under the terms of the Creative Commons Attribution 4.0 International License (http:// creativecommons.org/licenses/by/4.0/), which permits unrestricted use, distribution, and reproduction in any medium, provided you give appropriate credit to the original author(s) and the source, provide a link to the Creative Commons license, and indicate if changes were made.

\section{References}

1. Sotelo C, Wassef M. Cerebellar development: afferent organization and Purkinje cell heterogeneity. Philos Trans R Soc Lond B Biol Sci. 1991;331(1261):307-13.

2. Echevarría D, Vieira C, Gimeno L, Martínez S. Neuroepithelial secondary organizers and cell fate specification in the developing brain. Brain Res Brain Res Rev. 2003;43:179-91.
3. Joyner AL, Liu A, Millet S. Otx2, Gbx2 and Fgf8 interact to position and maintain a mid-hindbrain organizer. Curr Opin Cell Biol. 2000;12:736-41.

4. Martinez S, Andreu A, Mecklenburg N, Echevarria D. Cellular and molecular basis of cerebellar development. Front Neuroanat. 2013;7:18.

5. Martinez S, Wassef M, Alvarado-Mallart RM. Induction of a mesencephalic phenotype in the 2-day-old chick prosencephalon is preceded by the early expression of the homeobox gene engrailed. Neuron. 1991;6:971-81.

6. Sato T, Joyner AL. The duration of Fgf8 isthmic organizer expression is key to patterning different tectal-isthmo-cerebellum structures. Development. 2009;136(21):3617-26.

7. Nakamura H, Katahira T, Matsunaga E, Sato T. Isthmus organizer for midbrain and hindbrain development. Brain Res Brain Res Rev. 2005;49(2):120-6.

8. Crossley PH, Martinez S, Martin GR. Midbrain development induced by FGF8 in the chick embryo. Nature. 1996;380(6569):668.

9. Hamburger V, Hamilton HL. A series of normal stages in the development of the chick embryo. J Morphol. 1951;88(1):49-92.

10. Garda AL, Echevarría D, Martínez S. Neuroepithelial coexpression of Gbx2 and Otx2 precedes Fgf8 expression in the isthmic organizer. Mech Dev. 2001;101(1-2):111-8.

11. Millet S, Campbell K, Epstein DJ, Losos K, Harris E, Joyner AL. A role for Gbx2 in repression of Otx2 and positioning the mid/ hindbrain organizer. Nature. 1999;401(6749):161-4.

12. Broccoli V, Boncinelli E, Wurst W. The caudal limit of Otx2 expression positions the isthmic organizer. Nature. 1999;401(6749):164-8.

13. Liu A, Joyner AL. EN and GBX2 play essential roles downstream of FGF 8 in patterning the mouse $\mathrm{mid} /$ hindbrain region. Development. 2001;128(2):181-91.

14. Martinez-Barbera JP, Signore M, Boyl PP, Puelles E, Acampora $\mathrm{D}$, Gogoi R, et al. Regionalisation of anterior neuroectoderm and its competence in responding to forebrain and midbrain inducing activities depend on mutual antagonism between OTX2 and GBX2. Development. 2001;128(23):4789-800.

15. Wassarman KM, Lewandoski M, Campbell K, Joyner AL, Rubenstein JL, Martinez S, et al. Specification of the anterior hindbrain and establishment of a normal mid/hindbrain organizer is dependent on Gbx2 gene function. Development. 1997;124(15):2923-34.

16. Chi CL, Martinez S, Wurst W, Martin GR. The Isthmic organizer signal FGF8 is required for cell survival in the prospective midbrain and cerebellum. Development. 2003;130(12):2633-44.

17. Basson MA, Echevarria D, Ahn CP, Sudarov A, Joyner AL, Mason IJ, et al. Specific regions within the embryonic midbrain and cerebellum require different levels of FGF signaling during development. Development. 2008;135(5):889-98.

18. Nowak M, Machate A, Yu SR, Gupta M, Brand M. Interpretation of the FGF8 morphogen gradient is regulated by endocytic trafficking. Nat Cell Biol. 2011;13(2):153-8.

19. Millet S, Bloch-Gallego E, Simeone A, Alvarado-Mallart RM. The caudal limit of Otx2 gene expression as a marker of the midbrain/hindbrain boundary: a study using in situ hybridisation and chick/quail homotopic grafts. Development. 1996;122(12): 3785-97.

20. Wingate RJT, Hatten ME. The role of the rhombic lip in avian cerebellum development. Development. 1999;126(20):4395-404.

21. Chizhikov V, Millen KJ. Development and malformations of the cerebellum in mice. Mol Genet Metab. 2003;80(1-2):54-65.

22. Zervas M, Millet S, Ahn S, Joyner AL. Cell behaviors and genetic lineages of the mesencephalon and rhombomere 1. Neuron. 2004;43(3):345-57. 
23. Chizhikov VV, Lindgren AG, Currle DS, Rose MF, Monuki ES, Millen KJ. The roof plate regulates cerebellar cell-type specification and proliferation. Development. 2006;133:2793-804.

24. Ben-Arie N, Bellen HJ, Armstrong DL, McCall AE, Gordadze PR, Guo Q, et al. Math1 is essential for genesis of cerebellar granule neurons. Nature. 1997;390:169-72.

25. Machold R, Fishell G. Math1 is expressed in temporally discrete pools of cerebellar rhombic-lip neural progenitors. Neuron. 2005;48:17-24.

26. Wang VY, Rose MF, Zoghbi HY. Math1 expression redefines the rhombic lip derivatives and reveals novel lineages within the brainstem and cerebellum. Neuron. 2005;48:31-43.

27. Englund C, Kowalczyk T, Daza RA, Dagan A, Lau C, Rose MF, et al. Unipolar brush cells of the cerebellum are produced in the rhombic lip and migrate through developing white matter. J Neurosci. 2006;26:9184-95.

28. Sultan F, Czubayko U, Thier P. Morphological classification of the rat lateral cerebellar nuclear neurons by principal component analysis. J Comp Neurol. 2003;455:139-55.

29. Leto K, Carletti B, Williams IM, Magrassi L, Rossi F. Different types of cerebellar GABAergic interneurons originate from a common pool of multipotent progenitor cells. J Neurosci. 2006;26: 11682-94.

30. Hashimoto M, Mikoshiba K. Mediolateral compartmentalization of the cerebellum is determined on the "birth date" of Purkinje cells. J Neurosci. 2003;23:11342-51.

31. Sudarov A, Turnbull RK, Kim EJ, Lebel-Potter M, Guillemot F, Joyner AL. Ascl1 genetics reveals insights into cerebellum local circuit assembly. J Neurosci. 2011;31:11055-69.

32. Leto K, Bartolini A, Yanagawa Y, Obata K, Magrassi L, Schilling $\mathrm{K}$, et al. Laminar fate and phenotype specification of cerebellar GABAergic interneurons. J Neurosci. 2009;29:7079-91.

33. Fleming JT, He W, Hao C, Ketova T, Pan FC, Wright CV, et al. The Purkinje neuron acts as a central regulator of spatially and functionally distinct cerebellar precursors. Dev Cell. 2013;27: 278-92.

34. Hoshino M, Nakamura S, Mori K, Kawauchi T, Terao M, Nishimura YV, et al. Ptfla, a bHLH transcriptional gene, defines GABAergic neuronal fates in cerebellum. Neuron. 2005;47:20113.

35. Pascual M, Abasolo I, Mingorance-Le Meur A, Martinez A, Del Rio JA, Wright CV, et al. Cerebellar GABAergic progenitors adopt an external granule cell-like phenotype in the absence of Ptfla transcription factor expression. Proc Natl Acad Sci U S A. 2007;104:5193-8.

36. Yamada M, Seto Y, Taya S, Owa T, Inoue YU, Inoue T, et al. Specification of spatial identities of cerebellar neuronal progenitors by Ptfla and Atoh1 for proper production of GABAergic and glutamatergic neurons. J Neurosci. 2014;34:4786-800.

37. Alder J, Cho NK, Hatten ME. Embryonic precursor cells from the rhombic lip are specified to a cerebellar granule neuron identity. Neuron. 1996;17:389-99.

38. Fernandes M, Antoine M, Hebert JM. SMAD4 is essential for generating subtypes of neurons during cerebellar development. Dev Biol. 2012;365:82-90.

39. Tong KK, Kuwan KM. Common partner Smad-independent canonical bone morphogenetic protein signaling in the specification process of the anterior rhombic lip during cerebellum development. Mol Cell Biol. 2013;33:1925-37.

40. Machold RP, Kittell DJ, Fishell GJ. Antagonism between Notch and bone morphogenetic protein receptor signalling regulates neurogenesis in the cerebellar rhombic lip. Neural Dev. 2007;23: $2-5$.

41. Broom ER, Gilthorpe JD, Butts T, Campo-Payssa F, Wingate RJT. The roof plate boundary is a bi-directional organiser of dorsal neural tube and choroid plexus development. Development. 2012;139:4261-70.

42. Huang X, Liu J, Ketova T, Fleming JT, Grover VK, Cooper MK, et al. Transventricular delivery of Sonic hedgehog is essential to cerebellar ventricular zone development. Proc Natl Acad Sci U S A. 2010;107:8422-7.

43. Kawauchi D, Saito T. Transcriptional cascade from Math1 to Mbh1 and Mbh2 is required for cerebellar granule cell differentiation. Dev Biol. 2008;15:345-54.

44. Chizhikov VV, Lindgren AG, Mishima Y, Roberts RW, Aldinger KA, Miesegaes GR, et al. Lmxla regulates fates and location of cells originating from the cerebellar rhombic lip and telencephalic cortical hem. Proc Natl Acad Sci U S A. 2010;107:10725-30.

45. Cheng FY, Huang X, Sarangi A, Ketova T, Cooper MK, Litingtung Y, et al. Widespread contribution of Gdf7 lineage to cerebellar cell types and implications for hedgehog-driven medulloblastoma formation. PLoS ONE. 2012;7:e35541.

46. Seto Y, Nakatani T, Masuyama N, Taya S, Kumai M, Minaki Y, et al. Temporal identity transition from Purkinje cell progenitors to GABAergic interneuron progenitors in the cerebellum. Nat Commun. 2014;5:3337.

47. Mizuhara E, Minaki Y, Nakatani T, Kumai M, Inoue T, Muguruma $\mathrm{K}$, et al. Purkinje cells originate from cerebellar ventricular zone progenitors positive for Neph3 and E-cadherin. Dev Biol. 2010;338:202-14.

48. Hoshino M. Neural subtype specification in the cerebellum and dorsal hindbrain. Dev Growth Differ. 2012;54(3):317-26.

49. Zordan P, Croci L, Hawkes R, Consalez GG. A comparative analysis of proneural gene expression in the embryonic mouse cerebellum. Dev Dyn. 2008;237:1726-35.

50. Florio M, Leto K, Muzio L, Tinterri A, Badaloni A, Croci L, et al. Neurogenin 2 regulates progenitor cell-cycle progression and Purkinje cell dendritogenesis in cerebellar development. Development. 2012;139:2308-20.

51. Morales D, Hatten ME. Molecular markers of neuronal progenitors in the embryonic cerebellar anlage. J Neurosci. 2006;26: 12226-36.

52. Minaki $\mathrm{Y}$, Nakatani $\mathrm{T}$, Mizuhara $\mathrm{E}$, Inoue $\mathrm{T}$, Ono $\mathrm{Y}$. Identification of a novel transcriptional corepressor, Corl2, as a cerebellar Purkinje cell-selective marker. Gene Expr Patterns. 2008;8:418-23.

53. Muguruma K, Nishiyama A, Ono Y, Miyawaki H, Mizuhara E, Hori S, et al. Ontogeny-recapitulating generation and tissue integration of ES cell-derived Purkinje cells. Nat Neurosci. 2010;13: 1171-80.

54. Miale IL, Sidman RL. An autoradiographic analysis of histogenesis in the mouse cerebellum. Exp Neurol. 1961;4:277-96.

55. Alder J, Lee KJ, Jessell TM, Hatten ME. Generation of cerebellar granule neurons in vivo by transplantation of BMP-treated neural progenitor cells. Nat Neurosci. 1999;2:535-40.

56. Aruga J. The role of Zic genes in neural development. Mol Cell Neurosci. 2004;26:205-21.

57. Engelkamp D, Rashbass P, Seawright A, van Heyningen V. Role of Pax6 in development of the cerebellar system. Development. 1999;126:3585-96.

58. Gong S, Zheng C, Doughty ML, Losos K, Didkovsky N, Schambra UB, et al. A gene expression atlas of the central nervous system based on bacterial artificial chromosomes. Nature. 2003;425:917-25.

59. Lee KJ, Dietrich P, Jessell TM. Genetic ablation reveals that the roof plate is essential for dorsal interneuron specification. Nature. 2000;403:734-40.

60. Fink AJ, Englund C, Daza RA, Pham D, Lau C, Nivison $M$, et al. Development of the deep cerebellar nuclei: 
transcription factors and cell migration from the rhombic lip. J Neurosci. 2006;26:3066-76.

61. Green MJ, Myat AM, Emmenegger BA, Wechsler-Reya RJ, Wilson LJ, Wingate RJ. Independently specified Atoh1 domains define novel developmental compartments in rhombomere 1 . Development. 2014;141:389-98.

62. Wechsler-Reya RJ, Scott MP. Control of neuronal precursor proliferation in the cerebellum by Sonic Hedgehog. Neuron. 1999;22: 103-14.

63. Knoepfler PS, Cheng PF, Eisenman RN. N-myc is essential during neurogenesis for the rapid expansion of progenitor cell populations and the inhibition of neuronal differentiation. Genes Dev. 2002;16:2699-712.

64. Corrales JD, Blaess S, Mahoney EM, Joyner AL. The level of sonic hedgehog signaling regulates the complexity of cerebellar foliation. Development. 2006;133:1811-21.

65. Hatten ME, Roussel MF. Development and cancer of the cerebellum. Trends Neurosci. 2011;34:134-42.

66. Solecki DJ, Liu XL, Tomoda T, Fang Y, Hatten ME. Activated Notch2 signaling inhibits differentiation of cerebellar granule neuron precursors by maintaining proliferation. Neuron. 2001;31: $557-68$.

67. Zhao H, Ayrault O, Zindy F, Kim JH, Roussel MF. Posttranscriptional down-regulation of Atoh1/Math1 by bone morphogenic proteins suppresses medulloblastoma development. Genes Dev. 2008;22:722-7.

68. Salero E, Hatten ME. Differentiation of ES cells into cerebellar neurons. Proc Natl Acad Sci U S A. 2007;104:2997-3002.

69. Helms AW, Johnson JE. Specification of dorsal spinal cord interneurons. Curr Opin Neurobiol. 2003;3:42-9.

70. Miyata T, Maeda T, Lee JE. NeuroD is required for differentiation of the granule cells in the cerebellum and hippocampus. Genes Dev. 1999;13:1647-52.

71. Anne SL, Govek EE, Ayrault O, Kim JH, Zhu X, Murphy DA, et al. WNT3 inhibits cerebellar granule neuron progenitor proliferation and medulloblastoma formation via MAPK activation. PLoS One. 2013;8:e81769.

72. Penas C, Govek E, Fang Y, Ramachandran V, Daniel M, Wang W, et al. $\mathrm{CK} 1 \delta$ is an $\mathrm{APC} / \mathrm{C}^{\mathrm{cdh} 1}$ substrate regulating cerebellar granule cell progenitor neurogenesis. Cell Reports. http://dx.doi.org/ 10.1016/j.celrep.2015.03.016

73. Dang P, Smythe E, Furley AJ. TAG1 regulates the endocytic trafficking and signaling of the semaphorin $3 \mathrm{~A}$ receptor complex. J Neurosci. 2012;32:10370-82.

74. Furley AJ, Morton SB, Manalo D, Karagogeos D, Dodd J, Jessell TM. The axonal glycoprotein TAG-1 is an immunoglobulin superfamily member with neurite outgrowth-promoting activity. Cell. 1990;61:157-70.

75. Kerjan G, Dolan J, Haumaitre C, Schneider-Maunoury S, Fujisawa $\mathrm{H}$, Mitchell KJ, et al. The transmembrane semaphorin Sema6A controls cerebellar granule cell migration. Nat Neurosci. 2005;8:1516-24.

76. Renaud J, Kerjan G, Sumita I, Zagar Y, Georget V, Kim D, et al. Plexin-A2 and its ligand, Sema6A, control nucleus-centrosome coupling in migrating granule cells. Nat Neurosci. 2008;11:440-9.

77. Famulski JK, Trivedi N, Howell D, Yang Y, Tong Y, Gilbertson R, et al. Siah regulation of Pard3A controls neuronal cell adhesion during germinal zone exit. Science. 2010;330:1834-8.

78. Rakic P. Neuron-glia relationship during granule cell migration in developing cerebellar cortex. A Golgi and electronmicroscopic study in Macacus Rhesus. J Comp Neurol. 1971;141:283-312.

79. Adams NC, Tomoda T, Cooper M, Dietz G, Hatten ME. Mice that lack astrotactin have slowed neuronal migration. Development. 2002;129:965-72.
80. Edmondson J, Liem R, Kuster J, Hatten M. Astrotactin: a novel neuronal cell surface antigen that mediates neuron-astroglial interactions in cerebellar microcultures. J Cell Biol. 1988;106:505-17.

81. Fishell G, Hatten ME. Astrotactin provides a receptor system for CNS neuronal migration. Development. 1991;113:755-65.

82. Zheng C, Heintz N, Hatten ME. CNS gene encoding astrotactin, which supports neuronal migration along glial fibers. Science. 1996;272:417-9.

83. Edmondson JC, Hatten ME. Glial-guided granule neuron migration in vitro: a high-resolution time-lapse video microscopic study. J Neurosci. 1987;7:1928-34.

84. Gregory WA, Edmondson JC, Hatten ME, Mason CA. Cytology and neuron-glial apposition of migrating cerebellar granule cells in vitro. J Neurosci. 1988;8:1728-38.

85. Solecki DJ, Model L, Gaetz J, Kapoor TM, Hatten ME. Par6 $\alpha$ signaling controls glial-guided neuronal migration. Nat Neurosci. 2004;7:1195-203.

86. Solecki DJ, Trivedi N, Govek EE, Kerekes RA, Gleason SS, Hatten ME. Myosin II motors and F-actin dynamics drive the coordinated movement of the centrosome and soma during CNS glial-guided neuronal migration. Neuron. 2009;63:63-80.

87. Billings G, Piasini E, Lorincz A, Nusser Z, Silver RA. Network structure within the cerebellar input layer enables lossless sparse encoding. Neuron. 2014;83:960-74.

88. Wang W, Shin Y, Shi M, Kilpatrick DL. Temporal control of a dendritogenesis-linked gene via REST-dependent regulation of nuclear factor I occupancy. Mol Biol Cell. 2011;22:868-79.

89. Wang W, Stock RE, Gronostajski RM, Wong YW, Schachner M, Kilpatrick DL. A role for nuclear factor I in the intrinsic control of cerebellar granule neuron gene expression. J Biol Chem. 2004;279:53491-7.

90. Wang W, Mullikin-Kilpatrick D, Crandall JE, Gronostajski RM, Litwack ED, Kilpatrick DL. Nuclear factor I coordinates multiple phases of cerebellar granule cell development via regulation of cell adhesion molecules. J Neurosci. 2007;27:6115-27.

91. Ding B, Wang W, Selvakumar T, Xi HS, Zhu H, Chow CW, et al. Temporal regulation of nuclear factor one occupancy by calcineurin/NFAT governs a voltage-sensitive developmental switch in late maturing neurons. J Neurosci. 2013;33:2860-72.

92. Okazawa M, Abe H, Katsukawa M, Iijima K, Kiwada T, Nakanishi S. Role of calcineurin signaling in membrane potential-regulated maturation of cerebellar granule cells. J Neurosci. 2009;29:2938-47.

93. Sato M, Suzuki K, Yamazaki H, Nakanishi S. A pivotal role of calcineurin signaling in development and maturation of postnatal cerebellar granule cells. Proc Natl Acad Sci U S A. 2005;102: 5874-9.

94. Shalizi A, Gaudilliere B, Yuan Z, Stegmuller J, Shirogane T, Ge Q, et al. A calcium-regulated MEF2 sumoylation switch controls postsynaptic differentiation. Science. 2006;311:1012-7.

95. Abe H, Okazawa M, Nakanishi S. The Etv1/Er81 transcription factor orchestrates activity-dependent gene regulation in the terminal maturation program of cerebellar granule cells. Proc Natl Acad Sci U S A. 2011;108:12497-502.

96. Bell CC, Han V, Sawtell NB. Cerebellum-like structures and their implications for cerebellar function. Annu Rev Neurosci. 2008;31: $1-24$.

97. Kalinichenko SG, Okhotin VE. Unipolar brush cells - a new type of excitatory interneuron in the cerebellar cortex and cochlear nuclei of the brainstem. Neurosci Behav Physiol. 2005;35:21-36.

98. Oertel D, Young ED. What's a cerebellar circuit doing in the auditory system? Trends Neurosci. 2004;27:104-10.

99. Mugnaini E, Floris A. The unipolar brush cell: a neglected neuron of the mammalian cerebellar cortex. J Comp Neurol. 1994;339: 174-80. 
100. Mugnaini E, Sekerková G, Martina M. The unipolar brush cell: a remarkable neuron finally receiving deserved attention. Brain Res Rev. 2011;66:220-45.

101. Sekerková G, Watanabe M, Martina M, Mugnaini E. Differential distribution of phospholipase $\mathrm{C} \beta$ isoforms and diaglycerol kinase- $\beta$ in rodents cerebella corroborates the division of unipolar brush cells into two major subtypes. Brain Struct Funct. 2014;219:719-49.

102. Borges-Merjane C, Trussell LO. ON and OFF unipolar brush cells transform multisensory inputs to the auditory system. Neuron. 2015;85:1029-42.

103. Diño MR, Mugnaini E. Distribution and phenotypes of unipolar brush cells in relation to the granule cell system of the rat cochlear nucleus. Neuroscience. 2008;154:29-50.

104. Álvarez MI, Lacruz C, Toledano-Díaz A, Monleon E, Monzón M, Badiola JJ, et al. Calretinin-immunopositive cells and fibers in the cerebellar cortex of normal sheep. Cerebellum. 2008;7:417-29.

105. Bazwinsky I, Härtig W, Rübsamen R. Characterization of cochlear nucleus principal cells of Meriones unguiculatus and Monodelphis domestica by use of calcium-binding protein immunolabeling. J Chem Neuroanat. 2008;35:158-74.

106. Campbell HR, Meek J, Zhang J, Bell CC. Anatomy of the posterior caudal lobe of the cerebellum and the eminentia granularis posterior in a mormyrid fish. J Comp Neurol. 2007;502:714-35.

107. Diño MR, Willard FH, Mugnaini E. Distribution of unipolar brush cells and other calretinin immunoreactive components in the mammalian cerebellar cortex. J Neurocytol. 1999;28:99-123.

108. Meek J, Yang JY, Han VZ, Bell CC. Morphological analysis of the mormyrid cerebellum using immunohistochemistry, with emphasis on the unusual neuronal organization of the valvula. J Comp Neurol. 2008;510:396-421.

109. Takács J, Markova L, Borostyánkői Z, Görcs TJ, Hámori J. Metabotrop glutamate receptor type 1a expressing unipolar brush cells in the cerebellar cortex of different species: a comparative quantitative study. J Neurosci Res. 1999;55:733-48.

110. Takács J, Borostyánkői ZA, Veisenberger E, Vastagh C, Víg J, Görcs TJ, et al. Postnatal development of unipolar brush cells in the cerebellar cortex of cat. J Neurosci Res. 2000;61:107-15.

111. Víg J, Takács J, Abraham H, Kovács GG, Hámori J. Calretininimmunoreactive unipolar brush cells in the developing human cerebellum. Int J Dev Neurosci. 2005;23:723-9.

112. Diño MR, Schuerger RJ, Liu Y, Slater NT, Mugnaini E. Unipolar brush cell: a potential feedforward excitatory interneuron of the cerebellum. Neuroscience. 2000;98:625-36.

113. Berthié B, Axelrad H. Granular layer collaterals of the unipolar brush cell axon display rosette-like excrescences. A Golgi study in the rat cerebellar cortex. Neurosci Lett. 1994;167:161-5.

114. Nunzi MG, Mugnaini E. Unipolar brush cell axons form a large system of intrinsic mossy fibers in the postnatal vestibulocerebellum. J Comp Neurol. 2000;422:55-65.

115. Kim J-A, Sekerková G, Mugnaini E, Martina M. Electrophysiological, morphological, and topological properties of two histochemically distinct subpopulations of cerebellar unipolar brush cells. Cerebellum. 2012;1012-25.

116. van Dorp S, De Zeeuw CI. Variable timing of synaptic transmission in cerebellar unipolar brush cells. Proc Natl Acad Sci U S A. 2014;111:5403-8.

117. Chung SH, Marzban H, Watanabe M, Hawkes R. Phospholipase $\mathrm{C} \beta 4$ expression identifies a novel subset of unipolar brush cells in the adult mouse cerebellum. Cerebellum. 2009;8:267-76.

118. Chung SH, Sillitoe RV, Croci L, Badaloni A, Consalez G, Hawkes R. Purkinje cell phenotype restricts the distribution of unipolar brush cells. Neuroscience. 2009;164:1496-508.

119. Nunzi MG, Shigemoto R, Mugnaini E. Differential expression of calretinin and metabotropic glutamate receptor $\operatorname{mGluR} 1 \alpha$ defines subsets of unipolar brush cells in mouse cerebellum. J Comp Neurol. 2002;451:189-99.

120. Sekerková G, Ilijic E, Mugnaini E. Time of origin of unipolar brush cells in the rat cerebellum as observed by prenatal bromodeoxyuridine labeling. Neuroscience. 2004;127:845-58.

121. Sekerková G, Kim JA, Nigro MJ, Becker EB, Hartmann J, Birnbaumer L, et al. Early onset of ataxia in moonwalker mice is accompanied by complete ablation of type II unipolar brush cells and Purkinje cell dysfunction. J Neurosci. 2013;33:1968994.

122. Abbott LC, Jacobowitz DM. Development of calretininimmunoreactive unipolar brush-like cells and an afferent pathway to the embryonic and early postnatal mouse cerebellum. Anat Embryol (Berl). 1995; 191:541-59.

123. Ilijic E, Guidotti A, Mugnaini E. Moving up or moving down? Malpositioned cerebellar unipolar brush cells in reeler mouse. Neuroscience. 2005;136:633-47.

124. Hagan N, Zervas M. Wnt1 expression temporally allocates upper rhombic lip progenitors and defines their terminal cell fate in the cerebellum. Mol Cell Neurosci. 2012;49:217-29.

125. Kita Y, Kawakami K, Takahashi Y, Murakami F. Development of cerebellar neurons and glias revealed by in utero electroporation: Golgi-like labeling of cerebellar neurons and glias. PLoS One. 2013;8:e70091.

126. Morin F, Diño MR, Mugnaini E. Postnatal differentiation of unipolar brush cells and mossy fiber-unipolar brush cell synapses in rat cerebellum. Neuroscience. 2001;104:1127-39.

127. Anthony TE, Klein C, Fishell G, Heintz N. Radial glia serve as neuronal progenitors in all regions of the central nervous system. Neuron. 2004;41:881-90.

128. Goffinet AM. The embryonic development of the cerebellum in normal and reeler mutant mice. Anat Embryol. 1983;168:73-86.

129. Yuasa S, Kawamura K, Ono K, Yamakuni T, Takahashi Y. Development and migration of Purkinje cells in the mouse cerebellar primordium. Anat Embryol. 1991;184:195-212.

130. Altman J, Bayer SA. Development of the cerebellar system: in relation to its evolution, structure, and functions. Boca Raton: CRC press; 1997.

131. Miyata T, Ono Y, Okamoto M, Masaoka M, Sakakibara A, Kawaguchi A, et al. Migration, early axonogenesis, and Reelindependent layer-forming behavior of early/posterior-born Purkinje cells in the developing mouse lateral cerebellum. Neural Dev. 2010;5:23.

132. Croci L, Chung SH, Masserdotti G, Gianola S, Motti E, Tonini R, et al. A key role for the HLH transcription factor EBF2 (COE2, O/E-3) in Purkinje neuron migration and cerebellar cortical topography. Development. 2006;133:2719-29.

133. Miyata T, Nakajima K, Mikoshiba K, Ogawa M. Regulation of Purkinje cell alignment by Reelin as revealed with CR-50 antibody. J Neurosci. 1997;17:3599-609.

134. Magdaleno S, Keshvara L, Curran T. Rescue of ataxia and preplate splitting by ectopic expression of Reelin in reeler mice. Neuron. 2002;33:573-86.

135. Hatten ME, Heintz N. Mechanism of neural patterning and specialization in the developing cerebellum. Annu Rev Neurosci. 1995; 18:385-408.

136. Sillitoe RV, Gopal N, Joyner A. Embryonic origins of zebrinII parasagittal stripes and establishment of topographic Purkinje cell projections. Neuroscience. 2009;162:574-88.

137. Apps R, Hawkes R. Cerebellar cortical organization: a one-map hypothesis. Nat Rev Neurosci. 2009;10:670-81.

138. Armstrong CL, Hawkes R. Pattern formation in the cerebellar cortex. Biochem Cell Biol. 2000;78:551-62.

139. Pakan JMP, Iwaniuk AN, Wong Wylie DR, Hawkes R, Marzban H. Purkinje cell compartmentation as revealed by zebrin II 
expression in the cerebellar cortex of pigeons (Columba livia). $\mathrm{J}$ Comp Neurol. 2007;501:619-30.

140. Marzban H, Chung SH, Pezhouh MK, Feirabend H, Watanabe M, Voogd J, et al. Antigenic compartmentation of the cerebellar cortex in the chicken (Gallus domesticus). J Comp Neurol. 2010;518: 2221-39.

141. Sillitoe RV, Marzban H, Larouche M, Zahedi S, Affanni J, Hawkes R. Conservation of the architecture of the anterior lobe vermis of the cerebellum across mammalian species. Prog Brain Res. 2005;148:283-97.

142. Marzban H, Hawkes R. On the architecture of the posterior zone of the cerebellum. Cerebellum. 2011;10:422-34.

143. Brochu G, Maler L, Hawkes R. Zebrin II: a polypeptide antigen expressed selectively by Purkinje cells reveals compartments in rat and fish cerebellum. J Comp Neurol. 1990;291:538-52.

144. Sarna JR, Marzban H, Watanabe M, Hawkes R. Complementary stripes of phospholipase $C \beta 3$ and $C \beta 4$ expression by Purkinje cell subsets in the mouse cerebellum. J Comp Neurol. 2006;496:30313.

145. Armstrong CL, Krueger-Naug AM, Currie RW, Hawkes R. Constitutive expression of the $25 \mathrm{kDa}$ heat shock protein $\mathrm{Hsp} 25$ reveals novel parasagittal bands of Purkinje cells in the adult mouse cerebellar cortex. J Comp Neurol. 2000;416:383-97.

146. Consalez GG, Hawkes R. The compartmental restriction of cerebellar interneurons. Front Neural Circuits. 2013;6:123.

147. Sarna JR, Hawkes R. Patterned Purkinje cell death in the cerebellum. Prog Neurobiol. 2003;70:473-507.

148. Tano D, Napieralski JA, Eisenman LM, Messer A, Plummer J, Hawkes R. Novel developmental boundary in the cerebellum revealed by zebrin expression in the lurcher ( $\mathrm{Lc} /+)$ mutant mouse. J Comp Neurol. 1992;323:128-36.

149. Eisenman LM, Brothers R. Rostral cerebellar malformation ( $\mathrm{rcm} /$ $\mathrm{rcm}$ ): a murine mutant to study regionalization of the cerebellum. J Comp Neurol. 1998;394(1):106-17.

150. Armstrong CL, Hawkes R. Selective failure of Purkinje cell dispersion in the cerebellum of the weaver mouse. J Comp Neurol. 2001;439:151-61.

151. Beirebach E, Park C, Ackerman D, Goldowitz D, Hawkes R. Abnormal dispersion of a Purkinje cell subset in the mouse mutant cerebellum deficient folia (cdf). J Comp Neurol. 2001;436:42-51.

152. Ruigrok TJ. Ins and outs of cerebellar modules. Cerebellum. 2011;10:464-74.

153. Baader SL, Schilling ML, Rosengarten B, Pretsch W, Teutsch HF, Oberdick J, et al. Purkinje cell lineage and the topographic organization of the cerebellar cortex: a view from $\mathrm{X}$ inactivation mosaics. Dev Biol. 1996;174:393-406.

154. Mathis L, Bonnerot C, Puelles L, Nicolas JF. Retrospective clonal analysis of the cerebellum using genetic laacZ/lacZ mouse mosaics. Development. 1997;124:4089-104.

155. Hawkes R, Faulkner-Jones B, Tam P, Tan SS. Pattern formation in the cerebellum of murine embryonic stem cell chimeras. Europ J Neurosci. 1998;10:790-3.

156. Sgaier SK, Millet S, Villanueva MP, Berenshteyn F, Song C, Joyner AL. Morphogenetic and cellular movements that shape the mouse cerebellum; insights from genetic fate mapping. Neuron. 2005;45:27-40.

157. Karam SD, Burrows RC, Logan C, Koblar S, Pasquale EB, Bothwell M. Eph receptors and ephrins in the developing chick cerebellum: relationship to sagittal patterning and granule cell migration. J Neurosci. 2000;20:6488-500.

158. Larouche M, Hawkes R. From clusters to stripes: the developmental origins of adult cerebellar compartmentation. Cerebellum. 2006;5:77-88.

159. Chung SH, Marzban H, Croci L, Consalez GG, Hawkes R. Purkinje cell subtype specification in the cerebellar cortex:
EBF2 acts to repress the zebrin II-negative Purkinje cell phenotype. Neuroscience. 2008;153:721-32.

160. Namba K, Sugihara I, Hashimoto M. Close correlation between the birth date of Purkinje cells and the longitudinal compartmentalization of the mouse adult cerebellum. J Comp Neurol. 2011;519:2594-614.

161. Leclerc N, Gravel C, Hawkes R. Development of parasagittal zonation in the rat cerebellar cortex: mabQ113 antigenic bands are created postnatally by the suppression of antigen expression in a subset of Purkinje cells. J Comp Neurol. 1988;273:399-420.

162. Wassef M, Sotelo C, Thomasset M, Granholm A-C, Leclerc N, Rafrafi J, et al. Expression of compartmentation antigen zebrin I in cerebellar transplants. J Comp Neurol. 1990;294:223-34.

163. Seil FJ, Johnson ML, Hawkes R. Molecular compartmentation expressed in cerebellar cultures in the absence of neuronal activity and neuron-glial interactions. J Comp Neurol. 1995;356:398-407.

164. Armstrong CL, Krueger-Naug AM, Currie RW, Hawkes R. Expression of heat-shock protein Hsp25 in mouse Purkinje cells during development reveals novel features of cerebellar compartmentation. J Comp Neurol. 2001;429:7-21.

165. Croci L, Barili V, Chia D, Massimino L, van Vugt R, Masserdotti $\mathrm{G}$, et al. Local insulin-like growth factor I expression is essential for Purkinje neuron survival at birth. Cell Death Differ. 2011;18: 48-59.

166. Wassef M, Zanetta JP, Brehier A, Sotelo C. Transient biochemical compartmentalization of Purkinje cells during early cerebellar development. Dev Biol. 1985;111:129-37.

167. Smeyne RJ, Oberdick J, Schilling K, Berrebi AS, Mugnaini E, Morgan JI. Dynamic organization of developing Purkinje cells revealed by transgene expression. Science. 1991;254:719-21.

168. Oberdick J, Schilling K, Smeyne RJ, Corbin JG, Bocchiaro C, Morgan JI. Control of segment-like patterns of gene expression in the mouse cerebellum. Neuron. 1993;10:1007-18.

169. Millen KJ, Hui CC, Joyner AL. A role for En-2 and other murine homologues of Drosophila segment polarity genes in regulating positional information in the developing cerebellum. Development. 1995;121:3935-45.

170. Nunzi MG, Grillo M, Margolis FL, Mugnaini E. Compartmental organization of Purkinje cells in the mature and developing mouse cerebellum as revealed by an olfactory marker protein-lacZ transgene. J Comp Neurol. 1999;404:97-113.

171. Sillitoe RV, Joyner AL. Morphology, molecular codes, and circuitry produce the three-dimensional complexity of the cerebellum. Annu Rev Cell Dev Biol. 2007;23:549-77.

172. Dastjerdi FV, Consalez GG, Hawkes R. Pattern formation during development of the embryonic cerebellum. Front Neuroanat. 2012;6:10.

173. Rouse RV, Sotelo C. Grafts of dissociated cerebellar cells containing Purkinje cell precursors organize into zebrin I defined compartments. Exp Brain Res. 1990;82:401-7.

174. Redies C, Neudert F, Lin J. Cadherins in cerebellar development: translation of embryonic patterning into mature functional compartmentalization. Cerebellum. 2011;10:393-408.

175. Fujita H, Morita N, Furuichi T, Sugihara I. Clustered fine compartmentalization of the mouse embryonic cerebellar cortex and its rearrangement into the postnatal striped configuration. J Neurosci. 2012;32:15688-703.

176. Sugihara I, Fujita H. Peri- and postnatal development of cerebellar compartments in the mouse. Cerebellum. 2013;12:325-7.

177. Larouche M, Che PM, Hawkes R. Neurogranin expression identifies a novel array of Purkinje cell parasagittal stripes during mouse cerebellar development. J Comp Neurol. 2006;494:21527.

178. Furutama D, Morita N, Takano R, Sekine Y, Sadakata T, Shinoda $\mathrm{Y}$, et al. Expression of the IP3R1 promoter-driven nls-lacZ 
transgene in Purkinje cell parasagittal arrays of developing mouse cerebellum. J Neurosci Res. 2010;88:2810-25.

179. Marzban H, Chung SH, Watanabe M, Hawkes R. Phospholipase $\mathrm{C} ß 4$ expression reveals the continuity of cerebellar topography through development. J Comp Neurol. 2007;502:857-71.

180. Hawkes R, Beirebach E, Tan S-S. Granule cell dispersion is restricted across transverse boundaries in mouse chimeras. Eur J Neurosci. 1999;11:3800-8.

181. Sillitoe RV, Chung SH, Fritschy JM, Hoy M, Hawkes R. Golgi cell dendrites are restricted by Purkinje cell stripe boundaries in the adult mouse cerebellar cortex. J Neurosci. 2008;28:2820-6.

182. Chung S-H, Sillitoe RV, Croci L, Baldoni A, Consalez G, Hawkes R. Unipolar brush cells use Purkinje cells to restrict their topography. Neuroscience. 2009;164:1496-508.

183. Scott TG. A unique pattern of localization within the cerebellum. Nature. 1963;200:793.

184. Reeber SL, Arancillo M, Sillitoe RV. Bergmann glia are patterned into topographic molecular zones in the developing and adult mouse cerebellum. Cerebellum. 2014.

185. Sotelo C. Cellular and genetic regulation of the development of the cerebellar system. Prog Neurobiol. 2004;72:295-339.

186. Grishkat HL, Eisenman LM. Development of the spinocerebellar projection in the prenatal mouse. J Comp Neurol. 1995;363:93108.

187. Paradies MA, Eisenman LM. Evidence of early topographic organization in the embryonic olivocerebellar projection: a model system for the study of pattern formation processes in the central nervous system. Dev Dyn. 1993;197:125-45.

188. White JJ, Sillitoe RV. Postnatal development of cerebellar zones revealed by neurofilament heavy chain protein expression. Front Neuroanat. 2013;7:9.

189. Blatt GJ, Eisenman LM. Topographic and zonal organization of the olivocerebellar projection in the reeler mutant mouse. J Comp Neurol. 1988;267:603-15.

190. Sillitoe RV, Vogel MW, Joyner AL. Engrailed homeobox genes regulate establishment of the cerebellar afferent circuit map. J Neurosci. 2010;30:10015-24.

191. Reeber SL, Loeschel CA, Franklin A, Sillitoe RV. Establishment of topographic circuit zones in the cerebellum of scrambler mutant mice. Front Neural Circuits. 2013;7:122.

192. D'Arcangelo G, Miao GG, Chen SC, Soares HD, Morgan JI, Curran T. A protein related to extracellular matrix proteins deleted in the mouse mutant reeler. Nature. 1995;374:719-23.

193. D'Arcangelo G, Nakajima K, Miyata T, Ogawa M, Mikoshiba K, Curran T. Reelin is a secreted glycoprotein recognized by the CR50 monoclonal antibody. J Neurosci. 1997;17:23-31.

194. Tissir F, Goffinet AM. Reelin and brain development. Nat Rev Neurosci. 2003;4:496-505.

195. 196.D'Arcangelo G. Reelin in the years: controlling neuronal migration and maturation in the mammalian brain. Adv in Neurosci. 2014;2014.

196. Falconer DS. Two new mutants, Trembler and 'Reeler', with neurological actions in the house mouse. J Genet. 1951;50:182-201.

197. Mariani J, Crepel F, Mikoshiba K, Changeux JP, Sotelo C. Anatomical, physiological and biochemical studies of the cerebellum from reeler mutant mouse. Philos Trans R Soc Lond. 1977;281:1-28.

198. Larouche M, Beffert U, Herz J, Hawkes R. The Reelin receptors Apoer2 and Vldlr coordinate the patterning of Purkinje cell topography in the developing mouse cerebellum. PLoS ONE. 2008;3(2):e1653.

199. Trommsdorff M, Gotthardt M, Hiesberger T, Shelton J, Stockinger W, Nimpf J, et al. Reeler/Disabled-like disruption of neuronal migration in knockout mice lacking the VLDL receptor and ApoE receptor 2. Cell. 1999;97:689-701.
200. Strasser V, Fasching D, Hauser C, Mayer H, Bock HH, Hiesberger $\mathrm{T}$, et al. Receptor clustering is involved in Reelin signaling. Mol Cell Biol. 2004;24:1378-86.

201. Bock HH, Herz J. Reelin activates SRC family tyrosine kinases in neurons. Curr Biol. 2003;13:18-26.

202. Kuo G, Arnaud L, Kronstad-O'Brien P, Cooper JA. Absence of Fyn and Src causes a reeler-like phenotype. J Neurosci. 2005;25:8578-86.

203. Hiesberger T, Trommsdorff M, Howell BW, Goffinet A, Mumby MC, Cooper JA, et al. Direct binding of Reelin to VLDL receptor and ApoE receptor 2 induces tyrosine phosphorylation of disabled-1 and modulates tau phosphorylation. Neuron. 1999;24:481-9.

204. Howell BW, Herrick TM, Cooper JA. Reelin-induced tyrosine phosphorylation of disabled 1 during neuronal positioning. Genes Dev. 1999;13:643-8.

205. Goldowitz D, Cushing RC, Laywell E, D'Arcangelo G, Sheldon $\mathrm{M}$, Sweet HO, et al. Cerebellar disorganization characteristic of reeler in scrambler mutant mice despite presence of Reelin. J Neurosci. 1997;17:8767-77.

206. Howell BW, Hawkes R, Soriano P, Cooper JA. Neuronal position in the developing brain is regulated by mouse disabled-1. Nature. 1997;389:733-7.

207. Sheldon M, Rice DS, D'Arcangelo G, Yoneshima H, Nakajima K, Mikoshiba K, et al. Scrambler and yotari disrupt the disabled gene and produce a reeler-like phenotype in mice. Nature. 1997;389: 730-3.

208. Gallagher E, Howell BW, Soriano P, Cooper JA, Hawkes R. Cerebellar abnormalities in the disabled (mdab1-1) mouse. J Comp Neurol. 1998;402:238-51.

209. Rice DS, Sheldon M, D'Arcangelo G, Nakajima K, Goldowitz D, Curran T. Disabled-1 acts downstream of Reelin in a signaling pathway that controls laminar organization in the mammalian brain. Development. 1998;125:3719-29.

210. Howell BW, Herrick TM, Hildebrand JD, Zhang Y, Cooper JA. Dab1 tyrosine phosphorylation sites relay positional signals during mouse brain development. Curr Biol. 2000;10:877-85.

211. Ballif BA, Arnaud L, Arthur WT, Guris D, Imamoto A, Cooper JA. Activation of a Dab1/CrkL/C3G/Rap1 pathway in Reelinstimulated neurons. Curr Biol. 2004;14:606-10.

212. Franco SJ, Martinez-Garay I, Gil-Sanz C, Harkins-Perry SR, Müller U. Reelin regulates cadherin function via Dab1/Rap1 to control neuronal migration and lamination in the neocortex. Neuron. 2011:69:482-97.

213. White JJ, Arancillo M, Stay TL, George-Jones N, Levy SL, Heck $\mathrm{DH}$, et al. Cerebellar zonal patterning relies on Purkinje cell neurotransmission. J Neurosci. 2014;34:8231-45.

214. Arancillo M, White JJ, Lin T, Stay TL, Sillitoe RV. In vivo analysis of Purkinje cell firing properties during postnatal mouse development. J Neurophysiol. 2015;113:578-91.

215. Ji Z, Hawkes R. Topography of Purkinje cell compartments and mossy fiber terminal fields in lobules II and III of the rat cerebellar cortex: spinocerebellar and cuneocerebellar projections. Neuroscience. 1994;61:935-54.

216. Crépel F. Regression of functional synapses in the immature mammalian cerebellunm. Trends Neurosci. 1982;5:266-9.

217. Husson Z, Rousseau CV, Broll I, Zeilhofer HU, Dieudonne S. Differential GABAergic and glycinergic inputs of inhibitory interneurons and Purkinje cells to principal cells of the cerebellar nuclei. J Neurosci. 2014;34:9418-31.

218. Simat M, Parpan F, Fritschy JM. Heterogeneity of glycinergic and gabaergic interneurons in the granule cell layer of mouse cerebellum. J Comp Neurol. 2007;500:71-83.

219. Rakic P. Extrinsic cytological determinants of basket and stellate cell dendritic pattern in the cerebellar molecular layer. J Comp Neurol. 1972;146:335-54. 
220. Schilling K, Oberdick J. The treasury of the commons: making use of public gene expression resources to better characterize the molecular diversity of inhibitory interneurons in the cerebellar cortex. Cerebellum. 2010;8:477-89.

221. Lainé J, Axelrad H. The candelabrum cell: a new interneuron in the cerebellar cortex. J Comp Neurol. 1994;339:159-73.

222. Schilling K, Oberdick J, Rossi F, Baader SL. Besides Purkinje cells and granule neurons: an appraisal of the cell biology of the interneurons of the cerebellar cortex. Histochem Cell Biol. 2008;130:601-15.

223. Zhang L, Goldman JE. Generation of cerebellar interneurons from dividing progenitors in white matter. Neuron. 1996;16:47-54.

224. Zhang L, Goldman JE. Developmental fates and migratory pathways of dividing progenitors in the postnatal rat cerebellum. $\mathrm{J}$ Comp Neurol. 1996;370:536-50.

225. Weisheit G, Gliem M, Endl E, Pfeffer PL, Busslinger M, Schilling $\mathrm{K}$. Postnatal development of the murine cerebellar cortex: formation and early dispersal of basket, stellate and Golgi neurons. Eur J Neurosci. 2006;24:466-78.

226. Leto K, Rolando C, Rossi F. The genesis of cerebellar GABAErgic interneurons: fate potential and specification mechanisms. Front Neuroanat. 2012;6:6.

227. Parmigiani E, Leto K, Rolando C, Figueres-Onate M, LopezMascaraque L, Buffo A, et al. Heterogeneity and bipotency of astroglial-like cerebellar progenitors along the interneuron and glial lineages. J Neurosci. 2015;35(19):7388-402.

228. Maricich SM, Herrup K. Pax-2 expression defines a subset of GABAergic interneurons and their precursors in the developing murine cerebellum. J Neurobiol. 1999;41:281-94.

229. Ramón y Cajal S. Histologie du système nerveux de l'homme et des vertébrés. Paris: Maloine; 1911.

230. Altman J. Postnatal development of the cerebellar cortex in the rat. I. The external germinal layer and the transitional molecular layer. J Comp Neurol. 1972;145:353-98.

231. Hallonet ME, Teillet MA, Le Douarin NM. A new approach to the development of the cerebellum provided by the quail-chick marker system. Development. 1990;108:19-31.

232. Napieralski JA, Eisenman LM. Developmental analysis of the external granular layer in the meander tail mutant mouse: do cerebellar microneurons have independent progenitors? Dev Dyn. 1993;197:244-54.

233. Alvarez Otero R, Sotelo C, Alvarado-Mallart RM. Chick/quail chimeras with partial cerebellar grafts: an analysis of the origin and migration of cerebellar cells. J Comp Neurol. 1993;333:597615 .

234. Gao WQ, Hatten ME. Immortalizing oncogenes subvert the establishement of granule cell identity in developing cerebellum. Development. 1994;120:1059-70.

235. Lundell TG, Zhou Q, Doughty ML. Neurogenin1 expression in cell lineages of the cerebellar cortex in embryonic and postnatal mice. Dev Dyn. 2009;238:3310-25.

236. Obana EA, Lundell TG, Yi KJ, Radomski KL, Zhou Q, Doughty ML. Neurog1 genetic inducible fate mapping (GIFM) reveals the existence of complex spatiotemporal cyto-architectures in the developing cerebellum. Cerebellum. 2015;14:247-63.

237. Leto K, Bartolini A, Rossi F. The prospective white matter: an atypical neurogenic niche in the developing cerebellum. Arch Ital Biol. 2010;148:137-46.

238. De Luca AE, Tosatto G, Martire S, Hoshino M, Buffo A, et al. Exogenous sonic hedgehog modulates the pool of GABAergic interneurons during cerebellar development. Cerebellum. 2015; 14:72-85

239. Lee A, Kessler JD, Read TA, Kaiser C, Corbeil D, Huttner WB, et al. Isolation of neural stem cells from the postnatal cerebellum. Nat Neurosci. 2005;6:723-9.
240. Klein C, Butt SJ, Machold RP, Johnson JE, Fishell G. Cerebellumand forebrain-derived stem cells possess intrinsic regional character. Development. 2005;132:4497-508.

241. Grimaldi P, Parras C, Guillemot F, Rossi F, Wassef M. Origins and control of the differentiation of inhibitory interneurons and glia in the cerebellum. Dev Biol. 2009;328:422-33.

242. Silbereis J, Cheng E, Ganat YM, Ment LR, Vaccarino FM. Precursors with glial fibrillary acidic protein promoter activity transiently generate GABA interneurons in the postnatal cerebellum. Stem Cells. 2009;27:1152-63.

243. Ango F, Di CG, Higashiyama H, Bennett V, Wu P, Huang ZJ. Ankyrin-based subcellular gradient of neurofascin, an immunoglobulin family protein, directs GABAergic innervation at purkinje axon initial segment. Cell. 2004;119:257-72.

244. Buttermore ED, Piochon C, Wallace ML, Philpot BD, Hansel C, Bhat MA. Pinceau organization in the cerebellum requires distinct functions of neurofascin in Purkinje and basket neurons during postnatal development. J Neurosci. 2012;32:4724-42.

245. Cioni JM, Telley L, Saywell V, Cadilhac C, Jourdan C, Huber AB, et al. SEMA3A signaling controls layer-specific interneuron branching in the cerebellum. Curr Biol. 2013;23:850-61.

246. Mertz K, Koscheck T, Schilling K. Brain derived neurotrophic factor modulates dendritic morphology of cerebellar basket and stellate cells. Neuroscience. 2000;97:303-10.

247. Konno K, Matsuda K, Nakamoto C, Uchigashima M, Miyazaki T, Yamasaki M, et al. Enriched expression of GluD1 in higher brain regions and its involvement in parallel fiber-interneuron synapse formation in the cerebellum. J Neurosci. 2014;34:7412-24.

248. Houck BD, Person AL. Cerebellar premotor output neurons collateralize to innervate the cerebellar cortex. J Comp Neurol. 2015.

249. Chan-Palay V. Afferent axons and their relations with neurons in the nucleus lateralis of the cerebellum: a light microscopic study. Z Anat Entwicklungsgesch. 1973;142(1):1-21.

250. Chan-Palay V. A light microscope study of the cytology and organization of neurons in the simple mammalian nucleus lateralis: columns and swirls. Z Anat Entwicklungsgesch. 1973;141(2): 125-50.

251. Chan-Palay V. Neuronal circuitry in the nucleus lateralis of the cerebellum. Z Anat Entwicklungsgesch. 1973;142(3):259-65.

252. Fredette BJ, Mugnaini E. The GABAergic cerebello-olivary projection in the rat. Anat Embryol (Berl). 1991;184(3):225-43.

253. Uusisaari MY, Knopfel T. Neurons of the deep cerebellar nuclei. In M. Manto D.L. Gruol J.D. Schmahmann N. Koibuchi and F. Rossi (eds.) Handbook of the cerebellum and cerebellar disorders (2012): Springer.

254. Nieuwenhuys R, ten Donkelaar HJ, Nicholson C. The central nervous system of vertebrates. Berlin: Springer-Verlag; 1998.

255. Wingate R. Math-Map(ic)s. Neuron. 2005;48(1):1-4.

256. Altman J, Bayer SA. Embryonic development of the rat cerebellum. II. Translocation and regional distribution of the deep neurons. J Comp Neurol. 1985;231(1):27-41.

257. Green MJ, Wingate RJ. Developmental origins of diversity in cerebellar output nuclei. Neural Dev. 2014;9(1):1.

258. Wilson LJ, Wingate RJ. Temporal identity transition in the avian cerebellar rhombic lip. Dev Biol. 2006;297(2):508-21.

259. Alcantara S, Ruiz M, De Castro F, Soriano E, Sotelo C. Netrin 1 acts as an attractive or as a repulsive cue for distinct migrating neurons during the development of the cerebellar system. Development. 2000;127(7):1359-72.

260. Gilthorpe JD, Papantoniou EK, Chédotal A, Lumsden A, Wingate RJ. The migration of cerebellar rhombic lip derivatives. Development. 2002;129(20):4719-28.

261. Tamada A, Kumada T, Zhu Y, Matsumoto T, Hatanaka Y, Muguruma K, et al. Crucial roles of Robo proteins in midline crossing of cerebellofugal axons and lack of their up-regulation after midline crossing. Neural Dev. 2008;3:29. 
262. Lefler Y, Yarom Y, Uusisaari MY. Cerebellar inhibitory input to the inferior olive decreases electrical coupling and blocks subthreshold oscillations. Neuron. 2014;81(6):1389-400.

263. Uusisaari MY, Knopfel T. Diversity of neuronal elements and circuitry in the cerebellar nuclei. Cerebellum. 2012;11(2):420-1.

264. Palay S, Chan-Palay V. Cerebellar cortex. Berlin: SpringerVerlag; 1974.

265. Alvarez MI, Rivas L, Lacruz C, Toledano A. Astroglial cell subtypes in the cerebella of normal adults, elderly adults, and patients with Alzheimer's disease: a histological and immunohistochemical comparison. Glia. 2015;63:287-312.

266. Yuasa S. Bergmann glial development in the mouse cerebellum as revealed by tenascin expression. Anat Embryol. 1996;194:22334.

267. Anthony TE, Heintz N. Genetic lineage tracing defines distinct neurogenic and gliogenic stages of ventral telencephalic radial glial development. Neural Dev. 2008;3:30.

268. Mori T, Tanaka K, Buffo A, Wurst W, Kuehn R, Goetz M. Inducible gene deletion in astroglia and radial glia - a valuable tool for functional and lineage analysis. Glia. 2006;54:21-34.

269. Jensen P, Smeyne R, Goldowitz D. Analysis of cerebellar development in math1 null embryos and chimeras. J Neurosci. 2004;24: 2202-11.

270. Buffo A, Rossi F. Origin, lineage and function of cerebellar glia. Prog Neurobiol. 2013;109:42-63.

271. Yamada K, Watanabe M. Cytodifferentiation of Bergmann glia and its relationship with Purkinje cells. Anat Sci Int. 2002;77: 94-108.

272. Li K, Leung AW, Guo Q, Yang W, Li JYH. Shp2-dependent ERK signaling is essential for induction of Bergmann glia and foliation of the cerebellum. J Neurosci. 2014;34:922-31.

273. Zhang X, Santuccione A, Leung C, Marino S. Differentiation of postnatal cerebellar glial progenitors is controlled by Bmi1 through BMP pathway inhibition. Glia. 2011;59:1118-31.

274. Mecklenburg N, Garcia-López R, Puelles E, Sotelo C, Martinez S. Cerebellar oligodendroglial cells have a mesencephalic origin. Glia. 2011;59:1946-57.

275. Leoni G, Rattray M, Butt AM. NG2 cells differentiate into astrocytes in cerebellar slices. Mol Cell Neurosci. 2009;42:208-18.

276. Reynolds R, Wilkin GP. Development of macroglial cells in rat cerebellum. II. An in situ immunohistochemical study of oligodendroglial lineage from precursor to mature myelinating cell. Development. 1988;102:409-25.

277. Kapfhammer JP, Schwab ME. Inverse patterns of myelination and GAP-43 expression in the adult CNS: neurite growth inhibitors as regulators of neuronal plasticity? J Comp Neurol. 1994;340:194 206.

278. Gianola S, Savio T, Schwab M, Rossi F. Cell-autonomous mechanisms and myelin associated factors contribute to the development of Purkinje axon intracortical plexus in rat cerebellum. J Neurosci. 2003;23:4613-24.

279. Rossi F, Corvetti L, Gianola S. The strange case of Purkinje axon regeneration and plasticity. Cerebellum. 2006;5:163-73.

280. Emery B. Transcriptional and post-transcriptional control of CNS myelination. Curr Opin Neurobiol. 2010;20:601-7.

281. Emery B. Regulation of oligodendrocyte differentiation and myelination. Science. 2010;330:779-82.

282. Bouslama-Oueghlani L, Wehrlé R, Doulazmi M, Chen XR, Jaudon F, Lemaigre-Dubreuil Y, et al. Purkinje cell maturation participates in the control of oligodendrocyte differentiation: role of sonic hedgehog and vitronectin. PLoS One. 2012;7:e49015.

283. Dahmane N, Ruiz-i-Altaba A. Sonic hedgehog regulates the growth and patterning of the cerebellum. Development. 1999;126:3089-100.
284. Wallace VA. Purkinje-cell-derived Sonic hedgehog regulates granule neuron precursor cell proliferation in the developing mouse cerebellum. Curr Biol. 1999;9:445-8.

285. Lewis PM, Gritli-Linde A, Smeyne R, Kottmann A, McMahon AP. Sonic hedgehog signaling is required for expansion of granule neuron precursors and patterning of the mouse cerebellum. Dev Biol. 2004;270:393-410.

286. Izzi L, Levesque M, Morin S, Laniel D, Wilkes BC. Boc and Gas1 each form distinct Shh receptor complexes with Ptch1 and required for Shh-mediated cell proliferation. Dev Cell. 2011;20(6): 788-801.

287. Corbit KC, Aanstad P, Singla V, Norman AR, Stainier DY, Reiter JF. Vertebrate smoothened functions at the primary cilium. Nature. 2005;437:1018-21.

288. Rohatgi R, Milenkovic L, Scott MP. Patched1 regulates hedgehog signaling at the primary cilium. Science. 2007;317:372-6.

289. Ryan KE, Chiang C. Hedgehog secretion and signal transduction in vertebrates. J Biol Chem. 2012;287:17905-13.

290. Chizhikov VV, Davenport J, Zhang Q, Shih EK, Cabello OA, Fuchs JL, et al. Cilia proteins control cerebellar morphogenesis by promoting expansion of the granule progenitor pool. J Neurosci. 2007;27:9780-9.

291. Spassky N, Han Y-G, Aguilar A, Strehl L, Besse L, Laclef C, et al. Primary cilia are required for cerebellar development and Shhdependent expansion of progenitor pool. Dev Biol. 2008;317: 246-59.

292. Corrales JD, Rocco GL, Blaess S, Guo Q, Joyner AL. Spatial pattern of sonic hedgehog signaling through Gli genes during cerebellum development. Development. 2004;131:5581-90.

293. Kenney AM, Rowitch DH. Sonic hedgehog promotes G(1) cyclin expression and sustained cell cycle progression in mammalian neuronal precursors. Mol Cell Biol. 2000;20:9055-67.

294. Kenney AM, Cole MD, Rowitch DH. Nmyc upregulation by sonic hedgehog signaling promotes proliferation in developing cerebellar granule neuron precursors. Development. 2003;130:15-28.

295. Shi X, Zhang Z, Zhan X, Cao M, Satoh T, Akira S, et al. An epigenetic switch induced by Shh signalling regulates gene activation during development and medulloblastoma growth. Nat Commun. 2014;5:1-12.

296. Tiberi L, Bonnefont J, van den Ameele J, Le Bon S-D, Herpoel A, Bilheu A, et al. A BCL6/BCOR/SIRT1 complex triggers neurogenesis and suppresses medulloblastoma by repressing Sonic Hedgehog signaling. Cancer Cell. 2014;26:797-812.

297. Voogd J, Glickstein M. The anatomy of the cerebellum. Trends Neurosci. 1998;21(9):370-5.

298. Szulc KU, Nieman BJ, Houston EJ, Bartelle BB, Lerch JP, Joyner $\mathrm{AL}$, et al. MRI analysis of cerebellar and vestibular developmental phenotypes in Gbx2 conditional knockout mice. Magn Reson Med. 2013;70(6):1707-17.

299. Larsell O. The development and subdivisions of the cerebellum of birds. J Comp Neurol. 1948;89(2):123-89.

300. Larsell $\mathrm{O}$. The comparative anatomy and histology of the cerebellum from myxinoids through birds. Minneapolis: Univ. Minnesota Press; 1967.

301. Larsell O. The morphogenesis and adult pattern of the lobules and fissures of the cerebellum of the white rat. J Comp Neurol. 1952;97(2):281-356.

302. Larsell O, Jansen J. The comparative anatomy and histology of the cerebellum: from monotremes through apes. Minneapolis: Univ. Minnesota Press; 1970.

303. Park MT, Pipitone J, Baer LH, Winterburn JL, Shah Y, Chavez S, et al. Derivation of high-resolution MRI atlases of the human cerebellum at $3 \mathrm{~T}$ and segmentation using multiple automatically generated templates. NeuroImage. 2014;95:217-31. 
304. Buckner RL. The cerebellum and cognitive function: 25 years of insight from anatomy and neuroimaging. Neuron. 2013;80(3): $807-15$.

305. Clark DA, Mitra PP, Wang SS. Scalable architecture in mammalian brains. Nature. 2001;411(6834):189-93.

306. Yopak KE, Lisney TJ, Darlington RB, Collin SP, Montgomery JC, Finlay BL. A conserved pattern of brain scaling from sharks to primates. Proc Natl Acad Sci U S A. 2010;107(29):12946-51.

307. Herculano-Houzel S. Coordinated scaling of cortical and cerebellar numbers of neurons. Front Neuroanat. 2010;4:12.

308. Balsters JH, Cussans E, Diedrichsen J, Phillips KA, Preuss TM, Rilling JK, et al. Evolution of the cerebellar cortex: the selective expansion of prefrontal-projecting cerebellar lobules. NeuroImage. 2010;49(3):2045-52.

309. Rakic P, Sidman RL. Histogenesis of cortical layers in human cerebellum, particularly the lamina dissecans. J Comp Neurol. 1970;139(4):473-500.

310. Dobbing J, Sands J. Quantitative growth and development of human brain. Archives of disease in childhood. Arch Dis Child. 1973;48(10):757-67.

311. Tam EW, Miller SP, Studholme C, Chau V, Glidden D, Poskitt KJ, et al. Differential effects of intraventricular hemorrhage and white matter injury on preterm cerebellar growth. J Pediatr. 2011;158(3): 366-71.

312. Scott JA, Hamzelou KS, Rajagopalan V, Habas PA, Kim K, Barkovich AJ, et al. 3D morphometric analysis of human fetal cerebellar development. Cerebellum. 2012;11(3):761-70.

313. Tam EW. Potential mechanisms of cerebellar hypoplasia in prematurity. Neuroradiology. 2013;55 Suppl 2:41-6.

314. Szulc KU, Lerch JP, Nieman BJ, Bartelle BB, Friedel M, SueroAbreu $\mathrm{G}$, et al. 4D MEMRI atlas of neonatal FVB/N mouse brain development. NeuroImage. In revision.

315. Sudarov A, Joyner AL. Cerebellum morphogenesis: the foliation pattern is orchestrated by multi-cellular anchoring centers. Neural Dev. 2007;2:26.

316. Orvis GD, Hartzell AL, Smith JB, Barraza LH, Wilson SL, Szulc $\mathrm{KU}$, et al. The engrailed homeobox genes are required in multiple cell lineages to coordinate sequential formation of fissures and growth of the cerebellum. Dev Biol. 2012;367(1):25-39.

317. Cheng Y, Sudarov A, Szulc KU, Sgaier SK, Stephen D, Turnbull $\mathrm{DH}$, et al. The Engrailed homeobox genes determine the different foliation patterns in the vermis and hemispheres of the mammalian cerebellum. Development. 2010;137(3):519-29.

318. Sillitoe RV, Stephen D, Lao Z, Joyner AL. Engrailed homeobox genes determine the organization of Purkinje cell sagittal stripe gene expression in the adult cerebellum. J Neurosci. 2008;28(47):12150-62.

319. Millen KJ, Wurst W, Herrup K, Joyner AL. Abnormal embryonic cerebellar development and patterning of postnatal foliation in two mouse Engrailed-2 mutants. Development. 1994;120(3):695-706.

320. Joyner AL, Herrup K, Auerbach BA, Davis CA, Rossant J. Subtle cerebellar phenotype in mice homozygous for a targeted deletion of the En-2 homeobox. Science. 1991;251(4998):1239-43.

321. Mares V, Lodin Z, Srajer J. The cellular kinetics of the developing mouse cerebellum. I. The generation cycle, growth fraction and rate of proliferation of the external granular layer. Brain Res. 1970;23(3):323-42.

322. Haddara MA, Nooreddin MA. A quantitative study on the postnatal development of the cerebellar vermis of mouse. J Comp Neurol. 1966;128(2):245-54.

323. Van Essen DC. A tension-based theory of morphogenesis and compact wiring in the central nervous system. Nature. 1997;385(6614):313-8.

324. Espinosa JS, Luo L. Timing neurogenesis and differentiation: insights from quantitative clonal analyses of cerebellar granule cells. J Neurosci. 2008;28(10):2301-12.
325. Legue E, Riedel E, Joyner AL. Clonal analysis reveals granule cell behaviors and compartmentalization that determine the folded morphology of the cerebellum. Development. 2015

326. Leto K, Rossi F. Specification and differentiation of cerebellar GABAergic neurons. Cerebellum. 2012;11(2):434-5.

327. Chaplin N, Tendeng C, Wingate RJ. Absence of an external germinal layer in zebrafish and shark reveals a distinct, anamniote ground plan of cerebellum development. J Neurosci. 2010;30(8):3048-57.

328. Butts T, Modrell MS, Baker CV, Wingate RJ. The evolution of the vertebrate cerebellum: absence of a proliferative external granule layer in a non-teleost ray-finned fish. Evol Dev. 2014;16(2):92100.

329. Pose-Mendez S, Candal E, Mazan S, Rodriguez-Moldes I. Genoarchitecture of the rostral hindbrain of a shark: basis for understanding the emergence of the cerebellum at the agnathangnathostome transition. Brain struct Funct. 2015.

330. Pose-Mendez S, Candal E, Mazan S, Rodriguez-Moldes I. Morphogenesis of the cerebellum and cerebellum-related structures in the shark Scyliorhinus canicula: insights on the ground pattern of the cerebellar ontogeny. Brain struct Funct. 2015.

331. Butts T, Green MJ, Wingate RJ. Development of the cerebellum: simple steps to make a 'little brain'. Development. 2014;141(21): 4031-41.

332. Kani S, Bae YK, Shimizu T, Tanabe K, Satou C, Parsons MJ, et al. Proneural gene-linked neurogenesis in zebrafish cerebellum. Dev Biol. 2010;343(1-2):1-17.

333. Azevedo FA, Carvalho LR, Grinberg LT, Farfel JM, Ferretti RE, Leite RE, et al. Equal numbers of neuronal and nonneuronal cells make the human brain an isometrically scaled-up primate brain. J Comp Neurol. 2009;513(5):532-41.

334. Herculano-Houzel S, Mota B, Lent R. Cellular scaling rules for rodent brains. Proc Natl Acad Sci U S A. 2006;103(32):12138-43.

335. Doughty ML, Delhaye-Bouchaud N, Mariani J. Quantitative analysis of cerebellar lobulation in normal and agranular rats. J Comp Neurol. 1998;399(3):306-20.

336. Yopak KE, Lisney TJ, Collin SP, Montgomery JC. Variation in brain organization and cerebellar foliation in chondrichthyans: sharks and holocephalans. Brain Behav Evol. 2007;69(4):280 300 .

337. Crépel F, Mariani J, Delhaye-Bouchaud N. Evidence for a multiple innervation of Purkinje cells by climbing fibers in the immature rat cerebellum. J Neurobiol. 1976;7(6):567-78.

338. Chédotal A, Sotelo C. The 'creeper stage' in cerebellar climbing fiber synaptogenesis precedes the 'pericellular nest'-ultrastructural evidence with parvalbumin immunocytochemistry. Brain Res Dev Brain Res. 1993;76:207-20.

339. Hashimoto K, Kano M. Synapse elimination in the developing cerebellum. Cell Mol Life Sci. 2013;70:4667-80.

340. Watanabe M, Kano M. Climbing fiber synapse elimination in cerebellar Purkinje cells. Eur J Neurosci. 2011;34:1697-710.

341. Uesaka N, Uchigashima M, Mikuni T, Nakazawa T, Nakao H, Hirai $\mathrm{H}$, et al. Retrograde semaphorin signaling regulates synapse elimination in the developing mouse brain. Science. 2014;344: 1020-3.

342. Sotelo C, Rossi F. Purkinje cell migration and differentiation. In: Manto M, Gruol DL, Schmahmann JD, Koibuchi N, Rossi F, editors. Handbook of the cerebellum and cerebellar disorders. USA: Springer Science+Business Media; 2013. p. 147-78.

343. Oberdick J, Smeyne RJ, Mann JR, Zackson S, Morgan JI. A promoter that drives transgene expression in cerebellar Purkinje and retinal bipolar neurons. Science. 1990;248:223-6.

344. Nishiyama J, Hayashi Y, Nomura T, Miura E, Kakegawa W, Yuzaki M. Selective and regulated gene expression in murine Purkinje cells by in utero electroporation. Eur J Neurosci. 2012;36:2867-76. 
345. Tanaka M. Dendrite formation of cerebellar Purkinje cells. Neurochem Res. 2009;34:2078-88.

346. Boukhtouche F, Janmaat S, Vodjdani G, Gautheron V, Mallet J, Dusart I, et al. Retinoid-related orphan receptor alpha controls the early steps of Purkinje cell dendritic differentiation. J Neurosci. 2006;26:1531-8.

347. Kapfhammer JP. Cellular and molecular control of dendritic growth and development of cerebellar Purkinje cells. Prog Histochem Cytochem. 2004;39:131-82.

348. Rossi F, Tempia F. Unravelling the Purkinje neuron. Cerebellum. 2006;5:75-6.

349. y Cajal RS. Sur les fibres moussues et quelques points douteux de la texture de l'écorce cérébelleuse. Trab Lab Invest Biol Univ Madrid. 1926;24:215-51.

350. Armengol JA, Sotelo C. Early dendritic development of Purkinje cells in the rat cerebellum. A light and electron microscopic study using axonal tracing in 'in vitro' slices. Brain Res Dev Brain Res. 1991;64:95-114.

351. Berry M, Bradley P. The growth of the dendritic trees of Purkinje cells in the cerebellum of the rat. Brain Res. 1976;112:1-35.

352. Kaneko M, Yamaguchi K, Eiraku M, Sato M, Takata N, Kiyohara Y, et al. Remodeling of monoplanar Purkinje cell dendrites during cerebellar circuit formation. PLoS ONE. 2011;6:e20108.

353. van Welie I, Smith IT, Watt AJ. The metamorphosis of the developing cerebellar micro- circuit. Curr Opin Neurobiol. 2011;21: 245-53.

354. Dusart I, Flamant F. Profound morphological and functional changes of rodent Purkinje cells between the first and the second postnatal weeks: a metamorphosis? Front Neuroanat. 2012;6:11.

355. Avci HX, Lebrun C, Wehrle R, Doulazmi M, Chatonnet F, Morel M-P, et al. Thyroid hormone triggers the developmental loss of axonal regenerative capacity via thyroid hormone receptor $\alpha 1$ and kruppel-like factor 9 in Purkinje cells. Proc Natl Acad Sci U S A. 2012;109:14206-11.

356. Sotelo C, Dusart I. Intrinsic versus extrinsic determinants during the development of Purkinje cell dendrites. Neuroscience. 2009;162:589-600.

357. Tanaka M. The dendritic differentiation of Purkinje neurons: Unsolved mystery in formation of unique dendrites. Cerebellum. 2014.

358. Chen XR, Heck N, Lohof AM, Rochefort C, Morel MP, Wehrle R, et al. Mature Purkinje cells require the retinoic acid-related orphan receptor- $\alpha(\mathrm{ROR} \alpha)$ to maintain climbing fiber mono-innervation and other adult characteristics. J Neurosci. 2013;33:9546-62.

359. Lefebvre JL, Kostadinov D, Chen WV, Maniatis T, Sanes JR. Protocadherins mediate dendritic self-avoidance in the mammalian nervous system. Nature. 2013;488:517-21.

360. Gibson DA, Tymanskyj S, Yuan RC, Leung HC, Lefebvre JL, Sanes JR, et al. Dendrite self-avoidance requires cellautonomous Slit/Robo signaling in Purkinje cells. Neuron. 2014;81:1040-56.

361. Joo W, Hippenmeyer S, Luo L. Dendrite morphogenesis depends on relative levels of NT3/TrkC signaling. Science. 2014;346:6269.

362. Bolduc ME, Limperopoulos C. Neurodevelopmental outcomes in children with cerebellar malformations: a systematic review. Dev Med Child Neurol. 2009;51:256-67.

363. Tavano A, Grasso R, Gagliardi C, Triulzi F, Bresolin N, Fabbro F, et al. Disorders of cognitive and affective development in cerebellar malformations. Brain. 2007;130:2646-60.

364. Volpe JJ. Cerebellum of the premature infant: rapidly developing, vulnerable, clinically important. J Child Neurol. 2009;24:1085104.

365. Barkovich AJ, Millen KJ, Dobyns WB. A developmental and genetic classification for midbrain-hindbrain malformations. Brain. 2009;132:3199-230.
366. Parisi MA, Dobyns WB. Human malformations of the midbrain and hindbrain: review and proposed classification scheme. Mol Genet Metab. 2003;80:36-53.

367. Osenbach RK, Menezes AH. Diagnosis and management of the Dandy-Walker malformation: 30 years of experience. Pediatr Neurosurg. 1992;18:179-89.

368. Sato K, Kubota T, Nakamura Y. Adult onset of the Dandy-Walker syndrome. Br J Neurosurg. 1996;10:109-12.

369. Tal Y, Freigang B, Dunn HG, Durity FA, Moyes PD. Dandy-Walker syndrome: analysis of 21 cases. Dev Med Child Neurol. 1980;22:189-201.

370. Aldinger KA, Lehmann OJ, Hudgins L, Chizhikov VV, Bassuk $\mathrm{AG}$, Ades LC, et al. FOXC1 is required for normal cerebellar development and is a major contributor to chromosome 6p25.3 Dandy-Walker malformation. Nat Genet. 2009;41:1037-42.

371. Grinberg I, Northrup H, Ardinger H, Prasad C, Dobyns WB, Millen KJ. Heterozygous deletion of the linked genes ZIC1 and ZIC4 is involved in Dandy-Walker malformation. Nat Genet. 2004;36:1053-5.

372. Limperopoulos C, Folkerth R, Barnewolt CE, Connolly S, Du Plessis AJ. Posthemorrhagic cerebellar disruption mimicking Dandy-Walker malformation: fetal imaging and neuropathology findings. Semin Pediatr Neurol. 2010;17:75-81.

373. Haldipur P, Gillies GS, Janson OK, Chizhikov VV, Mithal DS, Miller RJ, et al. Foxc1 dependent mesenchymal signalling drives embryonic cerebellar growth. E-life. 2014;3.

374. Kroes HY, van Zon PH, van de Putte DF, Nelen MR, Nievelstein RJ, Wittebol-Post D, et al. DNA analysis of AHI1, NPHP1 and CYCLIN D1 in Joubert syndrome patients from the Netherlands. Eur J Med Genet. 2008;51:24-34.

375. Parisi MA, Doherty D, Chance PF, Glass IA. Joubert syndrome (and related disorders) (OMIM 213300). Eur J Hum Genet. 2007;15:511-21.

376. Maria BL, Quisling RG, Rosainz LC, Yachnis AT, Gitten J, Dede $\mathrm{D}$, et al. Molar tooth sign in Joubert syndrome: clinical, radiologic, and pathologic significance. J Child Neurol. 1999;14:368-76.

377. Romani M, Micalizzi A, Kraoua I, Dotti MT, Cavallin M, Sztriha L, et al. Mutations in B9D1 and MKS1 cause mild Joubert syndrome: expanding the genetic overlap with the lethal ciliopathy Meckel syndrome. Orphanet J Rare Dis. 2014;9:72.

378. Romani M, Micalizzi A, Valente EM. Joubert syndrome: congenital cerebellar ataxia with the molar tooth. Lancet Neurol. 2013;12: 894-905.

379. Aguilar A, Meunier A, Strehl L, Martinovic J, Bonniere M, AttieBitach T, et al. Analysis of human samples reveals impaired SHHdependent cerebellar development in Joubert syndrome/Meckel syndrome. Proc Natl Acad Sci U S A. 2012;109:16951-6.

380. Lancaster MA, Gopal DJ, Kim J, Saleem SN, Silhavy JL, Louie $\mathrm{CM}$, et al. Defective Wnt-dependent cerebellar midline fusion in a mouse model of Joubert syndrome. Nat Med. 2011;17:726-31.

381. Schneider L, Clement CA, Teilmann SC, Pazour GJ, Hoffmann EK, Satir P, et al. PDGFR $\alpha \alpha$ signaling is regulated through the primary cilium in fibroblasts. Curr Biol. 2005;15:1861-6.

382. Koster RW, Fraser SE. Direct imaging of in vivo neuronal migration in the developing cerebellum. Curr Biol. 2001;11(23):185863.

383. Battini R, D'Arrigo S, Cassandrini D, Guzzetta A, Fiorillo C, Pantaleoni C, et al. Novel mutations in TSEN54 in pontocerebellar hypoplasia type 2. J Child Neurol. 2014;29:520-5.

384. Bierhals T, Korenke GC, Uyanik G, Kutsche K. Pontocerebellar hypoplasia type 2 and TSEN2: review of the literature and two novel mutations. Eur J Med Genet. 2013;56:325-30.

385. Fallet-Bianco C, Laquerriere A, Poirier K, Razavi F, Guimiot F, Dias $\mathrm{P}$, et al. Mutations in tubulin genes are frequent causes of various foetal malformations of cortical development including microlissencephaly. Acta Neuropathol Commun. 2014;2:69. 
386. Hong SE, Shugart YY, Huang DT, Shahwan SA, Grant PE, Hourihane JO, et al. Autosomal recessive lissencephaly with cerebellar hypoplasia is associated with human RELN mutations. Nat Genet. 2000;26:93-6.

387. Miyata H, Chute DJ, Fink J, Villablanca P, Vinters HV. Lissencephaly with agenesis of corpus callosum and rudimentary dysplastic cerebellum: a subtype of lissencephaly with cerebellar hypoplasia. Acta Neuropathol. 2004;107:69-81.

388. Nakamura K, Nishiyama K, Kodera H, Nakashima M, Tsurusaki Y, Miyake N, et al. A de novo CASK mutation in pontocerebellar hypoplasia type 3 with early myoclonic epilepsy and tetralogy of Fallot. Brain Dev. 2014;36:272-3.

389. Rocas D, Alix E, Michel J, Cordier MP, Labalme A, Guilbert H, et al. Neuropathological features in a female fetus with OPHN1 deletion and cerebellar hypoplasia. Eur J Med Genet. 2013;56: 270-3.

390. Saitsu H, Kato M, Osaka H, Moriyama N, Horita H, Nishiyama K, et al. CASK aberrations in male patients with Ohtahara syndrome and cerebellar hypoplasia. Epilepsia. 2012;53:1441-9.

391. Tentler D, Gustavsson P, Leisti J, Schueler M, Chelly J, Timonen E, et al. Deletion including the oligophrenin-1 gene associated with enlarged cerebral ventricles, cerebellar hypoplasia, seizures and ataxia. Eur J Hum Genet. 1999;7:541-8.

392. Yu T, Meiners LC, Danielsen K, Wong MT, Bowler T, Reinberg $D$, et al. Deregulated FGF and homeotic gene expression underlies cerebellar vermis hypoplasia in CHARGE syndrome. E-life. 2013;2:e01305.

393. Barkovich AJ, Lindan CE. Congenital cytomegalovirus infection of the brain: imaging analysis and embryologic considerations. AJNR Am J Neuroradiol. 1994;15:703-15.

394. Bellini C, Massocco D, Serra G. Prenatal cocaine exposure and the expanding spectrum of brain malformations. Arch Intern Med. 2000;160:2393.

395. Bookstein FL, Streissguth AP, Connor PD, Sampson PD. Damage to the human cerebellum from prenatal alcohol exposure: the anatomy of a simple biometrical explanation. Anat Rec B New Anat. 2006;289:195-209.

396. de Vries LS, Gunardi H, Barth PG, Bok LA, Verboon-Maciolek MA, Groenendaal F. The spectrum of cranial ultrasound and magnetic resonance imaging abnormalities in congenital cytomegalovirus infection. Neuropediatrics. 2004;35:113-9.

397. Norman AL, Crocker N, Mattson SN, Riley EP. Neuroimaging and fetal alcohol spectrum disorders. Dev Disabil Res Rev. 2009;15:209-17.

398. Velioglu SK, Kuzeyli K, Zzmenoglu M. Cerebellar agenesis: a case report with clinical and MR imaging findings and a review of the literature. Eur J Neurol. 1998;5:503-6.

399. Timmann D, Dimitrova A, Hein-Kropp C, Wilhelm H, Dorfler A. Cerebellar agenesis: clinical, neuropsychological and MR findings. Neurocase. 2003;9:402-13.

400. Sellick GS, Barker KT, Stolte-Dijkstra I, Fleischmann C, Coleman RJ, Garrett C, et al. Mutations in PTF1A cause pancreatic and cerebellar agenesis. Nat Genet. 2004;36:1301-5.

401. Hayashi M, Poretti A, Gorra M, Farzin A, Graham EM, Huisman TA, et al. Prenatal cerebellar hemorrhage: fetal and postnatal neuroimaging findings and postnatal outcome. Pediatr Neurol. 2015;52(5):529-34.

402. Koibuchi N, Chin WW. Thyroid hormone action and brain development. Trends Endocrinol Metab. 2000;11:123-8.

403. Koibuchi N, Jingu H, Iwasaki T, Chin WW. Current perspectives on the role of thyroid hormone in growth and development of cerebellum. Cerebellum. 2003;2:279-89.

404. Porterfield SP, Hendrich CE. The role of thyroid hormones in prenatal and neonatal neurological development-current perspectives. Endocr Rev. 1993;14:94-106.
405. Calvo R, Obregon MJ, de Ruiz Ona C, del Escobar Rey F, de Morreale Escobar G. Congenital hypothyroidism, as studied in rats. J Clin Invest. 1990;86:889-99.

406. Guadano-Ferraz A, Obregon MJ, St Germain DL, Bernal J. The type 2 iodothyronine deiodinase is expressed primarily in glial cells in the neonatal rat brain. Proc Natl Acad Sci U S A. 1997;94:10391-6.

407. Heuer H, Maier MK, Iden S, Mittag J, Friesema ECH, Visser TJ, et al. The monocarboxylate transporter 8 linked to human psychomotor retardation is highly expressed in thyroid hormone-sensitive neuron populations. Endocrinology. 2005;146:1701-6.

408. Lazar MA. Thyroid hormone receptors: multiple forms, multiple possibilities. Endocr Rev. 1993;14:184-93.

409. Lauder JM, Altman J, Krebs H. Some mechanisms of cerebellar foliation: effects of early hypo- and hyperthyroidism. Brain Res. 1974;76:33-40.

410. Bradley DJ, Towle HC, Young III WS. Spatial and temporal expression of alpha- and beta-thyroid hormone receptor mRNAs, including the beta 2-subtype, in the developing mammalian nervous system. J Neurosci. 1992;12:2288-302.

411. Koibuchi N, Yamaoka S, Chin WW. Effect of altered thyroid status on neurotrophin gene expression during postnatal development of the mouse cerebellum. Thyroid. 2001;11:205-10.

412. Strait KA, Zou L, Oppenheimer JH. $\beta 1$ isoform-specific regulation of a triiodothyronine-induced gene during cerebellar development. Mol Endocrinol. 1992;6:1874-80.

413. Oppenheimer JH, Schwartz HL. Molecular basis of thyroid hormone-dependent brain development. Endocr Rev. 1997;18: $462-75$.

414. Koibuchi N. Animal models to study thyroid hormone action in cerebellum. Cerebellum. 2009;8:89-97.

415. Portella AC, Carvalho F, Faustino L, Wondisford FE, OrtigaCarvalho TM, Gomes FC. Thyroid hormone receptor $\beta$ mutation causes severe impairment of cerebellar development. Mol Cell Neurosci. 2010;44:68-77.

416. Venero C, Guadaño-Ferraz A, Herrero AI, Nordström K, Manzano J, de Escobar GM, et al. Anxiety, memory impairment, and locomotor dysfunction caused by a mutant thyroid hormone receptor $\alpha 1$ can be ameliorated by T3 treatment. Genes Dev. 2005;19: 2152-63.

417. Fauquier T, Chatonnet F, Picou F, Richard S, Fossat N, Aguilera $\mathrm{N}$, et al. Purkinje cells and Bergmann glia are primary targets of the TR $\alpha 1$ thyroid hormone receptor during mouse cerebellum postnatal development. Development. 2014;141:166-75.

418. Yu L, Iwasaki T, Xu M, Lesmana R, Xiong Y, Shimokawa N, et al. Aberrant cerebellar development of transgenic mice expressing dominant-negative thyroid hormone receptor in cerebellar Purkinje cells. Endocrinology. 2015;156(4):1565-76.

419. Ibhazehiebo K, Koibuchi N. Impact of endocrine disrupting chemicals on thyroid function and brain development. Expert Rev Endocrinol Metab. 2014;9:579-91.

420. Klockgether T, Paulson H. Milestones in ataxia. Mov Disord. 2011;26:1134-41.

421. Manto M, Marmolino D. Cerebellar ataxias. Curr Opin Neurol. 2009;22:419-29.

422. Hersheson J, Haworth A, Houlden H. The inherited ataxias: genetic heterogeneity, mutation databases, and future directions in research and clinical diagnostics. Hum Mutat. 2012;33:1324-32.

423. Mancuso M, Orsucci D, Siciliano G, Bonuccelli U. The genetics of ataxia: through the labyrinth of the Minotaur, looking for Ariadne's thread. J Neurol. 2014;261:528-41.

424. Orr HT. SCA1-phosphorylation, a regulator of Ataxin-1 function and pathogenesis. Prog Neurobiol. 2012;99:179-85.

425. Serra HG, Duvick L, Zu T, Carlson K, Stevens S, Jorgensen N, et al. ROR $\alpha$-mediated Purkinje cell development determines disease severity in adult SCA1 mice. Cell. 2006;127:697-708. 
426. Ebner BA, Ingram MA, Barnes JA, Duvick LA, Frisch JL, Clark $\mathrm{HB}$, et al. Purkinje cell ataxin-1 modulates climbing fiber synaptic input in developing and adult mouse cerebellum. J Neurosci. 2013;33:5806-20.

427. Duvick L, Barnes J, Ebner B, Agrawal S, Andresen M, Lim J, et al. SCA1-like disease in mice expressing wild-type ataxin-1 with a serine to aspartic acid replacement at residue 776 . Neuron. 2010;67:929-35.

428. Gold DA, Gent PM, Hamilton BA. ROR $\alpha$ in genetic control of cerebellum development: 50 staggering years. Brain Res. 2007;1140:19-25.

429. Mitsumura K, Hosoi N, Furuya N, Hirai H. Disruption of metabotropic glutamate receptor signalling is a major defect at cerebellar parallel fibre-Purkinje cell synapses in staggerer mutant mice. $\mathrm{J}$ Physiol. 2011;589:3191-209.

430. Torashima T, Koyama C, Iizuka A, Mitsumura K, Takayama K, Yanagi S, et al. Lentivector-mediated rescue from cerebellar ataxia in a mouse model of spinocerebellar ataxia. EMBO Rep. 2008;9: 393-9.

431. Konno A, Miyake N, Miyake K, Matsuura S, Huda F, Nakamura $\mathrm{K}$, et al. Mutant Ataxin-3 with an abnormally expanded polyglutamine chain disrupts dendritic development and metabotropic glutamate receptor signaling in mouse cerebellar Purkinje cells. Cerebellum. 2013;13:29-41

432. Gao Y, Perkins EM, Clarkson YL, Tobia S, Lyndon AR, Jackson $\mathrm{M}$, et al. $\beta$-III spectrin is critical for development of Purkinje cell dendritic tree and spine morphogenesis. J Neurosci. 2011;31: 16581-90.

433. Seki T, Shimahara T, Yamamoto K, Abe N, Amano T, Adachi N, et al. Mutant $\gamma \mathrm{PKC}$ found in spinocerebellar ataxia type 14 induces aggregate-independent maldevelopment of dendrites in primary cultured Purkinje cells. Neurobiol Dis. 2009;33:260-73.

434. Shuvaev AN, Horiuchi H, Seki T, Goenawan H, Irie T, Iizuka A, et al. Mutant PKC $\gamma$ in spinocerebellar ataxia type 14 disrupts synapse elimination and long-term depression in Purkinje cells in vivo. J Neurosci. 2011;31:14324-34.

435. Ji J, Hassler ML, Shimobayashi E, Paka N, Streit R, Kapfhammer JP. Increased protein kinase $\mathrm{C} \gamma$ activity induces Purkinje cell pathology in a mouse model of spinocerebellar ataxia 14 . Neurobiol Dis. 2014;70:1-11.

436. Becker EBE, Oliver PL, Glitsch MD, Banks GT, Achilli F, Hardy A, et al. A point mutation in TRPC 3 causes abnormal Purkinje cell development and cerebellar ataxia in moonwalker mice. Proc Natl Acad Sci U S A. 2009;106:6706-11.

437. Becker EBE. The Moonwalker mouse: new insights into TRPC3 function, cerebellar development, and ataxia. Cerebellum. 2014;13:628-36.

438. Hartmann J, Dragicevic E, Adelsberger H, Henning HA, Sumser M, Abramowitz J, et al. TRPC3 channels are required for synaptic transmission and motor coordination. Neuron. 2008;59:392-8.

439. Mitsumura K, Hosoi N, Furuya N, Hirai H. Disruption of metabotropic glutamate receptor signalling is a major defect at cerebellar parallel fibre-Purkinje cell synapses in staggerer mutant mice. J Physiol. 2011;589(Pt 13):3191-209.

440. Skinner PJ, Vierra-Green CA, Clark HB, Zoghbi HY, Orr HT. Altered trafficking of membrane proteins in Purkinje cells of SCA1 transgenic mice. Am J Pathol. 2001;159:905-13.

441. Konno A, Shuvaev AN, Miyake N, Miyahe K, Iizuka A, Matsuura $\mathrm{S}$, et al. Mutant ataxin-3 with an abnormally expanded polyglutamine chain disrupts dendritic development and metabotropic glutamate receptor signaling in mouse cerebellar Purkinje cells. Cerebellum. 2014;13(1):29-41.

442. Armbrust KR, Wang X, Hathorn TJ, Cramer SW, Chen G, Zu T, et al. Mutant $\beta$-III spectrin causes mGluR1 $\alpha$ mislocalization and functional deficits in a mouse model of spinocerebellar ataxia type 5. J Neurosci. 2014;34:9891-904.
443. Louis DN, Ohgaki H, Wiestler OD, Cavenee WK, Burger PC, Jouvet A, et al. The 2007 WHO classification of tumours of the central nervous system. Acta Neuropathol. 2007;114:97-109.

444. Kool M, Korshunov A, Remke M, Jones DT, Schlanstein M, Northcott PA, et al. Molecular subgroups of medulloblastoma: an international meta-analysis of transcriptome, genetic aberrations, and clinical data of WNT, SHH, Group 3, and Group 4 medulloblastomas. Acta Neuropathol. 2012;123:473-84.

445. Taylor MD, Northcott PA, Korshunov A, Remke M, Cho YJ, Clifford SC, et al. Molecular subgroups of medulloblastoma: the current consensus. Acta Neuropathol. 2012;123:465-72.

446. Yang ZJ, Ellis T, Markant SL, Read TA, Kessler JD, Bourboulas $\mathrm{M}$, et al. Medulloblastoma can be initiated by deletion of Patched in lineage-restricted progenitors or stem cells. Cancer Cell. 2008; $14: 135-45$.

447. Oliver TG, Read TA, Kessler JD, Mehmeti A, Wells JF, Huynh TT, et al. Loss of patched and disruption of granule cell development in a pre-neoplastic stage of medulloblastoma. Development. 2005; 132:2425-39.

448. Grammel D, Warmuth-Metz M, von Bueren AO, Kool M, Pietsch T, Kretzschmar HA, et al. Sonic hedgehog-associated medulloblastoma arising from the cochlear nuclei of the brainstem. Acta Neuropathol. 2012;123:601-14.

449. Gibson P, Tong Y, Robinson G, Thompson MC, Currle DS, Eden $\mathrm{C}$, et al. Subtypes of medulloblastoma have distinct developmental origins. Nature. 2010;468:1095-9.

450. Perreault S, Ramaswamy V, Achrol AS, Chao K, Liu TT, Shih D, et al. MRI surrogates for molecular subgroups of medulloblastoma. AJNR Am J Neuroradiol. 2014;35:1263-9.

451. Wefers AK, Warmuth-Metz M, Poschl J, von Bueren AO, Monoranu CM, Seelos K, et al. Subgroup-specific localization of human medulloblastoma based on pre-operative MRI. Acta Neuropathol. 2014;127:931-3.

452. Ellison DW, Dalton J, Kocak M, Nicholson SL, Fraga C, Neale G, et al. Medulloblastoma: clinicopathological correlates of $\mathrm{SHH}$, WNT, and non-SHH/WNT molecular subgroups. Acta Neuropathol. 2011;121:381-96.

453. Shakhova O, Leung C, van Montfort E, Berns A, Marino S. Lack of $\mathrm{Rb}$ and p53 delays cerebellar development and predisposes to large cell anaplastic medulloblastoma through amplification of $\mathrm{N}$ Myc and Ptch2. Cancer Res. 2006;66:5190-200.

454. Sutter R, Shakhova O, Bhagat H, Behesti H, Sutter C, Penkar S, et al. Cerebellar stem cells act as medulloblastoma-initiating cells in a mouse model and a neural stem cell signature characterizes a subset of human medulloblastomas. Oncogene. 2010;29:1845-56.

455. Pei Y, Moore CE, Wang J, Tewari AK, Eroshkin A, Cho YJ, et al. An animal model of MYC-driven medulloblastoma. Cancer Cell. 2012;21:155-67.

456. Elsen G, Juric-Sejkhar G, Daza R, Hevner RF. Development of cerebellar nuclei. In: Manto M, Gruol D, Schmahmann J, Koibuchi N, Rossi F, editors. Handbook of cerebellum and cerebellum disorders. Heidelberg: Springer; 2010.

457. Kim E, Wang Y, Kim SJ, Bornhorst M, Jecrois ES, Anthony TE, et al. Transient inhibition of the ERK pathway prevents cerebellar developmental defects and improves long-term motor functions in murine models of neurofibromatosis type 1. E-life. 2014;3.

458. Meier F, Giesert F, Delic S, Faus-Kessler T, Matheus F, Simeone A, et al. FGF/FGFR2 signaling regulates the generation and correct positioning of Bergmann glia cells in the developing mouse cerebellum. PLoS One. 2014;9:e101124.

459. Sathyamurthy A, Yin DM, Barik A, Shen C, Bean JC, Figueiredo D, et al. ERBB3-mediated regulation of Bergmann glia proliferation in cerebellar lamination. Development. 2015;142:522-32. 